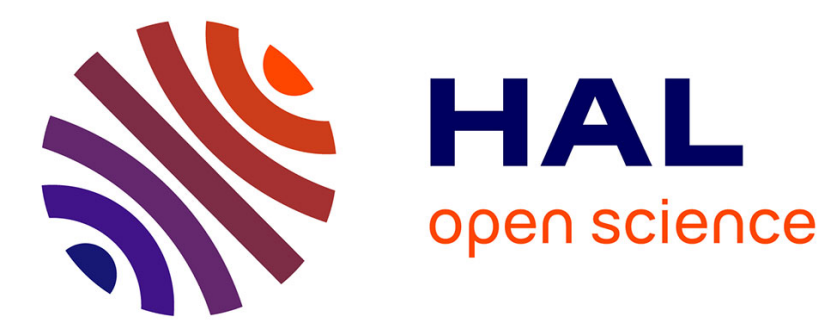

\title{
Recent Progress on NHC-stabilized Early Transition Metal (Group 3-7) Complexes: Synthesis and Applications
}

Charles Romain, Stéphane Bellemin-Laponnaz, Samuel Dagorne

\section{To cite this version:}

Charles Romain, Stéphane Bellemin-Laponnaz, Samuel Dagorne. Recent Progress on NHC-stabilized Early Transition Metal (Group 3-7) Complexes: Synthesis and Applications. Coordination Chemistry Reviews, 2020, 422, pp.213411. 10.1016/j.ccr.2020.213411 . hal-02998103

\section{HAL Id: hal-02998103 https://hal.science/hal-02998103}

Submitted on 10 Nov 2020

HAL is a multi-disciplinary open access archive for the deposit and dissemination of scientific research documents, whether they are published or not. The documents may come from teaching and research institutions in France or abroad, or from public or private research centers.
L'archive ouverte pluridisciplinaire HAL, est destinée au dépôt et à la diffusion de documents scientifiques de niveau recherche, publiés ou non, émanant des établissements d'enseignement et de recherche français ou étrangers, des laboratoires publics ou privés. 
Recent Progress on NHC-stabilized Early Transition Metal (Group 3-7) Complexes: Synthesis and Applications

Charles Romain, ${ }^{* * c}$ Stéphane Bellemin-Laponnaz, ${ }^{* b}$ Samuel Dagorne*a

${ }^{\text {a }}$ Institut de Chimie, CNRS - Strasbourg University, Strasbourg, France

b Institut de Physique et Chimie des Matériaux de Strasbourg, Université de Strasbourg-

CNRS UMR 7504, 23 rue du Loess, BP 43, 67034 Strasbourg cedex 2, France.

${ }^{\mathrm{c}}$ Imperial College London, Molecular Science and Research Hub, W12 0BZ, London, UK

* Correspondence to: c.romain@imperial.ac.uk, bellemin@unistra.fr, dagorne@unistra.fr 
Abstract. The present paper comprehensively reviews group 3-7 metal NHC complexes reported since 2014, with emphasis on their current applications and fundamental reactivity. Thanks to NHC stabilization, such metal complexes have witnessed significant and diversified developments, essentially in the area of homogeneous catalysis. Catalytic applications primarily include their use in unsaturated/polar monomer polymerization catalysis, hydroelementation of $\mathrm{C}=\mathrm{O}$ and $\mathrm{C}=\mathrm{N}$ substrates, metathesis-based catalytic reactions, hydroelementation of $\mathrm{C}=\mathrm{O}$ substrates and oxidation reactions. Apart from additional stability, the use of NHC fine-tuned steric/electronic properties was demonstrated to be crucial for catalytic performances. NHC-bearing Group 6 and 7 complexes, which have been most studied recently, have also been exploited as luminescent molecules and for biomedical applications (as radiopharmaceutical and theranostic agents). The large pool of available NHCs should further promote developments and application of such metal complexes in future years. 


\section{Abbreviations}

$a \mathrm{NHC}$ : C4-bonded NHC

CAAC: Cyclic Alkyl Amino Carbene

COD: 1,5-Cyclooctadiene

Cy: Cyclohexyl

DFT: Density functional theory

Dipp: 2,6-Diisopropylphenyl

FLP: Frustrated Lewis Pair

IDipp: 1,3-Bis(2,6-diisopropylphenyl)imidazol-2-ylidene

IMe: 1,3-Dimethylimidazol-2-ylidene

IMes: 1,3-Bis(2,4,6-trimethylphenyl)imidazol-2-ylidene

IPr: 1,3-Diisopropylimidazol-2-ylidene

It Bu: 1,3-Di-tert-butylimidazol-2-ylidene

IXy: 1,3-Bis(2,6-dimethylphenyl)imidazol-2-ylidene

LDA: Lithium diisopropylamide

MeIMe: 1,3,4,5-tetramethylimidazol-2-ylidene

Mes: 2,4,6-Trimethylphenyl

NHC: $N$-heterocyclic carbene

Pn: Pentalene

RCM: Ring-Closing Metathesis

ROMP: Ring-Opening Metathesis Polymerization

ROP: Ring-Opening Polymerization

SIDipp: 1,3-Bis(2,6-diisopropylphenyl)-4,5-dihydroimidazol-2-ylidene

SIMes: 1,3-Bis(2,4,6-trimethylphenyl)-4,5-dihydroimidazol-2-ylidene 


\section{Introduction}

$\mathrm{N}$-heterocyclic carbenes (NHC) have found widespread use across chemical science over past 20 years thanks to their exceptional electronic properties (strong $\sigma$-donation and $\pi$-accepting). ${ }^{1}$ Most notably, the use of NHCs as ligands to various metal centers has greatly impacted the field of organometallic chemistry and derived applications, in particular the area of homogeneous catalysis. ${ }^{2,3}$ NHC-bonded metal complexes typically exhibit an inert M-NHC bond resulting in an enhanced stability of the resulting metal complexes, leading to the development of various and numerous robust NHC-incorporating metal compounds with increased activity/selectivity in catalysis and possibly novel fundamental reactivity. The synthesis of various NHC ligand scaffolds, the development and applications of metal NHC complexes (including transition metals and main group metals), have been the subject of numerous reviews. ${ }^{1,2,3,4,5}$

Historically and to date, the coordination of NHCs to early transition metal centers (group 37), which are typically oxophilic and electropositive metal centers, have been much less studied than with more carbophilic mid- or late-transition metals for which the M-NHC bond is certainly more inert and stable. Yet, since NHCs are exceptionally strong $\sigma$-donating ligands, they also impart enhanced stability to most oxophilic and electron-poor metal centers, including group 3-7 metal centers. ${ }^{6,7,8,9,10,11}$ Beside the electronic features of the NHC unit, appropriate ligand design, such as the use of NHC-bearing chelating ligand, may be crucial for further stability and robustness of the resulting $\mathrm{M}-\mathrm{NHC}$ complexes, in particular in the case of oxophilic metal centers. ${ }^{12}$ Since the last comprehensive review on the subject in $2014,{ }^{6}$ numerous developments on NHC-stabilized early transition metal (group 3-7) complexes for use in various applications ranging from catalysis to optical and medical applications have been achieved. 
The present review comprehensively covers group 3-7 metal NHC complexes reported since 2014, with a particular emphasis on the current and potential applications as well as the fundamental reactivity of such organometallics. It is structured by type of NHC ligands for group 3 and group 4 metals since these metal centers are most frequently studied in the literature as group series for a given class of ligands. Group metals from group 5 through group 7 are sub-structured by metal center. Given the importance of $\mathrm{M}-\mathrm{NHC}$ bond distances to probe/evaluate $\mathrm{NHC}$ coordination, the range of $\mathrm{M}-\mathrm{NHC}$ bond distances are also compiled (Table 1), taking into account all thus far X-ray characterized M-NHC (M = group 3-7 metal) according to the CCDC database. NMR data on the M-NHC complexes, including the characteristic ${ }^{13} \mathrm{C}$ NMR chemical shift of $\mathrm{M}-C_{N H C}$ carbons, are not further discussed herein since the general trends, when any, have already been clearly established and reviewed. ${ }^{13}$

Table 1: Range of $\mathrm{M}-\mathrm{C}_{\mathrm{NHC}}$ bond length $(\AA)$ for $\mathrm{M}=$ Group $3-$ Group metal $^{a}$

\begin{tabular}{|c|c|c|c|}
\hline \multicolumn{2}{|c|}{ Metal } & \multirow{2}{*}{$\begin{array}{c}\text { Range of M-C } \mathrm{C}_{\mathrm{NHC}} \text { bond length }(\AA) \\
\text { (all types of NHC ligands) }\end{array}$} & \multirow{2}{*}{$\begin{array}{c}\begin{array}{c}\text { Overall number of } \\
\text { structures } \\
(\mathrm{CSD} \text { v5.41) }\end{array} \\
18 \\
\end{array}$} \\
\hline Groun 3 & Sc & & \\
\hline Group 3 & $\mathbf{Y}$ & {$[2.44-2.80]$} & 30 \\
\hline \multirow{3}{*}{ Group 4} & $\mathbf{T i}$ & {$[2.09-2.35]$} & 74 \\
\hline & $\mathbf{Z r}$ & {$[2.30-2.47]$} & 45 \\
\hline & Hf & {$[2.16-2.43]$} & 18 \\
\hline \multirow{3}{*}{ Group 5} & $\mathbf{V}$ & {$[2.04-2.27]$} & 21 \\
\hline & $\mathbf{N b}$ & {$[2.20-2.40]$} & 22 \\
\hline & Ta & {$[2.22-2.45]$} & 29 \\
\hline \multirow{3}{*}{ Group 6} & $\mathrm{Cr}$ & {$[1.98-2.25]$} & 84 \\
\hline & Mo & {$[2.06-2.33],[2.55-2.72]$} & 144 \\
\hline & $\mathbf{W}$ & {$[2.13-2.31]$} & 59 \\
\hline \multirow{3}{*}{ Group 7} & Mn & {$[1.93-2.28]$} & 110 \\
\hline & Tc & {$[2.07-2.23]$} & 10 \\
\hline & $\mathbf{R e}$ & {$[2.06-2.25]$} & 167 \\
\hline
\end{tabular}

a See also the Supporting Information for additional details. 


\section{Group 3 metals}

Over the past few years, NHC-bearing Sc(III) and Y(III) complexes have remained the subject of continuous interest for fundamental reactivity studies (including small molecules activation) and use in catalysis, most notably in olefin/styrene polymerization.

\section{a) Monodentate NHC ligands}

The reactivity of $\mathrm{Y}(\mathrm{III})$ complexes $\left[\left(\mathrm{Cp}^{\mathrm{Me}}\right) \mathrm{Y}(\mathrm{III})-n \mathrm{Bu}\right]_{2}$ and $\left[\left(\mathrm{Cp}^{\mathrm{Me}}\right)_{3} \mathrm{Y}\right]$ with IMes and IDipp was studied by Layfield and co-workers and greatly depends on NHC steric bulk. ${ }^{14}$ Thus, while both Y(III) precursors do not react with $\mathrm{I} i \mathrm{Pr},\left[\left(\mathrm{Cp}{ }^{\mathrm{Me})} \mathrm{Y}(\mathrm{III})-n \mathrm{Bu}\right]_{2}\right.$ readily undergoes a protonolysis reaction with less bulky IMes to form the $\mathrm{C}-\mathrm{H}$ activation product $\mathbf{1}$, constituting a rare instance of $M e$-Mes functionalization in group metal chemistry. The Y-NHC bond length (2.532(2) $\AA$ ) in 1 lies in the normal range for $\mathrm{Y}-\mathrm{NHC}$ adducts thus far characterized $(2.44 \AA<\mathrm{Y}-\mathrm{NHC}<2.80 \AA$, see Table 1$)$. In contrast, the reaction of dimer $\left[\left(\mathrm{Cp}^{\mathrm{Me})} \mathrm{Y}(\mathrm{III})-\right.\right.$ $n \mathrm{Bu}]_{2}$ with IMes affords the corresponding mononuclear abnormal $\mathrm{NHC}$ adduct $\left[\left(\mathrm{C} \mathrm{p}^{\mathrm{Me}}\right) \mathrm{Y}\right.$ aIMes) (2). The formation of 2 likely proceeds via initial C2-coordination of IMes to the Y(III) center followed by a sterically driven normal-to-abnormal NHC rearrangement. Though such NHC reactivity is well-established for late transition and main group metal NHC complexes, ${ }^{15,16}$ well-characterized $a \mathrm{NHC}$-supported remain rare for $d^{0}$ metal center. The M$a \mathrm{NHC}$ bond length in $\mathbf{2}(2.5786(6) \AA)$ is a bit longer than the $\mathrm{Y}-\mathrm{NHC}$ bond in chelate $\mathbf{1}$.
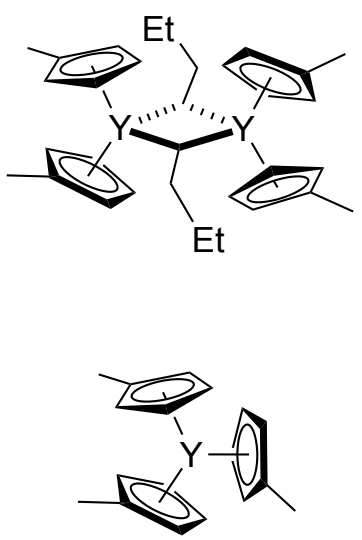

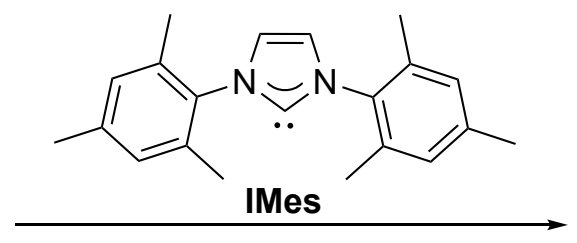

2

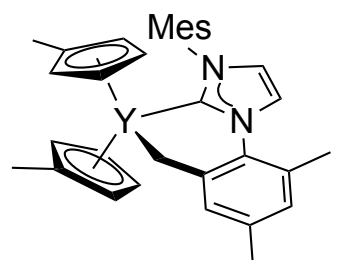

1

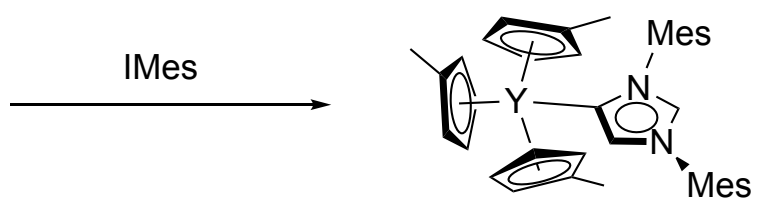


Scheme 1. Synthesis and $\mathrm{Y}-\mathrm{NHC}$ and $\mathrm{Y}-a \mathrm{NHC}$ adducts $\mathbf{1}$ and $\mathbf{2}$.

Liddle and co-workers reported an elegant and straightforward method to access $a$ NHCsupported Y(III) adduct 3 (Scheme 2), by reaction between $\left[\mathrm{Y}\left(\mathrm{N}(\mathrm{TMS})_{2}\right)_{3}\right]$ and a $\mathrm{N}$ heterocyclic olefin (NHO). ${ }^{17}$ The reaction involves a 1,4-proton shift and is proposed to proceed via an initial deprotonation at the $\mathrm{C} 4$ position of the $\mathrm{NHO}$ by a $\mathrm{Y}-\mathrm{N}(T M S)_{2}$ moiety, with a subsequent protonation of the methylene to yield adduct $\mathbf{3}$. The $\mathrm{Y}$-carbene bond in adduct 3 $(2.495(7) \AA)$ is the one of the shortest to date, in line with the trend that $\mathrm{M}-a \mathrm{NHC}$ bonds are generally shorter than C2-bonded M-NHC bonds. ${ }^{15}$

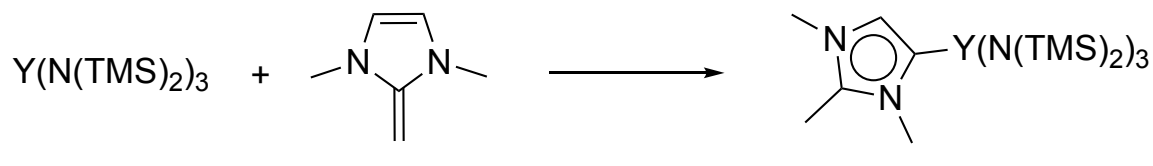

3

Scheme 2. Access to Y(III)- $a \mathrm{NHC}$ from $\left[\mathrm{Y}\left(\mathrm{N}(\mathrm{TMS})_{2}\right)_{3}\right]$ and a $N$-heterocyclic olefin.

Though most NHC moieties supporting $d^{0}$ metal complexes are typically part of a multidentate ligand to enhance M-NHC stability (vide infra), He and co-workers showed that a Sc(III) adduct of monodentate chiral bis-oxazoline-derived NHC (BOX-NHC) (4, Scheme 3) is a highly active and well-behaved olefin polymerization catalyst, unlike its Y(III) analogue 5. ${ }^{18}$ For instance, activation of 4 with 2 equiv of $\left[\mathrm{Ph}_{3} \mathrm{C}\right]\left[\mathrm{B}\left(\mathrm{C}_{6} \mathrm{~F}_{5}\right)_{4}\right]$ in the presence of 1 -hexene (4000 equiv) led to the production of well-defined poly(1-hexene) $\left(M_{\mathrm{n}}=8.7 \times 10^{-4}\right.$ g.mol ${ }^{-1}, Ð$ $=2.04$ ) at room temperature (activity $=285 \mathrm{~kg} \cdot \mathrm{mol}_{\mathrm{Sc}^{-1}} \cdot \mathrm{atm}^{-1} \cdot \mathrm{h}^{-1}$ ). In contrast, the $\mathrm{Y}(\mathrm{III})$ analogue $\mathbf{5}$ is inactive under such conditions. Pre-catalyst $\mathbf{4}$ was further exploited in the copolymerization of 1-hexene and 1,7-octadiene to yield random copolymers with diene incorporation ranging from 30 to $70 \%$ (depending on co-monomer feed) with about $20 \%$ 
pendant vinyl groups (Scheme 3). Such materials are particularly interesting since their properties may readily tuned through functionalization of the vinyl groups.

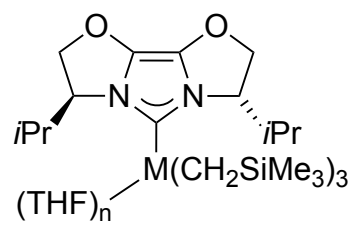

4, $M=$ Sc, $n=0$

5, $M=Y, n=1$
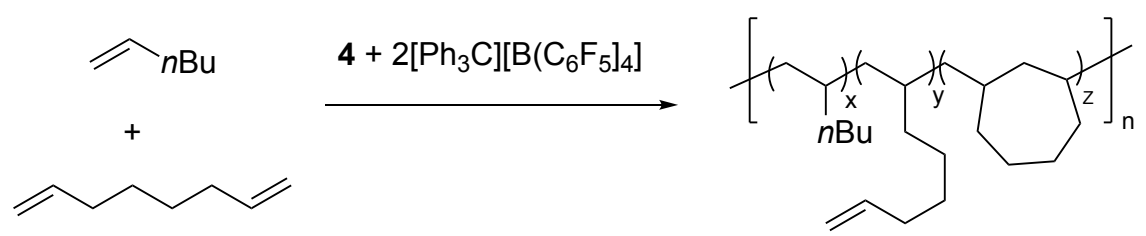

Scheme 3. Molecular structure of $\mathbf{4}$ and $\mathbf{5}$ and ethylene/1,7-octadiene polymerization catalyzed by 4 .

\section{b) Bidentate NHC ligands}

Over the past 10-15 years, anionic chelating NHC ligands have by far been the most studied with oxophilic early transition metal centers to afford robust M-NHC complexes. Among them, bidentate ligands typically incorporate an anionic hard donor $(\mathrm{O}$ - and $\mathrm{N}$-based usually), anchoring the ligand to the oxophilic metal center, to promote NHC coordination through chelation.

In a recent development, Arnold and co-workers prepared and structurally characterized various homo- and hetero-leptic Sc(III) and Y(III) complexes bearing bidentate alkoxy NHC ligands (6-9, Scheme 4) through salt metathesis reactions with the corresponding NHC precursor. ${ }^{19}$ The Sc-NHC bond in chelate $6(2.337(2) \AA$ is the shortest Sc-carbene bond distance reported thus far $(2.34 \AA<\mathrm{Sc}-\mathrm{NHC}<2.50 \AA$, see Table 1$)$, while a mean value of $2.436 \AA$ for the Sc-NHC bonds is observed in 9). The Y-NHC bonds in 7 and 8 (2.489(5) and 2.568(3) $\AA$ ) lie in the expected range though the former is among the shortest Y-NHC distance reported thus far (Table 1). 


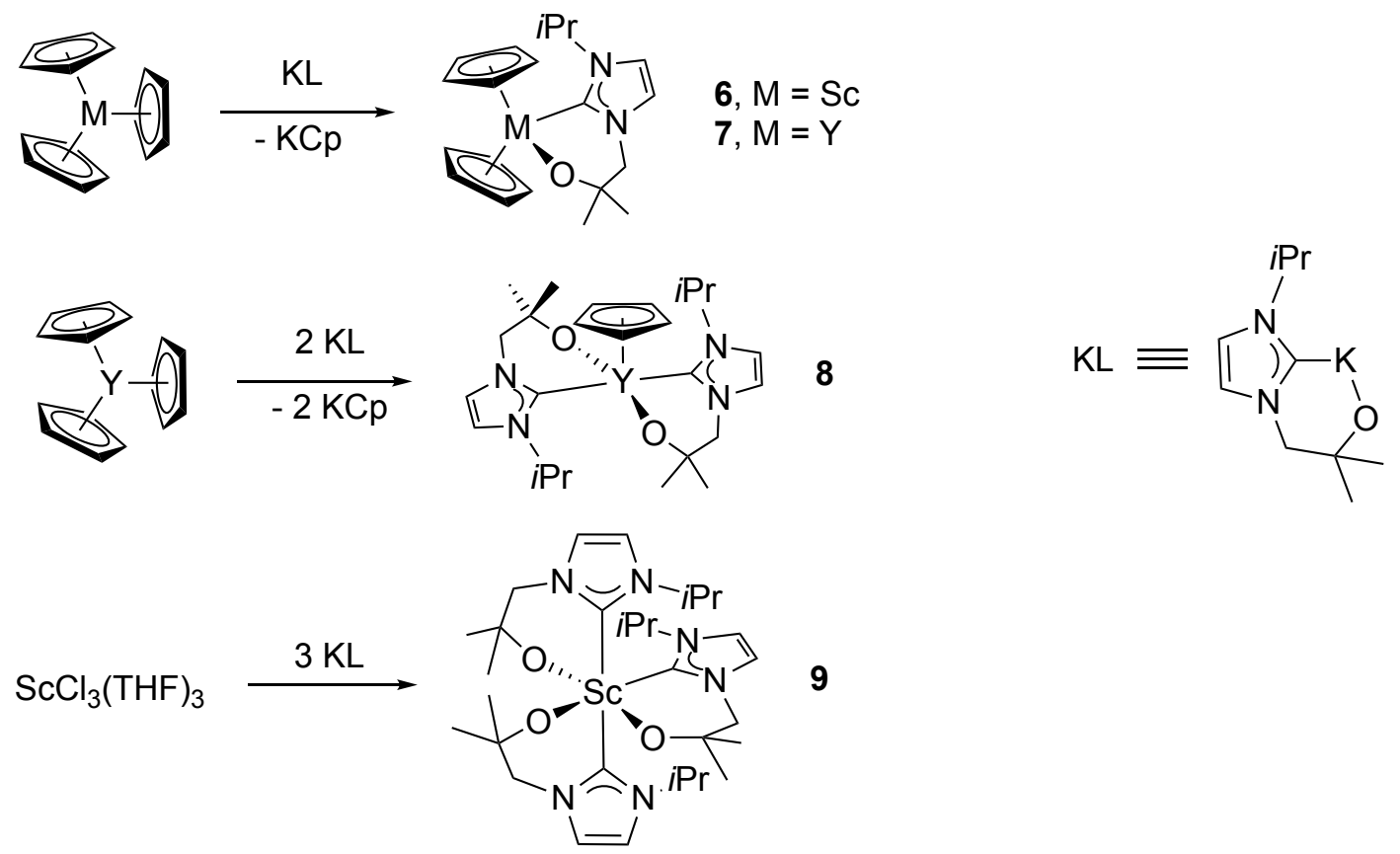

Scheme 4. Synthesis of Sc and Y 6-9 complexes supported by bidentate alkoxy NHC ligands.

The reactivity of complexes 6-9 was studied with a set of N-H and C-H acidic organic substrates including pyrrole, indole, $\mathrm{CpH}$, terminal alkynes and 1,1-diphenylacetone, leading in most cases to the corresponding N-H and C-H heterolytic cleavage products via protonolysis of the polar metal-NHC bond. For instance, complex 7 readily reacts with 1,1-diphenylacetone to generate the zwitterionic Y(III)-enolate imidazolium zwitterion 10 (Scheme 5).

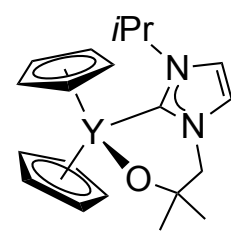

7

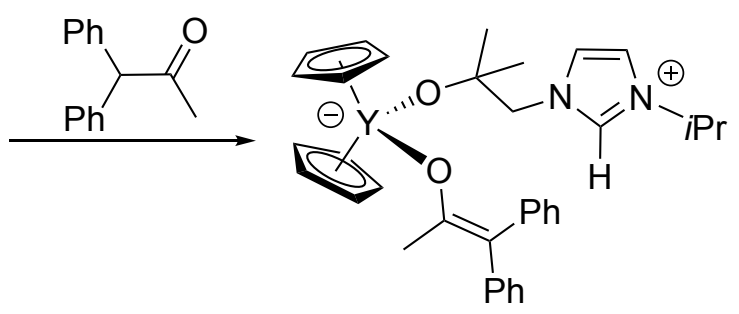

10

Scheme 5. Reactivity of Y-NHC species 7 with 1,1-diphenylacetone. 
Interestingly, the $\mathrm{Sc}(\mathrm{III})-\mathrm{NHC}$ bonds of homoleptic species 9 are stable in the presence of pyrrole, which was attributed to the steric hindrance at $\mathrm{Sc}(\mathrm{III})$, a smaller metal cation than $\mathrm{Y}(\mathrm{III})$, provided by the three bidentate ligands. Chelate 9 however reacts fast with $\mathrm{CO}_{2}$ at room temperature to produce coordination polymer $\mathbf{1 1}$ (Scheme 6) resulting from $\mathrm{CO}_{2}$ insertion into the three Sc-NHC bonds, demonstrating the potential use of the highly polar Sc-NHC bond for FLP-type behavior $($ FLP $=$ Frustrated Lewis Pair $) .{ }^{20}$
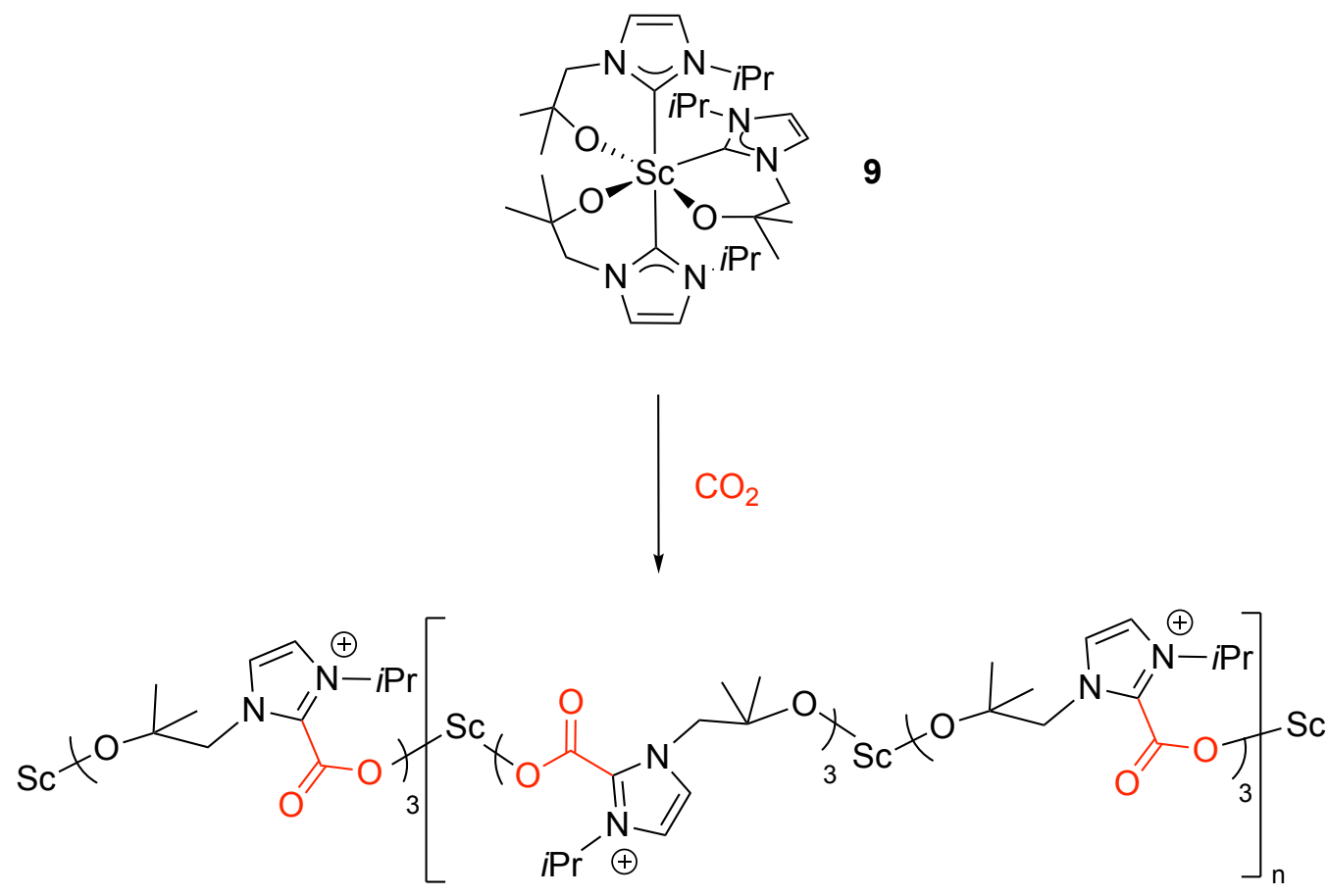

11

Scheme 6. Reactivity of homoleptic Sc-NHC complex 9 with $\mathrm{CO}_{2}$.

The insertion of $\mathrm{CS}_{2}$ into the Sc-NHC of 9 also readily occurs, yet only into two ScNHC bonds to form the corresponding dialkoxide bis-NHC dimer 12 (Scheme 7). 


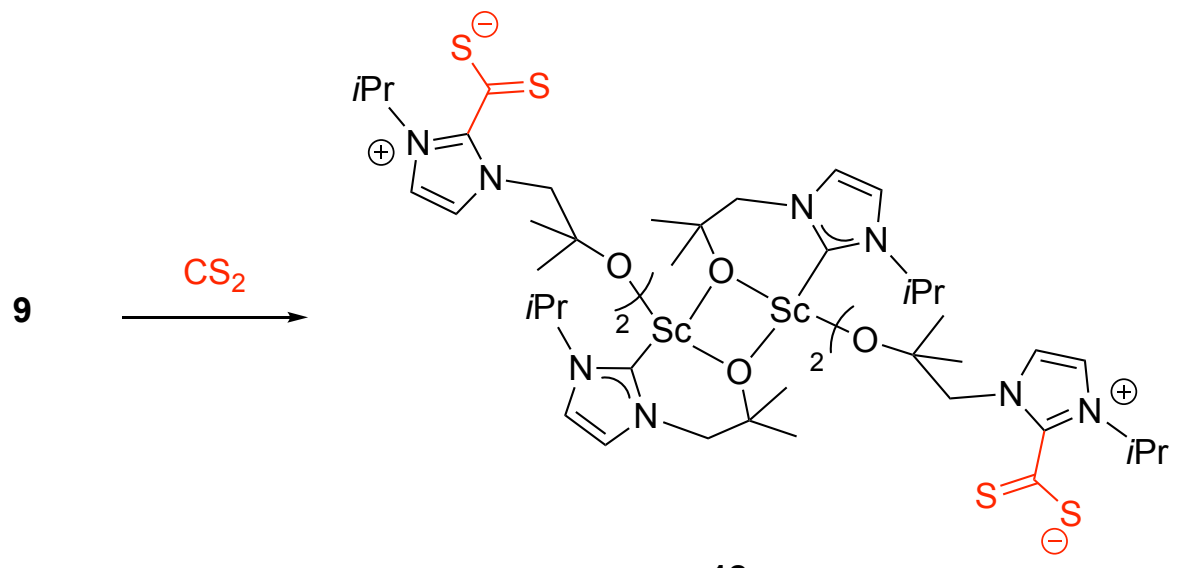

12

Scheme 7. Reactivity of homoleptic Sc-NHC complex 9 with $\mathrm{CS}_{2}$.

Using related bidentate alkoxy NHC ligands, Cui and co-workers reported on $\mathrm{Sc}(\mathrm{III})$ and Y(III) di-carbyl chelates 13-15 (Figure 1), which, due to a more open coordination sphere at $\mathrm{M}(\mathrm{III})$, are isolated and structurally characterized as dimers with $\mathrm{M}-\mathrm{NHC}$ bond distances in the normal range. ${ }^{21}$ The activation of the $\mathrm{Sc}(\mathrm{III})$ species $\mathbf{1 3}$ with one equiv of $\left[\mathrm{Ph}_{3} \mathrm{C}\right]\left[\mathrm{B}\left(\mathrm{C}_{6} \mathrm{~F}_{5}\right)_{4}\right]$ in the presence of 10 equiv of $\mathrm{Al}\left({ }^{i} \mathrm{Bu}\right)_{3}$ allowed isoprene polymerization catalysis with the production of poly(isoprene) with a moderate $c i s-1,4$ selectivity $(84.3 \%)$.

$R=M e, M=S c$

14: $\mathrm{R}=i \mathrm{Pr}, \mathrm{M}=\mathrm{Y}$
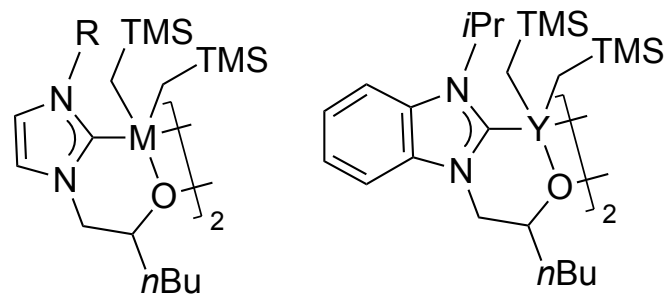

15

Figure 1. Molecular structures of compounds 13-15.

Following an earlier study of Arnold and co-workers on amido NHC Y(III) species 16 (Scheme 8) as lactide ring-opening polymerization (ROP) catalyst, Luo and co-workers investigated the ROP mechanism through DFT calculations using modelled $\mathbf{1 6}$ as catalyst. ${ }^{22}$ The authors concluded on an operative coordination-insertion mechanism with ROP initiation occurring preferentially via lactide insertion into the $\mathrm{Y}-\mathrm{N}\left(\mathrm{SiMe}_{3}\right)_{2} v s$. Sc-NHC bond. 
<smiles></smiles>

16

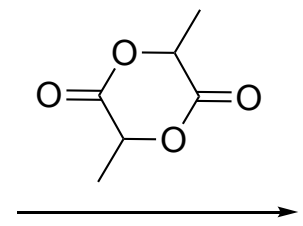
from DFT calculations

Scheme 8. DFT-computed ring-opening of lactide by complex 16.

The use of bidentate fluorenyl NHC ligands for coordination to group 3 metal salts has been primarily studied for use of the resulting chelates as olefin polymerization catalysts, taking advantage of the steric tunability of NHC ligands for fine-tuned catalyst design. In the area, Cui and co-workers recently showed that fluorenyl NHC Sc(III) complex 17 (Scheme 9), upon activation with $\left[\mathrm{HNMe}_{2} \mathrm{Ph}\right]\left[\mathrm{B}\left(\mathrm{C}_{6} \mathrm{~F}_{5}\right)_{4}\right]$ and in the presence of $\mathrm{Al}\left({ }^{i} \mathrm{Bu}\right)_{3}$, is an exceptionally active and selective catalyst for the alternative copolymerization of ethylene and polar styrene derivatives, opening the way to a range of unprecedented materials with precise microstructures. ${ }^{23}$

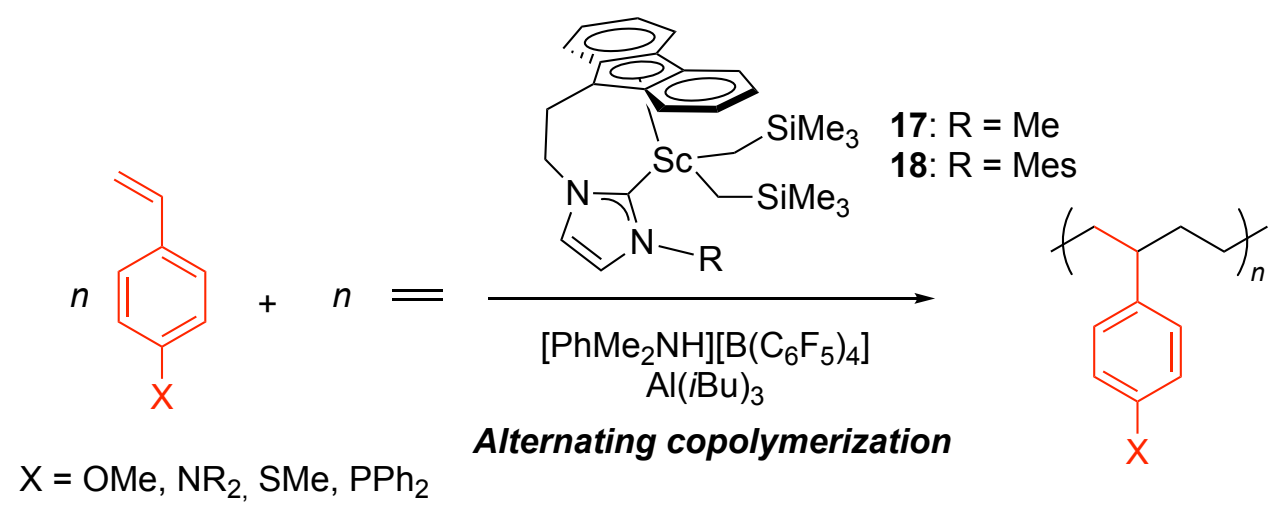

Scheme 9. Alternative copolymerization of ethylene and polar styrene monomers catalyzed by Sc-NHC species $\mathbf{1 7}$ and $\mathbf{1 8}$. 
For instance, the ethylene/ $p$-methoxystyrene copolymerization mediated by such a Sc-NHC system afforded a narrow disperse copolymer with a pseudo-alternating microstructure in high activity of $3.19 \times 10^{5}$ g.molsc ${ }^{-1} \cdot \mathrm{h}^{-1}$ (toluene, $70^{\circ} \mathrm{C}$ ) and a high comonomer conversion. A perfectly alternating material was even produced from the ethylene $/ p-(N, N-$ dimethylamino)styrene copolymerization. The use of a Me-substituted NHC ligand, as in 17, appears crucial for catalytic activity. Thus, species 18, which bears a more sterically demanding Mes-substituted NHC, is ten times less active in ethylene/ $p$-methoxystyrene copolymerization than its counterpart 17, which was ascribed to severe steric crowding at $\mathrm{Sc}(\mathrm{III})$ in $\mathbf{1 8}$. The observed alternative copolymerization activity was rationalized both by steric and electronic factors. While favored electronically, chain propagation of polar styrenes is precluded for steric reasons after initial monomer insertion, thus de facto promoting ethylene insertion. The sterically relieved $\mathrm{Sc}(\mathrm{III})$ coordination site may then insert the more Lewis basic styrene comonomer. In a related study by Luo and co-workers, the reactivity of styrene with the Y(III) cation 19 (Figure 2) was DFT computed showing that the styrene first insertion product was stable but that subsequent chain propagation was disfavored for steric reasons, accounting for the inactivity of $\mathbf{1 9}$ in styrene polymerization catalysis. ${ }^{24}$

The bidentate fluorenyl NHC Sc(III) species 20 (Figure 2) was also used by Hou and coworkers as an ethylene/1,6-heptadiene cyclopolymerization catalyst to afford new cyclopolymers containing primarily with six-membered rings $\left(M_{\mathrm{n}}=1.2 \times 10^{4}-5.1 \times 10^{4}\right.$ g.mol ${ }^{-}$ ${ }^{1}, Ð=1.73-2.72$ ) in good activity (up to $\left.640 \mathrm{~kg} \cdot \mathrm{mol}_{\mathrm{Sc}}{ }^{-1} \cdot \mathrm{atm}^{-1} \cdot \mathrm{h}^{-1}\right) \cdot{ }^{25}$

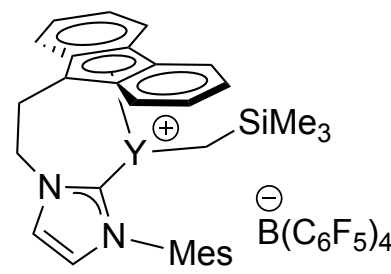

19

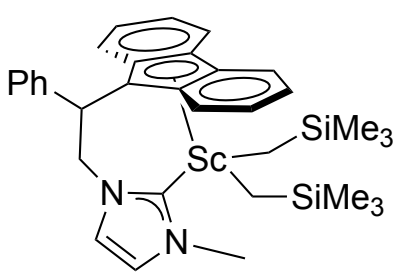

20 
Figure 2. Molecular structure of complexes 19 and 20.

\section{c) Tridentate NHC ligands}

Compared to their bidentate analogues, tridentate NHC ligands are of potential interest for additional stabilization of the $\mathrm{M}-\mathrm{NHC}$ bond through chelate formation. The coordination of such ligands to group 3 metal centers have been the subject of a few studies since 2014. Thus, Ni and co-workers synthesized through an amine elimination reaction the homoleptic Y(III) salt species 21 and 22 (Scheme 10), which contain a central Y(III) center supported by two $\kappa^{3}-O, C, O$-bonded bis-phenolate NHC ligand. ${ }^{26,27}$ Species 21 polymerizes lactide, yet through a poorly controlled ROP process leading to ill-defined PLA. Homoleptic complexes $\mathbf{2 1}$ and $\mathbf{2 2}$ were found to be effective catalysts in $n$-hexyl-isocyanate polymerization to yield high molecular weight and narrow disperse polyisocyanates $\left(M_{\mathrm{n}}\right.$ up 97 x $10^{4} \mathrm{~g}^{\mathrm{mol}} \mathrm{mol}^{-1}$, $Ð=1.84-1.91)$. Control experiments suggest the involvement of the NHC moiety as a Bronstedt base for polymerization initiation.
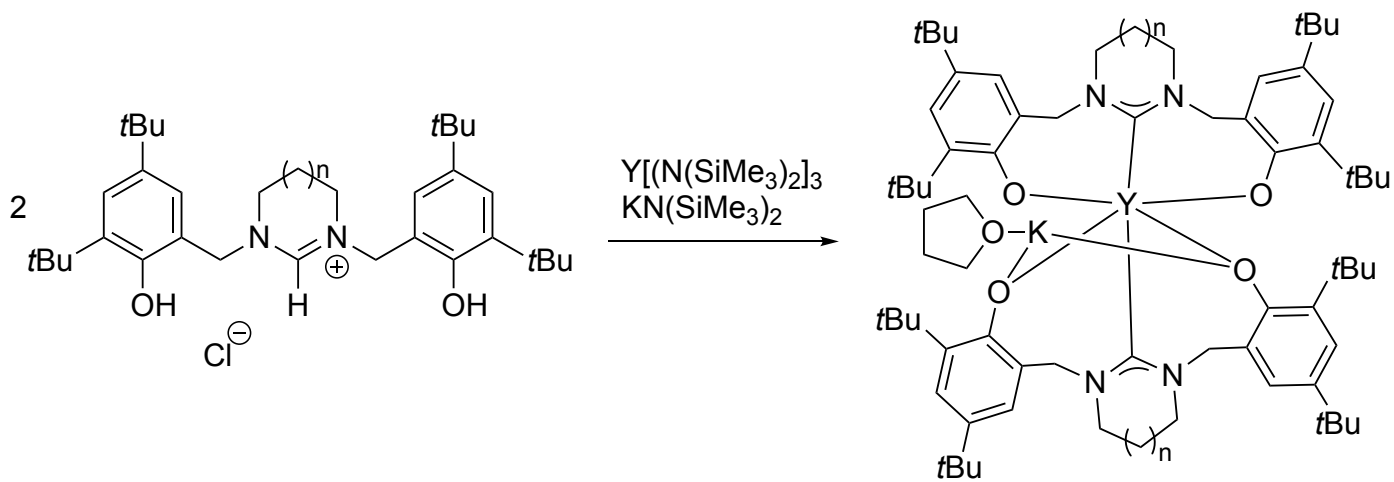

21: $\mathrm{n}=0$ 22: $\mathrm{n}=1$

Scheme 10. Synthesis of Y-NHC chelates 21 and 22.

The coordination of a bis-NHC amido pincer ligand to Y(III), studied by Wang and co-workers, led to the characterization of heteroleptic and homoleptic complexes $\mathbf{2 3}$ and 24 , prepared via salt metathesis routes (Scheme 11). ${ }^{28}$ The Y-NHC bond distances in chelates 23 and 24 (2.525(4) and 2.518(3) $\AA$, respectively) are comparable to those in known Y-NHC complexes 
(Table 1). Compound $\mathbf{2 3}$ was successfully exploited for the catalytic $\mathrm{C}-\mathrm{H}$ addition of terminal alkynes to carbodiimides at room temperature to form the corresponding amidine products (Scheme 12).

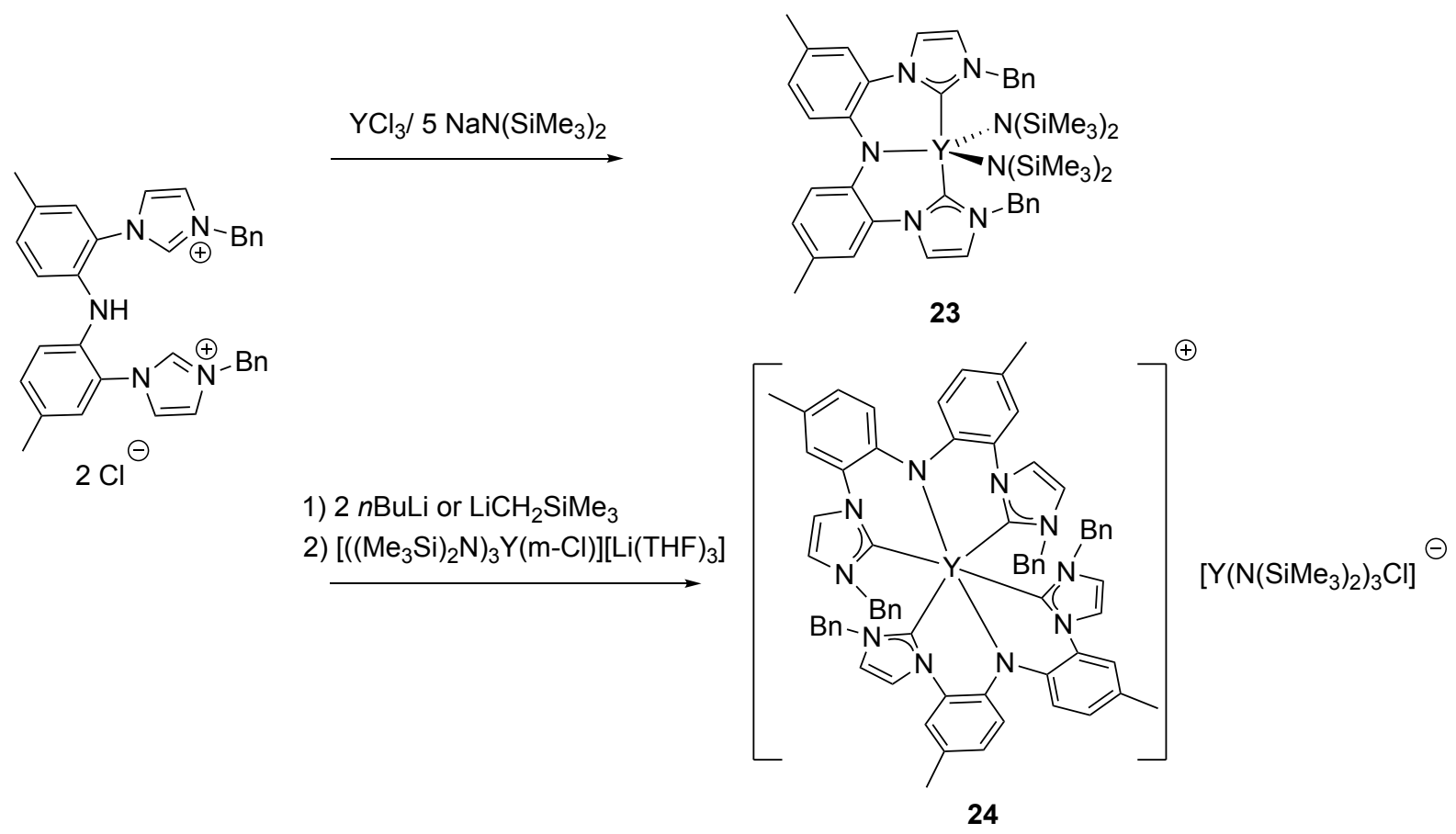

Scheme 11. Synthesis of heteroleptic and homoleptic complexes 23 and 24.

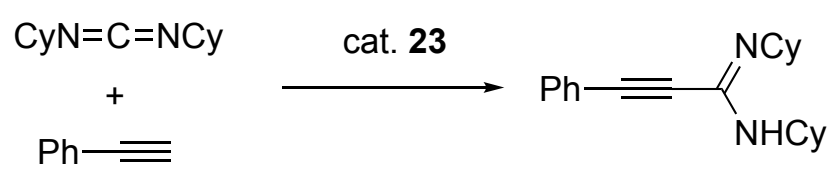

Scheme 12. Addition of terminal alkynes to carbodiimides catalyzed by $\mathbf{2 3}$.

An Y(III) amido complex bearing two tridentate amidate-functionalized NHC ligand (25, Scheme 13) was recently prepared by Wang and co-workers through a one-step reaction. ${ }^{29}$ The rather long Y-NHC bond distances in species 25 (2.640 and 2.800 $\AA$ ) presumably reflects steric hindrance at the Y(III) center. Interestingly, amido species $\mathbf{2 5}$ efficiently catalyzes the hydroboration of imines and nitriles in the presence of pinacolborane (pinB-H), albeit under rather harsh conditions (Scheme 13). Based on monitoring NMR studies, the actual 
hydroboration catalyst is proposed to be an Yttrium hydride species that would initially form by $\sigma$-bond metathesis between the $\mathrm{Y}-\mathrm{N}\left(\mathrm{SiMe}_{3}\right)_{2}$ group of $\mathbf{2 5}$ and pinB-H.

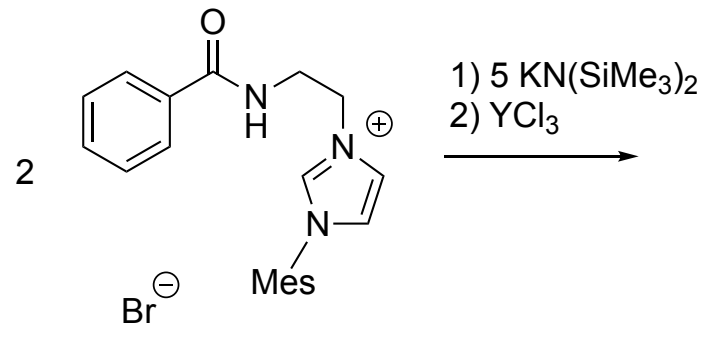

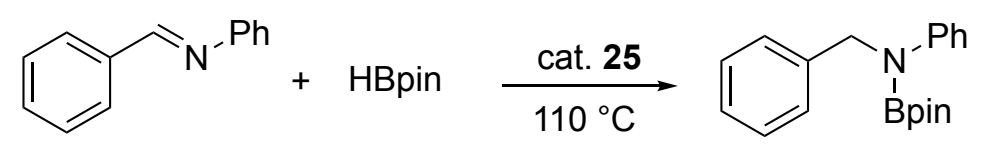

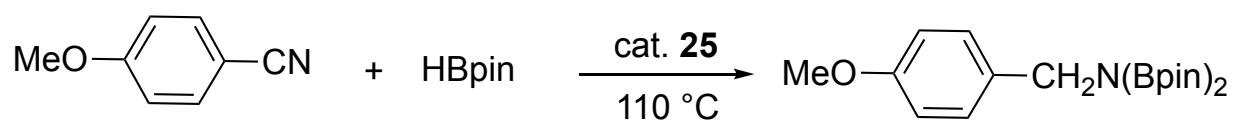

Scheme 13. Synthesis of Y-NHC complex 25 and its use in imines and nitriles hydroboration catalysis.

\section{Group 4 Metals}

\section{a) Monodentate NHCs}

Low valent $M-N H C$ complexes. Over the recent years, the use of monodentate NHC ligands, including Cyclic Alkyl Amino Carbene (CAAC) ligands, ${ }^{3 \mathrm{k}}$ for the stabilization of low valent $\mathrm{M}(0), \mathrm{M}(\mathrm{I})$ and $\mathrm{M}(\mathrm{II})$ group 4 metal centers has attracted a particular attention. Thus, Braunschweig and co-workers reported that bis(benzene) $\operatorname{Ti}(0)$ species $\left[\operatorname{Ti}\left(\eta^{6}-\mathrm{C}_{6} \mathrm{H}_{6}\right)_{2}\right]$ reacts with carbene IMe to afford the bent sandwich Ti(0)-NHC adduct $\mathbf{2 6}$ (Scheme 14). ${ }^{30}$ The Ti-NHC bond distance in $\mathbf{2 6}(2.323 \AA)$ lies in the upper range of Ti-NHC bond distances (Table 1) and is significantly longer than those in $\mathrm{TiCl}_{4}-\mathrm{NHC}$ adducts $(2.197 \AA$ in average), in line with a less Lewis acidic Ti center. 


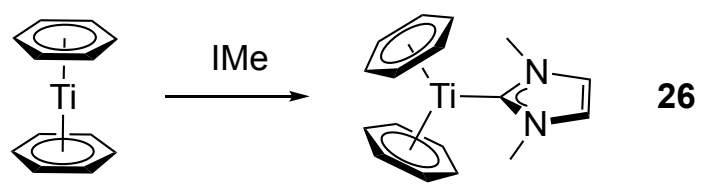

Scheme 14. Synthesis of Ti(0)-NHC adduct 26

Studying the coordination chemistry of $\operatorname{bis}\left(\eta^{5}: \eta^{1}\right.$-pentafulvene) Ti(IV) complexes, Beckhaus and co-workers characterized the formally Ti(0)-NHC adducts 27 (Scheme 15), now featuring two $\eta^{4}$-coordinated pentafulvene moieties due to a haptotropic shift of the pentafulvene ligands, thus reflecting the structural flexibility of the Ti-pentafulvene coordination. ${ }^{31}$ The rather long Ti-NHC bond distance $(2.342 \AA)$ in 27 (R = adamantylidene) is comparable to that in related adduct $\mathbf{2 6 .}$
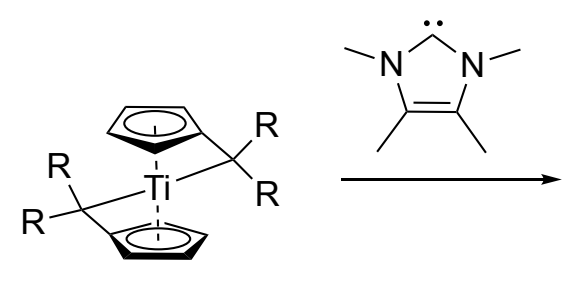

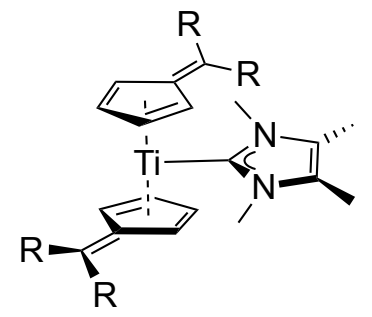

27
$\mathrm{R}=\mathrm{Ph}, p$-Tol, adamantylidene

Scheme 15. Synthesis of bis-pentafulvene Ti-NHC adducts 27.

Cloke and co-workers investigated the coordination of 1,3,4,5-tetramethylimidazol-2-ylidene ( $\left.{ }^{\mathrm{Me}} \mathrm{IMe}\right)$ to bis-pentalene $\mathrm{Ti}(\mathrm{II})$ complexes, which resulted in $\mathrm{C}-\mathrm{H}$ and $\mathrm{H}-\mathrm{H}$ activation chemistry. Thus, coordination of strong Lewis base ${ }^{\mathrm{Me}} \mathrm{IMe}$ to $\left[\mathrm{Ti}\left(\mu: \eta^{5}, \eta^{5}-\mathrm{Pn}\right)_{2}\right](\mathrm{Pn}=$ pentalene $)$ promotes $\mathrm{C}-\mathrm{H}$ activation of an ${ }^{i} \mathrm{Pr}$ group of $\mathrm{Si}\left({ }^{\mathrm{i}} \mathrm{Pr}\right)_{3}$ to afford adduct complex $\mathbf{2 8}$ containing a bridging Ti-H-Ti hydride (Scheme 16). ${ }^{32}$ Species 28 reversibly reacts with $\mathrm{H}_{2}$ to produce Ti dihydrido 29 (Scheme 16), thus reversing the $\mathrm{C}-\mathrm{H}$ activation reaction. Labelling experiments and DFT calculations suggest that the reaction of $\mathrm{H}_{2}$ with $\mathbf{2 8}$ does not proceed through $\sigma$-bond metathesis (of the $\mathrm{Ti}-\mathrm{CH}_{2}$ bond): rather, steric compression induced by $\mathrm{H}_{2}$ approach appears 
sufficient to reverse the $\mathrm{C}-\mathrm{H}$ activation reaction. ${ }^{32,33}$ The Ti-NHC bond distances in $\mathbf{2 8}$ and $\mathbf{2 9}$ are nearly identical (average $2.300 \AA$ ) and are consistent with a low-valent Ti center.

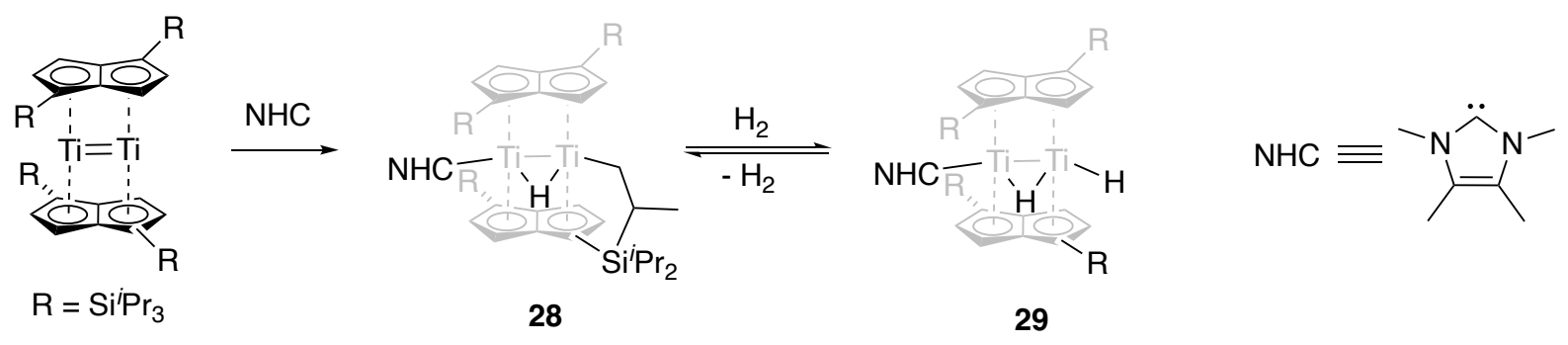

Scheme 16. Formation of Ti-NHC complexes from $\mathrm{C}-\mathrm{H}$ and $\mathrm{H}-\mathrm{H}$ activation of a bis-pentalene di-Ti species.

CAAC ligands, due to their stronger $\sigma$-donating and $\pi$-accepting properties (vs. classical NHCs), are well-suited carbene ligands for the stabilization of low valent metal complexes, which has motivated recent studies in the area of group 4 metal species. ${ }^{3 \mathrm{k}}$

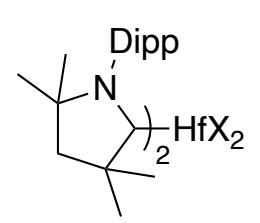

30a: $\mathrm{R}=\mathrm{Cl}$

30b: $R=B n$

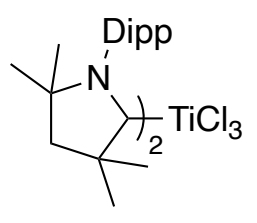

31<smiles>CC1(C)CC(C)(C)N([Pb])C1C(Cl)Cl</smiles>

32<smiles></smiles>

33

Figure 3. Molecular structures of carbene-stabilized low valent metal species 30-33.

Deng and co-workers reported in 2018 the structure and characterization of CAACsupported $\mathrm{Hf}(\mathrm{II})$ species 30a-b via reduction of $\mathrm{HfCl}_{4}$ by $\mathrm{KC}_{8}$ in the presence of 2 equiv of a CAAC, affording $(\mathrm{CAAC})_{2} \mathrm{HfCl}_{2}\left(\mathbf{3 0 a}\right.$, Figure 3). ${ }^{34}$ The latter was functionalized to the $\mathrm{HfBn}_{2}$ derivative 30b by reaction with 2 equiv. of KBn. Species 30a-b, which are the first examples of CAAC-supported group 4 metal species, are diamagnetic and DFT calculations suggest a 
closed-shell singlet state as ground state for these complexes. The Hf-carbene bond distances in 30a-b (2.167 $\AA$ average) are the shortest Hf-carbene bonds to date. In particular, they are significantly shorter than those in $\mathrm{Hf}(\mathrm{IV})-\mathrm{NHC}$ analogues (for instance, $\mathrm{M}-\mathrm{NHC}=2.405 \AA$ in (IPr) $\mathrm{HfCl}_{4}$, and $2.401 \AA$ in $\left.(\operatorname{IPr})_{2} \mathrm{HfCl}_{4}\right)$, reflecting the stronger $\sigma$-donor character of CAAC ligands. In a similar vein, Ye and coll. prepared CAAC-supported $\mathrm{Ti}(\mathrm{I})$ and $\mathrm{Ti}(\mathrm{II})$ metal complexes 31 and 32 (Figure 3), concomitantly with the group of Radius in the case of $\mathbf{3 1} .^{35,36}$ The Ti-NHC bond distances for 32 (2.095 and 2.122 $\AA$ ) are the shortest Ti-carbene bonds to date for monodentate carbene ligands. The bis-NHC Ti(I) adduct [(IMes) $\left.)_{2} \mathrm{TiCl}_{3}\right](\mathbf{3 3}$, Figure 3) was also characterized. All structural characterization data on $d^{1}$ metal complexes $\mathbf{3 1}$ and $\mathbf{3 3}$ agree with delocalization of the additional electron in the carbene $\mathrm{p}_{\pi}$ orbitals. ${ }^{36}$

M(IV)-NHC complexes. Recent noteworthy developments on group 4 metal species bearing a monodentate NHC include the use of anionic $\mathrm{N}$-Heterocyclic Carbenes (NHC functionalized with a weakly coordinating borate moiety, WCA-NHC) by Nomura, Tamm and co-workers for the synthesis of half-titanocenes $\mathbf{3 4 a - b}$ and their dimethyl analogues $\mathbf{3 5 a} \mathbf{a}-\mathbf{b}$ (Scheme 17) ${ }^{37}$ Despite the anionic nature of the NHC ligand, the Ti-NHC bond distances for 34a-b (average $2.216 \AA$ ) lie in the mid-range for Ti-NHC species (Table 1) and are similar to those of other Ti(IV)-NHC adducts. Such complexes were found to be highly active in ethylene polymerization (activity up to $4590 \mathrm{~kg}$-PE. $\mathrm{mol}_{\mathrm{Ti}}{ }^{-1} \cdot \mathrm{h}^{-1}$ with $\mathbf{3 4 b}$ as pre-catalyst and in the presence of $\mathrm{Al}\left({ }^{i} \mathrm{Bu}\right)_{3} /\left[\mathrm{Ph}_{3} \mathrm{C}\right]\left[\mathrm{B}\left(\mathrm{C}_{6} \mathrm{~F}_{5}\right)_{4}\right]$ as co-catalyst) to afford high molecular weight $\mathrm{PE}$. Species 34b is also an highly effective ethylene/1-hexene copolymerization catalyst, showing 1-hexene incorporation comparable to the best group 4 metal catalysts developed thus far, such as landmark constrained-geometry catalyst $\left[\left\{\mathrm{Me}_{2} \mathrm{Si}\left(\mathrm{C}_{5} \mathrm{Me}_{4}\right)\left(\mathrm{N}^{t} \mathrm{Bu}\right)\right\} \mathrm{TiCl}_{2}\right] .{ }^{38}$ 
$\left(\mathrm{C}_{6} \mathrm{~F}_{5}\right)_{3} \mathrm{~B}$

$\mathrm{Ar}=2,6-\mathrm{Me}_{2} \mathrm{C}_{6} \mathrm{H}_{3}$

WCA-NHC
$\stackrel{(\mathrm{Cp}-\mathrm{R}) \mathrm{TiCl}_{3}}{\longrightarrow}$

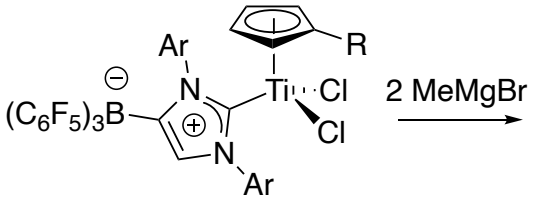

34a: $\mathrm{R}=\mathrm{H}$

34b: $R={ }^{t} \mathrm{Bu}$

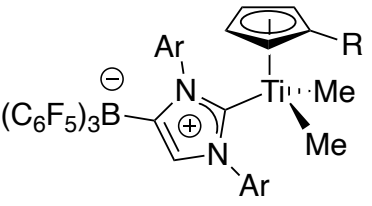

35a: $\mathrm{R}=\mathrm{H}$ 35b: $R={ }^{t} \mathrm{Bu}$

Scheme 17. Synthesis of Ti complexes 34a-b and 35a-b supported a WCA-NHC ligand.

Other monodentate M(IV)-NHC group 4 metal complexes are depicted in Figure 4 and include the recent characterization of adducts $\left[(\mathrm{IMes})_{2} \mathrm{TiCl}_{4}\right](\mathrm{Ti}-\mathrm{NHC}=2.336 \AA$ average, 36), $\left[\left(\mathrm{IMes}_{)} \mathrm{TiCl}_{4}\left(\mathrm{PMe}_{3}\right)\right](\mathbf{3 7}),\left[\left(\mathrm{I}^{i} \mathrm{PrMe}\right) \mathrm{TiCl}_{4}\right](\mathrm{Ti}-\mathrm{NHC}=2.176 \AA\right.$ average, 38), [(CAAC)TiCl 4$]$ $(2.198 \AA, 39 a),\left[(\mathrm{CAAC})_{2} \mathrm{TiCl}_{4}\right](\mathrm{Ti}-\mathrm{NHC}=2.331 \AA$ average, 39b $)$ and the more unusual Hfgermylene zwitterionic NHC adduct 40 (Hf-NHC $=2.365 \AA$ ) ${ }^{36,39}$ Also, a theoretical DFT study on a wide range of Lewis adducts of the type $\mathrm{L}-\mathrm{TiF}_{4}$ (including $\mathrm{L}=\mathrm{NHC}$ and $a \mathrm{NHC}$ ) concluded on the essentially electrostatic nature of the NHC-Ti and $a \mathrm{NHC}-\mathrm{Ti}$ bonds. ${ }^{40}$<smiles></smiles>

36

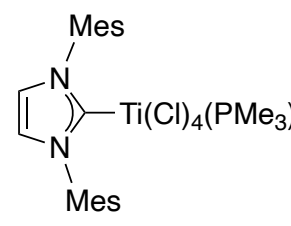

37

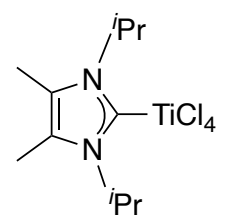

38<smiles>CC1CN([Pb])C(C)(C)C1</smiles>

39a: $\mathrm{n}=1$

$39 \mathrm{~b}: \mathrm{n}=2$

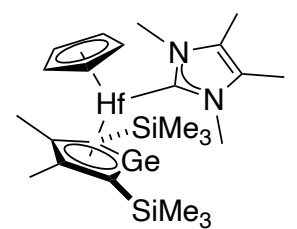

40

Figure 4. Molecular structures of Ti(IV) carbene adducts 36-39 and Hf-NHC species 40.

\section{b) Bidentate NHC ligands}

A few examples of group 4 metal species supported by bidentate NHC ligands have been studied since 2014, essentially using bidentate NHC-phenolate-type ligands. Thus, Buchmeiser and co-workers developed $\left[\kappa^{2}-C, O\right] \mathrm{TiCl}_{3}(\mathrm{THF})$ and $\left[\kappa^{2}-C, O\right](\mathrm{OAr}) \mathrm{TiCl}_{2}$ monochelate complexes incorporating sterically bulky Ar groups, 43-45 (Scheme 18), for use in olefin homo-/co-polymerization catalysis. ${ }^{41}$ Complex $44 a$ performed best both in ethylene 
polymerization (activity $=190 \mathrm{~kg}-\mathrm{PE} \cdot \mathrm{mol}_{\mathrm{Ti}}{ }^{-1} \cdot \mathrm{h}^{-1} \cdot \mathrm{bar}^{-1}$ ) to afford high-density $\mathrm{PE}$, and in ethylene/norbornene co-polymerization (activity $=70 \mathrm{~kg}-\mathrm{PE} \cdot \mathrm{mol}_{\mathrm{Ti}^{-1}} \cdot \mathrm{h}^{-1} \cdot \mathrm{bar}^{-1}$ ). In contrast, a much lower polymerization activity $\left(25 \mathrm{~kg}-\mathrm{PE} \cdot \mathrm{mol}_{\mathrm{Ti}}^{-1} \cdot \mathrm{h}^{-1} \cdot \mathrm{bar}{ }^{-1}\right)$ was observed using $\left[\kappa^{2}-\right.$ $C, O] \mathrm{TiCl}_{3}(\mathrm{THF})$ derivatives such as $\mathbf{4 3 a - c}$, indicating that the incorporation of a bulky $\mathrm{OAr}$ moiety is of importance for high activity. The authors proposed that the steric and electronic properties of catalyst 44a are properly balanced for an effective suppression of $\beta$-hydride elimination reactions during polymer chain growth, thus the better performance.

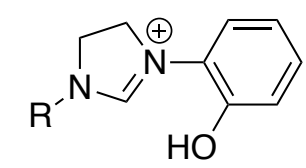

\begin{tabular}{l} 
1) $\mathrm{KN}\left(\mathrm{SiMe}_{3}\right)_{2}$ \\
2) $\mathrm{TiCl}_{4}(\mathrm{THF})_{2}$ \\
\hline
\end{tabular}<smiles></smiles>

ArOLi 43a: $\mathrm{R}=2,6-\mathrm{Pr}_{2} \mathrm{C}_{6} \mathrm{H}_{3}$

43b: $R=$ Mes

43c: $\mathrm{R}=2,6-\mathrm{Me}_{2} \mathrm{C}_{6} \mathrm{H}_{3}$<smiles></smiles>

44a: $\mathrm{R}=2,6-\mathrm{Pr}_{2} \mathrm{C}_{6} \mathrm{H}_{3}$ 44b: $R=$ Mes<smiles>CC(C)C1=CC(C(C)C)=C(c2cccc(-c3c(C(C)C)cc(C(C)C)cc3C(C)C)c2OC(C)(C)C)[Te](Cl)(Cl)(Cl)C2N(C)CCN2c2ccccc2O1</smiles>

45

Scheme 18. Synthesis of Ti-NHC complexes 43-45.

Le Roux and co-workers prepared and characterized $\left[\kappa^{2}-C, O\right]_{2} \mathrm{Ti}(\mathrm{IV})$ bis-chelates 46ab, found to be moderately active as ethylene polymerization catalysts (Figure 5). ${ }^{42}$ The steric hindrance of the NHC moiety appears crucial to the stability of such bis-chelates since less hindering $N$-substituents (such as Mes and 2,6- $\mathrm{Et}_{2}-\mathrm{C}_{6} \mathrm{H}_{3}$ ) led to the unexpected formation of $\left[\kappa^{4}-O, N, N, O\right]$-bis-(imidazolidinylidene) $\mathrm{TiCl}_{2}$ complexes $47 \mathbf{a}-\mathbf{b}$ (Figure 5), presumably via a $\mathrm{C}_{\text {carbene }}-\mathrm{C}_{\text {carbene }}$ coupling reaction of the initially formed $\left[\kappa^{2}-C, O\right]_{2} \mathrm{TiCl}_{2}$ chelates. 


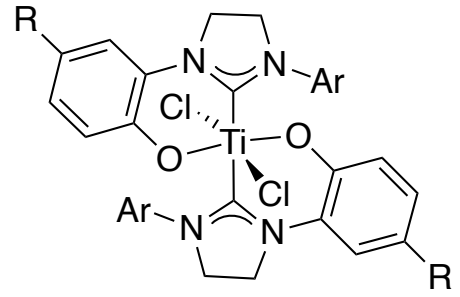

46a: $\mathrm{Ar}=2,6-{ }^{-} \mathrm{PrC}_{6} \mathrm{H}_{3}, \mathrm{R}=\mathrm{H}$

46b: $\mathrm{Ar}=2,6-\mathrm{PrC}_{6} \mathrm{H}_{3}, \mathrm{R}=\mathrm{Me}$

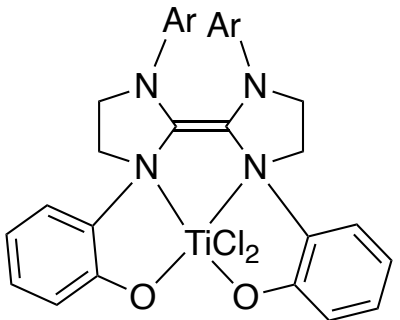

47a: $\mathrm{Ar}=$ Mes

47b: $\mathrm{Ar}=2,6-\mathrm{Et}_{2}-\mathrm{C}_{6} \mathrm{H}_{3}$

Figure 5. Molecular structures of Ti(IV) chelates $\mathbf{4 6}$ and 47.

Slaughter and co-workers studied the coordination chemistry of bidentate imino-NHC ligands with $\mathrm{Hf}(\mathrm{IV})$ precursors. ${ }^{43}$ While the expected bis-adduct Hf(IV) species 47 (Scheme 19) was characterized with $\mathrm{HfCl}_{4}$, the reaction with $\mathrm{HfBn}_{4}$ afforded product 49, in which the carbene center of the NHC unit is replaced by the Hf(IV) center. The formation of 49 is proposed to occur via the initial formation of the expected (NHC-imino)Hf chelate followed by three sequential benzyl migrations to the $\mathrm{NCN}$ center. The benzyl migration reactivity, related of that earlier observed with $\mathrm{Zr}(\mathrm{IV})-\mathrm{NHC}$ systems, ${ }^{44}$ was rationalized by an enhanced electrophilicity of the $\mathrm{C}_{\mathrm{NHC}}$ center due the electronic activation of the imino group and coordination to Lewis acidic $\mathrm{Hf}(\mathrm{IV})$ center.

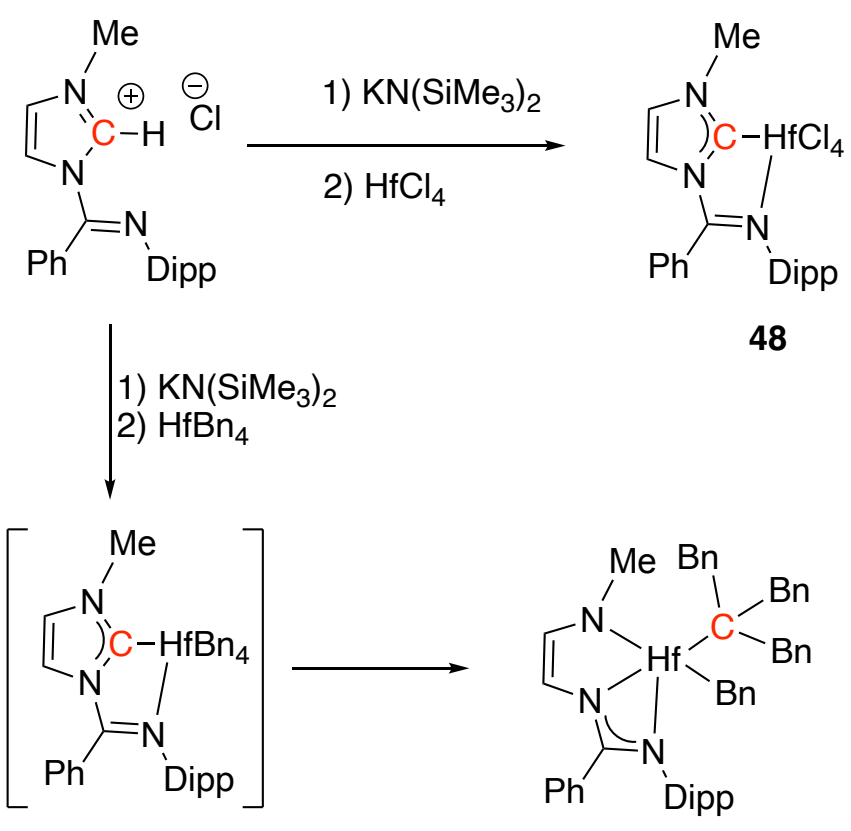


Scheme 19. Reactivity of imino-NHC bidentate ligands with Hf(IV) precursors.

\section{c) Tridentate NHC ligands}

Among group 4 carbene complexes, group 4 metal complexes stabilized NHC-bearing tridentate ligands have the most studied over the past five years, especially using NHC-bisphenolate-type chelating ligands.

NHC-bis-phenolate ligands. Following their early studies in the area, Dagorne, Bellemin-Laponnaz and co-workers reported on air-stable homoleptic group 4 metal complexes of the type $\left[\kappa^{2}-O, C, O\right]_{2} \mathrm{M}(\mathbf{5 0 a}-\mathbf{c}$, Figure 6$)$ with preliminary studies of their redox and optical properties. ${ }^{45}$ The $\mathrm{Zr}(\mathrm{IV})$ and $\mathrm{Hf}(\mathrm{IV})$ chelates 50b and 50c readily undergo ligand-centered multiple oxidations in a controlled manner. They are also luminescent upon excitation at 362 $\mathrm{nm}$ (in the absorption band) with emissions at 485 and $534 \mathrm{~nm}$ with good quantum yields $(\phi=$ 0.08 and 0.12 , respectively).
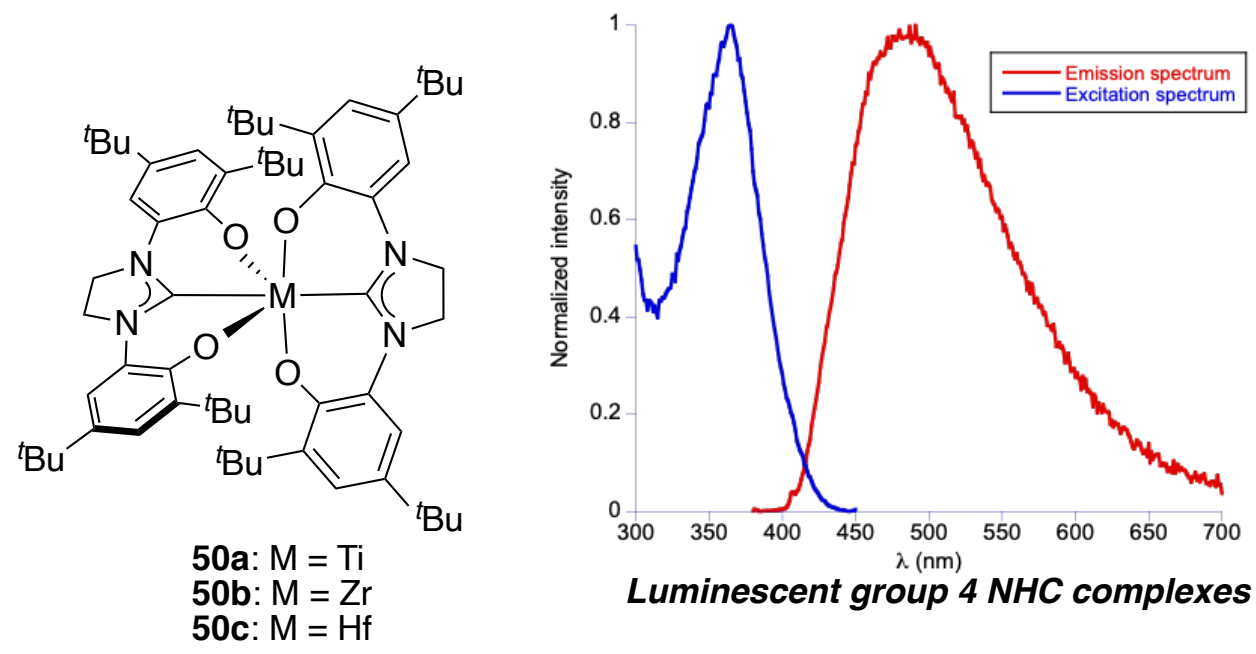

Figure 6. Luminescent homoleptic group 4 metal NHC complexes 50a-c.

Reflecting the electrophilic nature of the $\mathrm{C}_{\mathrm{NHC}}$ center in group 4 metal $\mathrm{M}(\mathrm{IV})-\mathrm{NHC}$, monochelates of the type $\left[\kappa^{2}-O, C, O\right] \mathrm{M}(\mathrm{X})\left(\mathrm{X}^{\prime}\right)_{2}\left(\mathrm{X}, \mathrm{X}^{\prime}=\mathrm{Cl}, \mathrm{Bn}\right.$; 51a-f, Scheme 20) were reported 
by Dagorne, Bellemin-Laponnaz and co-workers to undergo an intramolecular 1,2 benzyl migration reaction (from the metal center to $\mathrm{C}_{\mathrm{NHC}}$ ) in the presence of THF to heptacoordinated species 52a-f. ${ }^{46}$ Thorough kinetic studies combined with DFT calculations agree with such a reaction proceeding through a transient heptacoordinated bis-THF adduct species $\left[\kappa^{2}-\right.$ $O, C, O] \mathrm{M}(\mathrm{Cl})(\mathrm{Bn})(\mathrm{THF})_{2}$.
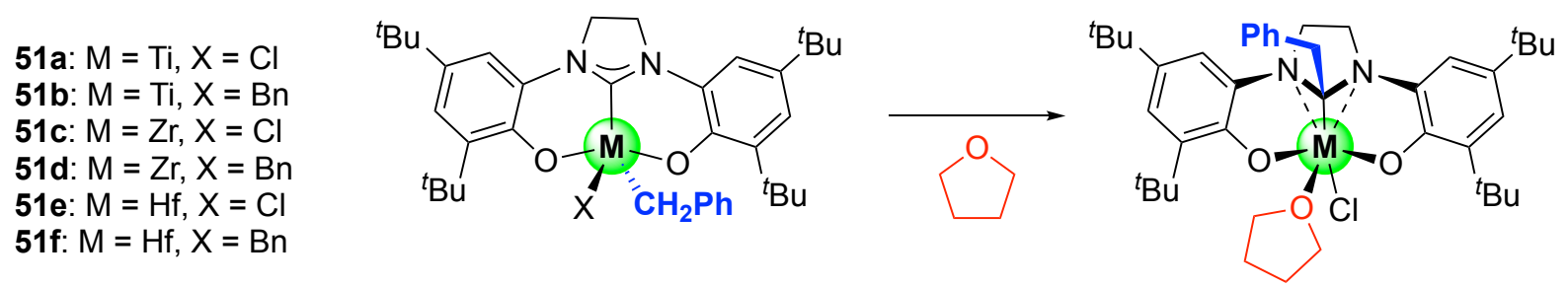

52a-f

Scheme 20. THF-promoted benzyl migration reaction of NHC complexes 51a-f.

Bercaw, Despagnet-Ayoub and co-workers further studied and exploited such reactivity using a related $\left[\kappa^{2}-O, C, O\right] \mathrm{ZrBn}_{2}$ species $(\mathbf{5 3}$, Scheme 21) leading to the observation of a reversible 1,2 benzyl migration through coordination/decoordination of $\mathrm{PMe}_{3}$ affording $54 .{ }^{47}$ The electrophilic character of the NHC center in these systems was further evidenced by the ready reaction of $\mathbf{5 3}$ with excess $\mathrm{NH}_{3}$, which first acts as a Lewis base to promote benzyl migration and then undergoes protonolysis of the remaining $\mathrm{Zr}-\mathrm{Bn}$ bond, to afford dimeric diamido $\operatorname{Zr}(\mathrm{IV})$ species 55 (Scheme 21). The same authors also studied species 53 in 1-hexene polymerization catalysis and achieved a controlled switch from 1-hexene oligomerization to polymerization through the absence/presence of additional L-type ligands, which was rationalized by a detailed and insightful mechanistic study. ${ }^{48}$ 


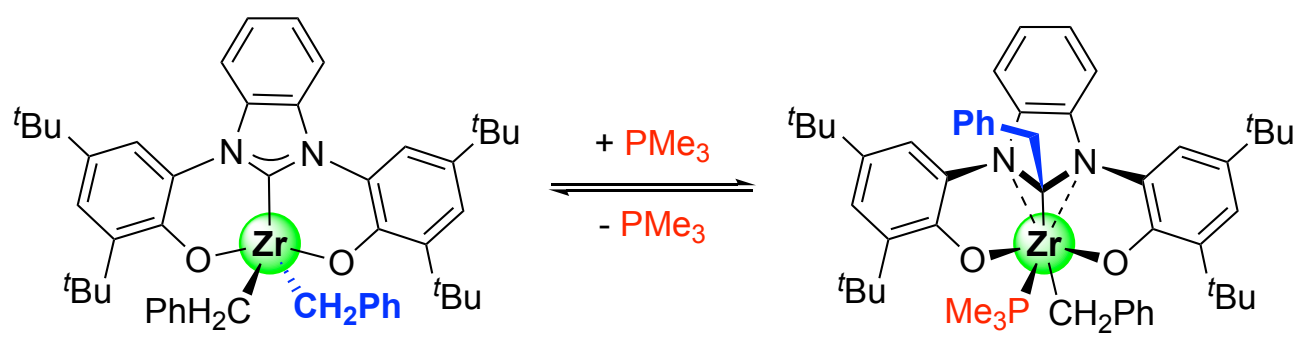

53

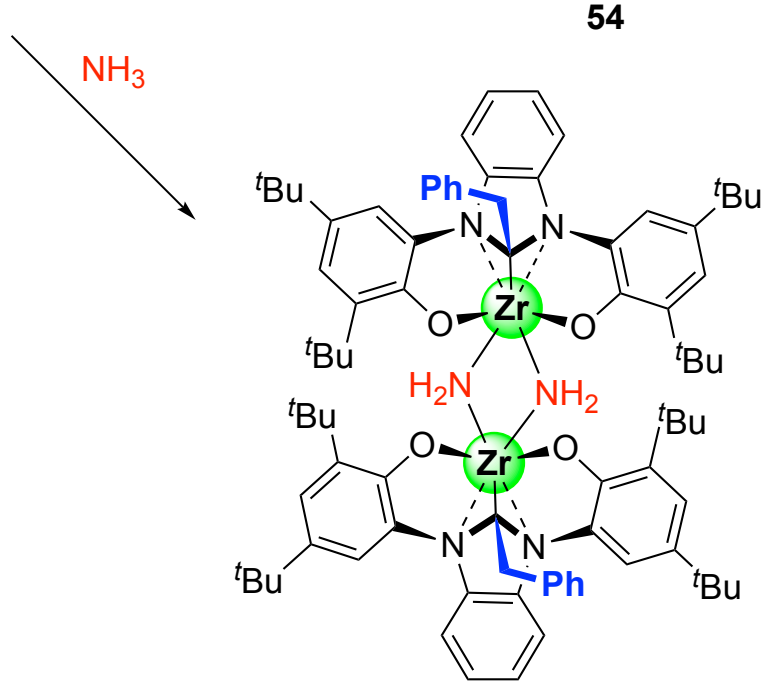

55

Scheme 21. $\mathrm{PMe}_{3}$ - and $\mathrm{NH}_{3}$-promoted benzyl migration of $\mathrm{Zr}-\mathrm{NHC}$ species 53.

Le Roux and co-workers studied a wide range of group 4 metal complexes supported by NHC-bis-phenolate ligands as epoxide $/ \mathrm{CO}_{2}$ alternate co-polymerization catalysts for the controlled production of polycarbonates, essentially using cyclohexene oxide $(\mathrm{CHO})$ as an epoxide source (Figure 7). Overall, the most studied sterically bulky Ti(IV) systems $\mathbf{5 6}$ and $\mathbf{5 7}$ in combination with $[\mathrm{PPN}] \mathrm{Cl}$ as co-catalyst performed best with the production of perfectly poly $\left(\mathrm{CHO}-\right.$ alt $\left.-\mathrm{CO}_{2}\right)$ materials $\left(M_{\mathrm{n}}=4500 \mathrm{~g} \cdot \mathrm{mol}^{-1}\right)$ with TOFs up to $930 \mathrm{~h}^{-1}$ under low $\mathrm{CO}_{2}$ pressure $\left(\mathrm{PCO}_{2}<0.5\right.$ bar) at $60{ }^{\circ} \mathrm{C} .{ }^{49,50}$ In contrast, less sterically $\mathrm{Ti}(\mathrm{IV})$ derivatives 58-60 showed poor catalytic activity, while the studied $\operatorname{Zr}(\mathrm{IV})$ complexes 61-63 also displayed moderate performances. ${ }^{51,52}$ Studies on chelates $\mathbf{6 4}$ and $\mathbf{6 5}$, which are the first Hf-based catalysts for use in epoxide/ $\mathrm{CO}_{2}$ copolymerization, showed that structurally characterized 
anionic $\mathrm{Hf}(\mathrm{IV})$ species $\mathbf{6 5}$ performed best with an efficient and selective production of welldefined PCHC $\left(\mathrm{TOF}=500 \mathrm{~h}^{-1}, M_{\mathrm{n}}=19400 \mathrm{~g} \cdot \mathrm{mol}^{-1}\right)$ under 1 bar of $\mathrm{CO}_{2} .{ }^{53}$

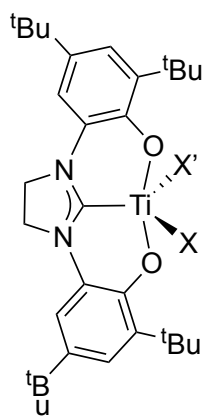

56a: $\mathrm{X}=\mathrm{Cl}, \mathrm{X}^{\prime}=\mathrm{O} \mathrm{Pr}$ 56b: $X=X^{\prime}=\mathrm{Cl}$ 56c: $X=X^{\prime}=\mathrm{O} i \mathrm{Pr}$ 56d: $X=X^{\prime}=O B n$ 56e: $X=\mathrm{Cl}, \mathrm{X}^{\prime}=\mathrm{OSi}(\mathrm{OtBu})_{3}$ 56f: $X=O$ OPr, $X^{\prime}=$ OSi(OtBu $)_{3}$ 56g: $X=X^{\prime}=O A C$ 56h: $X=X^{\prime}=N_{3}$

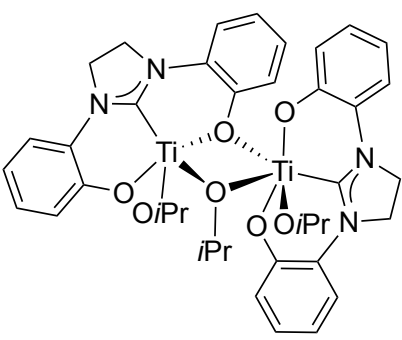

60

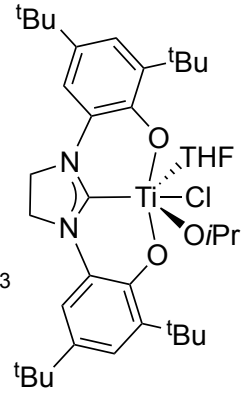

57<smiles></smiles>

58a: $L=T H F$ 58b: $L=M e C N$<smiles></smiles>

59a: $\mathrm{X}=\mathrm{Cl}$

$59 b: X=2,6-t \mathrm{Bu}_{2}-4-\mathrm{Me}-$ $\mathrm{C}_{6} \mathrm{H}_{2} \mathrm{O}$<smiles>[X][Z]1([H])Oc2c(cc(C(C)(C)C)cc2C(C)(C)C)N2CCN3c4cc(C(C)(C)C)cc(C(C)(C)C)c4O[Z]1([Y])OC23</smiles>

61a: $X=X^{\prime}=\mathrm{Cl}$

61b: $X=X^{\prime}=O i P r$

61c: $X=\mathrm{Cl}, \mathrm{X}^{\prime}=\mathrm{OiPr}$

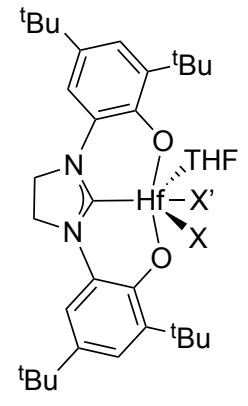

64a: $X=X^{\prime}=C l$

64b: $\mathrm{X}=\mathrm{Cl}, \mathrm{X}^{\prime}=\mathrm{O} i \mathrm{Pr}$

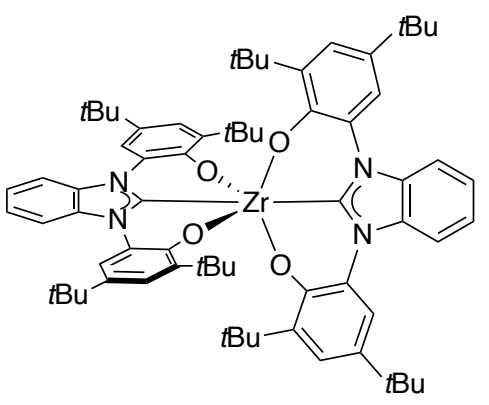

62

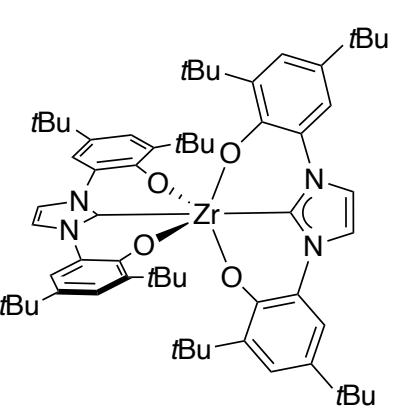

63

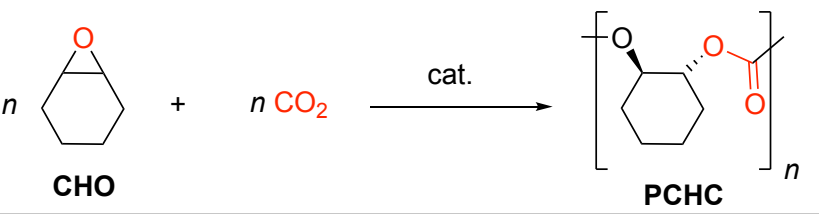

Figure 7. NHC-supported group 4 metal complexes tested in $\mathrm{CHO} / \mathrm{CO}_{2}$ copolymerization catalysis. 
More flexible NHC-bis-phenolate ligands, through the introduction of a $\mathrm{CH}_{2}$ benzylic group between the phenolate moiety and the central NHC unit, were also recently investigated by several groups. Thus, Walter and co-workers prepared and structurally characterized a series of chiral $\mathrm{Ti}(\mathrm{IV}), \mathrm{Zr}(\mathrm{IV})$ and $\mathrm{Hf}(\mathrm{IV})$ amido complexes of the type $\left[\kappa^{2}-O, C, O\right] \mathrm{M}(\mathrm{X})\left(\mathrm{X}^{\prime}\right)(\mathrm{THF})$ (66, Scheme 22) via amine elimination routes from the corresponding chiral imidazolinium salts. ${ }^{54}$ In the presence of ${ }^{i} \mathrm{PrOH}$, these complexes catalyze the controlled ring-opening polymerization (ROP) of rac-lactide to afford chain-length-controlled and heterotacticenriched PLA material ( $P_{\mathrm{r}}$ up to 0.74 ), with, at best, the quantitative conversion of 250 equiv of rac-LA to PLA within $30 \mathrm{~min}$ at $70{ }^{\circ} \mathrm{C}$. The $\mathrm{Zr}(\mathrm{IV})$ imidazol-2-ylidene analogues $\mathbf{6 7 a - b}$ (Figure 8) were also synthesized by Martins and co-workers and found to mediate the intramolecular hydroamination of amino-olefins, though a stoichiometric amount of $\mathbf{6 7 a - b}$ was required. ${ }^{55}$<smiles>[Y]/C=C(/[X])C(C)(C)C</smiles>

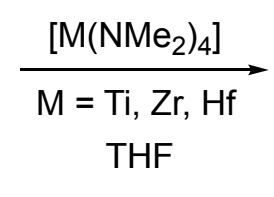

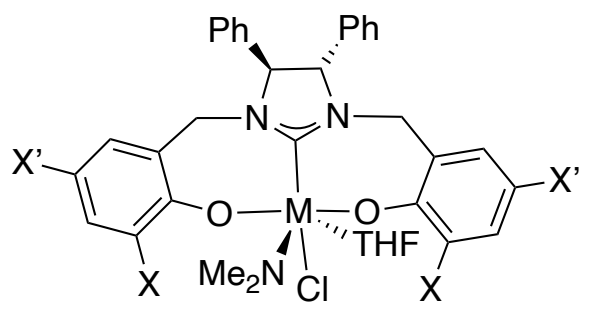

66<smiles>CC1OC(=O)C(C)OC1=O</smiles>

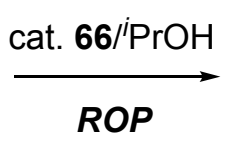<smiles>CCOC(C)C(C)=O</smiles>
heterotactic-enriched $P L A\left(P_{r}\right.$ up to 0.74)

Scheme 22. Synthesis of metal complexes $\mathbf{6 6}$ and their use as lactide ROP initiators.

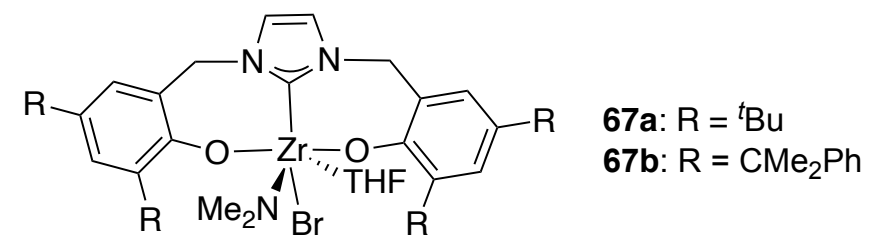


Figure 8. Molecular structure of $\mathrm{Zr}-\mathrm{NHC}$ complexes 67.

Hohloch and co-workers characterized a set of Ti(IV) complexes chelated by a 1,2,3triazolylidene-bis-phenolate tridentate ligand, including hetero- and homo-leptic complexes 68-70 (Figure 9). ${ }^{56}$ Such chelates, which are rare examples of abnormal/mesoionic carbene coordination to $d^{0}$-metal center, were shown to be accessible through various routes, including salt metathesis and alcohol elimination reactions. The Ti-oxo species 69 was isolated as a byproduct resulting from partial hydrolysis of $\mathbf{6 8}$. Electrochemical studies of homoleptic compound 70 showed that it is harder to oxidize than the Ti-NHC analogue 50a discussed above (Figure 9), indicating that the nature of the central carbene unit influences the redox properties of $(\mathrm{OCO})_{2} \mathrm{M}$ chelates.

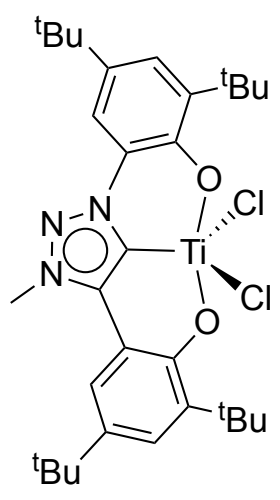

68

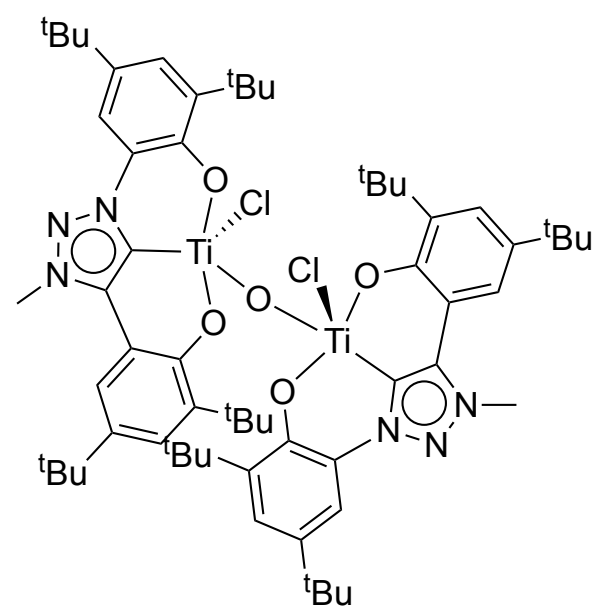

69

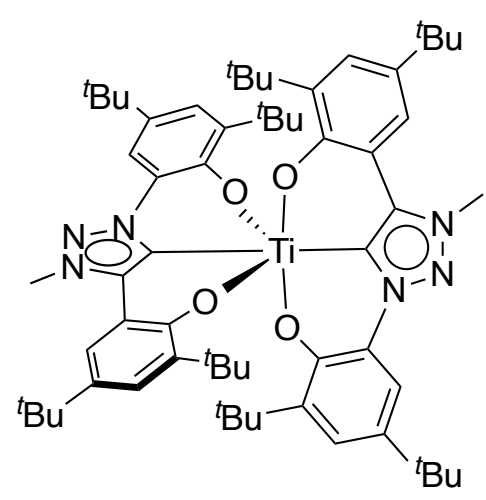

70

Figure 9. Molecular structures of group 4 metal chelates 68-70 bearing a mesoionic carbene.

C,C',C' '-based tridentate ligands. Hollis and co-workers prepared a series of $\mathrm{Zr}(\mathrm{IV})$ and $\mathrm{Hf}(\mathrm{IV})$ chelates using phenyl-bis-NHC monoanionic type pincer ligands through an amine elimination reaction, leading to the dihalido species 71 (Scheme 23). ${ }^{57}$ These compounds were found to catalyze, though under harsch conditions $\left(160^{\circ} \mathrm{C}\right.$, toluene $)$, the intramolecular 
hydroamination of unactivated amino-alkenes to afford the corresponding pyrrolidine derivatives (Scheme 23). A superior activity was observed for $\mathrm{Zr}(\mathrm{IV})$ catalysts and with the $\mathrm{Zr}-$ I derivative 71c $(\mathrm{I}>\mathrm{Br}>\mathrm{Cl})$, with a complete and selective conversion to 2,2-diphenylpent4-ene to the cyclized product within 50 min using 5 mol \% of 71c. Detailed kinetic studies combined with DFT calculations agree with the catalysis occurring a $\mathrm{Zr}$-imido-[2+2] cycloaddition mechanism, thus requiring the initial formation of a $\mathrm{Zr}$-imido species from amido pre-catalyst. ${ }^{58}$
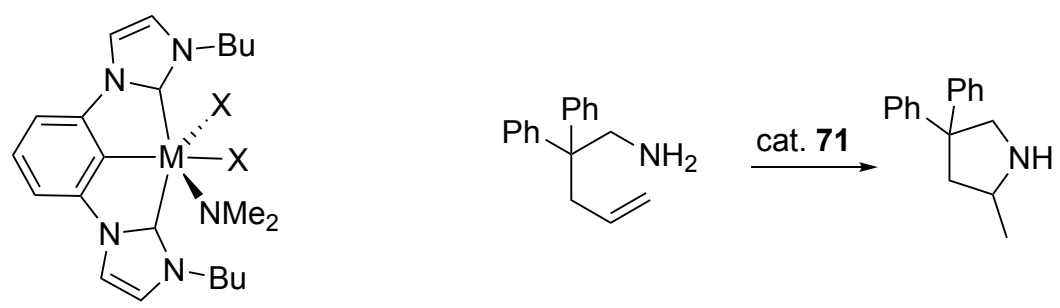

71a-c: $\mathrm{M}=\mathrm{Zr}, \mathrm{X}=\mathrm{Cl}, \mathrm{Br}$, I

71d-f: $\mathrm{M}=\mathrm{Hf}, \mathrm{X}=\mathrm{Cl}, \mathrm{Br}$, I

Scheme 23. Molecular structure of phenyl-bis-NHC metal complexes 71 and their use in intramolecular hydroamination catalysis.

It is worthy of note that phenyl-bis-NHC metal species of type $\mathbf{7 1}$ may act as effective transmetallating agents, as demonstrated by Hollis and coll. with the reaction of compound 71c with $\mathrm{Co}(\mathrm{acac})_{3}$ to selectively afford the corresponding the phenyl-bis-NHC Co(III) chelate $\mathbf{7 2}$ (Scheme 24). ${ }^{59}$ The in situ generation of such $\mathrm{Zr}(\mathrm{IV})$ pincer complex also allowed the direct synthesis of $\left[\kappa^{3}-\mathrm{C}, \mathrm{C}, \mathrm{C}^{\prime}\right.$ ' $] \mathrm{PtCl}(\mathbf{7 3})$ from the corresponding bis-imidazolium salt, $\left[\mathrm{Zr}\left(\mathrm{NMe}_{2}\right)_{4}\right]$ and $\left[(\mathrm{COD}) \mathrm{PtCl}_{2}\right]{ }^{60}$ 


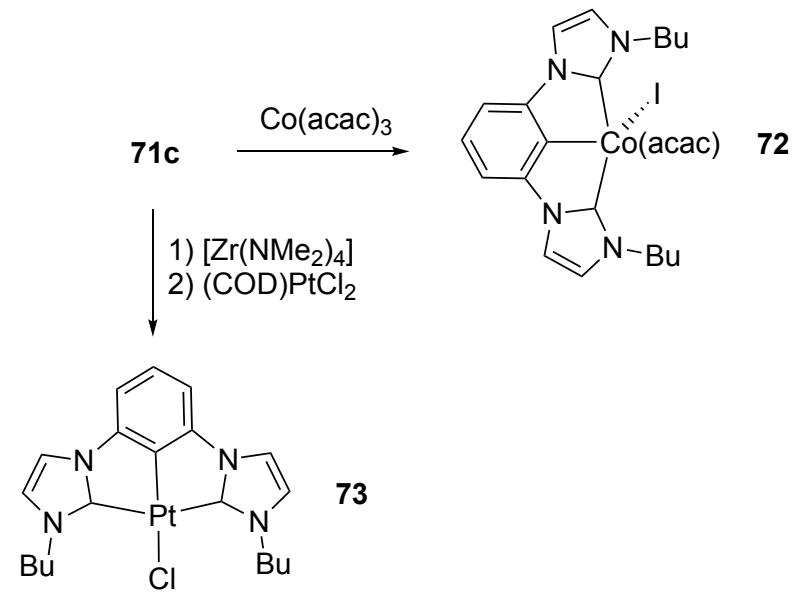

Scheme 24. Transmetallation of phenyl-bis-NHC ligand from $\mathrm{Zr}(\mathrm{IV})$ to $\mathrm{Co}(\mathrm{III})$ and $\operatorname{Pt}(\mathrm{II})$.

\section{Group 5 metals}

\section{a) Vanadium}

The coordination of anionic $N$-Heterocyclic Carbenes (NHC) with a weakly coordinating borate moiety (WCA-NHC) to early-transition metal centers remain little explored. ${ }^{37,61}$ WCA-NHC $\mathrm{V}(\mathrm{V})$ adducts have been synthesized by reaction of the WCA-NHC $\mathrm{Li}(\mathrm{I})$ adduct with various Vanadium imido precursors $\mathrm{V}(\mathrm{NR}) \mathrm{Cl}_{3}(\mathbf{7 4 - 7 6}, \mathrm{R}=\mathrm{Ad}, \mathrm{Ph}, \mathrm{Xyl}$; Scheme 25). ${ }^{61}$ All complexes feature significantly shorter V-NHC bonds [2.039(3)-2.049(2) $\left.\AA\right]$ than known NHC-V(V) complexes (i.e. 2.095(3) $\AA$, observed for $(\mathrm{OCO}) \mathrm{V}(=\mathrm{O}) \mathrm{Cl}$ chelate) ${ }^{62}$ in line with the WCA-NHC ligand acting as a strong $\sigma$-donor stabilizing the cationic $\mathrm{V}(\mathrm{NR}) \mathrm{Cl}_{2}$ moiety. Complexes 74-76 were tested in ethylene polymerization in the presence of MAO, $\mathrm{Al}^{i} \mathrm{Bu}_{3}$ or $\mathrm{Et}_{2} \mathrm{AlCl}$ as co-catalysts. In the presence of MAO, 76 was the most active catalyst of the series $\left(\right.$ activity $=1580 \mathrm{~kg}$-polymer.mol- $\left.\mathrm{V}^{-1} \cdot \mathrm{h}^{-1}\right)$ and led to rather high molar mass polymers with low dispersity $\left(M_{\mathrm{n}}=15.3 \mathrm{~kg} \cdot \mathrm{mol}^{-1}, Ð=1.9\right)$ but does not outperform aryloxo Vanadium analogues. However, it should be noted that complex $\mathbf{7 6}$ shows very high activity in the 
presence of $\mathrm{Al}^{i} \mathrm{Bu}_{3}$ (activity up to $11000 \mathrm{~kg}$-polymer.mol- $\mathrm{V}^{-1} \cdot \mathrm{h}^{-1}$ ), conditions under which other metallocenes, half-titanocene and related (imido)vanadium dichloride complexes are usually inactive. This highlights the efficient stabilization of the cationic vanadium center by the WCANHC ligand. Further characterization of these reactions by X-ray absorption spectroscopy (XAS) have been carried out to elucidate the oxidation state of the active species. ${ }^{63,64}$ Norbornene and ethylene/norbornene copolymerization were also investigated with catalysts 74-76. ${ }^{65}$

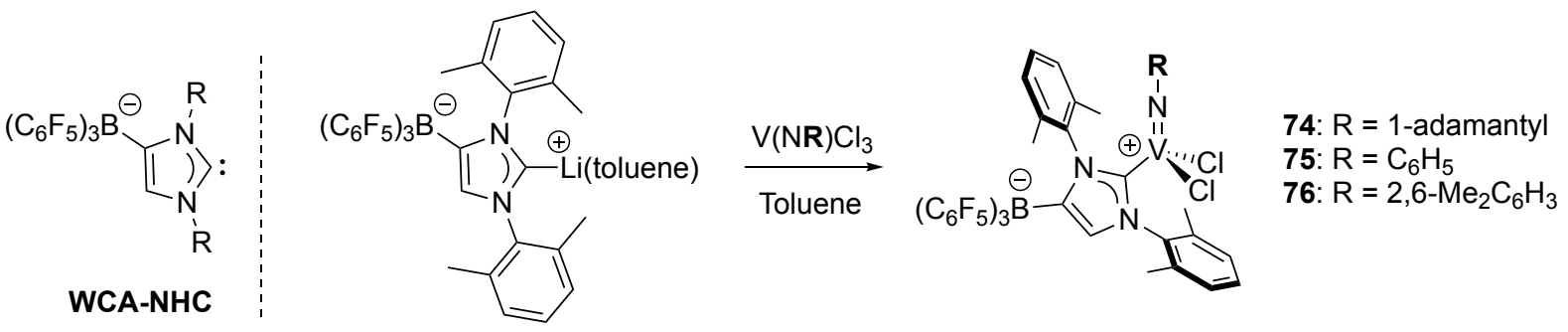

Scheme 25. Synthesis of WCA-NHC V(V) complexes 74-76.

Zhang, $\mathrm{Wu}$ and co-workers reported a series of monodentate $\mathrm{NHC}-\mathrm{V}(\mathrm{V})$ and monodentate NHC-V(III) complexes that were tested in olefin copolymerization. ${ }^{66,67}$ Reaction of the free carbene with $\mathrm{VOCl}_{3}$ or $\mathrm{VCl}_{3}(\mathrm{THF})_{3}$ led to the corresponding adducts depicted in Scheme 26 . All $\mathrm{V}-\mathrm{Cl}$ adducts were tested in ethylene/propylene copolymerization in the presence of $\mathrm{Et}_{3} \mathrm{Al}_{2} \mathrm{Cl}_{3}$ as co-catalyst. Species $79 \mathrm{a}$ was found to be the most active of the series $(64.8 \mathrm{~kg}$ polymer.mol- $\mathrm{V}^{-1} \cdot \mathrm{h}^{-1}$ ) to afford the more random ethylene/propylene copolymers. Quasi-living polymerization was observed with the production of ultra-high molecular weight copolymers were obtained $\left(M_{\mathrm{w}}\right.$ up to $\left.1,427 \mathrm{~kg} \cdot \mathrm{mol}^{-1}, \mathrm{Ð}=2.05\right)$, which was attributed to the high stability of the active species provided by the bulky IDipp ligand. Interestingly, the NHC-V(III) derivative 81 showed a lower activity than the NHC-V(V) counterparts 79 (19.8 kgpolymer.mol- $\left.\mathrm{V}^{-1} \cdot \mathrm{h}^{-1}\right)$. 


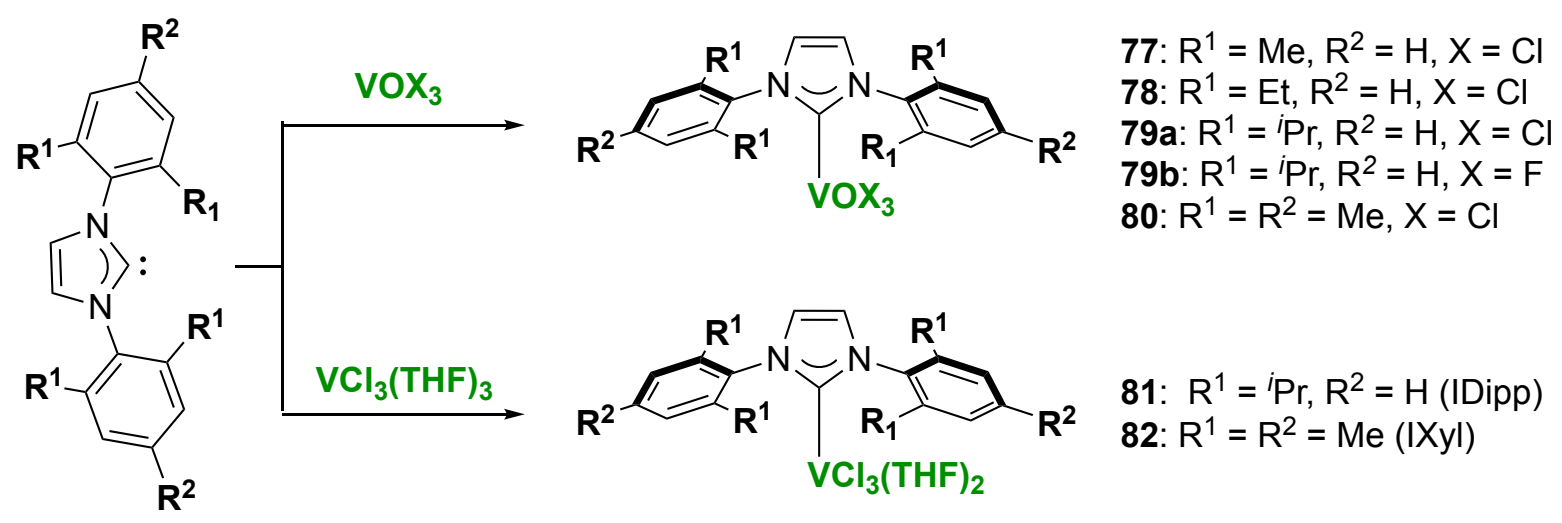

Scheme 26. Synthesis of NHC-V(V) and NHC-V(III) 77-82.

Recently, Arnold and co-workers reported that $\mathrm{NHC}-\mathrm{V}(\mathrm{V})$ adducts 79, 80 and (ICy) $\mathrm{VOCl}_{3}$ were efficient stoichiometric reagents for the destruction of chemical warfare agent simulants ( $\mathrm{H}$ agent and $\mathrm{V}$ agents) through cooperation of the $\mathrm{V}(\mathrm{V})$ metal center and the NHC ligand. ${ }^{68}$ Thanks to NHC stabilization, Tavčar and coll. structurally characterized the first example of a $\left[(\mathrm{L}) \mathrm{VOF}_{3}\right]$ adduct $\left(\mathbf{7 9 b}\right.$, Scheme 26). ${ }^{69}$

\section{c) Niobium and Tantalum}

Monodentate NHC ligands. NHC-Nb(V) and $\mathrm{NHC}-\mathrm{Ta}(\mathrm{V})$ adducts 83-89 were successfully prepared by stoichiometric reaction of free carbene IMes or IDipp with the corresponding pentahalide metal precursors $\mathrm{MX}_{5}(\mathrm{M}=\mathrm{Nb}$ or Ta, $\mathrm{X}=\mathrm{F}, \mathrm{Cl}$ or $\mathrm{Br})$ (Scheme 27). ${ }^{70,71,72,73}$ The Ta-NHC bond distances in these adducts lie in the expected range for $\mathrm{Ta}-$ NHC bonds (Table 1). Interestingly, by slightly changing reactions and work-up conditions, Cai, Wei and co-workers isolated cationic bis-NHC-Nb(V) 90 and bis-NHC-Ta(V) 91 with an hexachloride metal anion. ${ }^{72}$ In the presence of adventitious water, $\mathrm{NHC}-\mathrm{Nb}(\mathrm{V})$ oxo fluoride complex 92 was isolated from the reaction between $\mathrm{NbF}_{5}$ and IDipp. ${ }^{74}$ Adducts $\mathbf{8 8 ,}, \mathbf{9 0}$ and 91 were tested as catalysts of the coupling reaction between propylene oxide and $\mathrm{CO}_{2}(\mathrm{RT}, 10$ bars of $\mathrm{CO}_{2}$ and 10 mol. \% catalyst loading). Under these conditions, catalyst $\mathbf{8 8}$ was found to be 
the most active (>99\% conversion, $10 \mathrm{~h}$ ) and the most selective catalyst of the series for the formation of cyclic carbonate $\left(95 \%\right.$ selectivity) ${ }^{72}$ Rare NHC-Nobium(IV) oxo dihalide complexes 93 and 94 were also characterized by reaction of the free carbene IMes and IXyl with dimeric $\mathrm{Nb}(\mathrm{IV}) \mathrm{OX}_{2} \mathrm{~L}_{2}\left(\mathrm{X}=\mathrm{Cl}\right.$ or $\mathrm{Br}, \mathrm{L}=$ dme, THF or $\left.\mathrm{CH}_{3} \mathrm{CN}\right) .{ }^{75}$ The complexes are paramagnetic and fairly air stable (decomposition within 5 to $15 \mathrm{~min}$ ). The molecular structures of 93-94 shows that the metal centre adopts a distorted trigonal bipyramidal geometry.
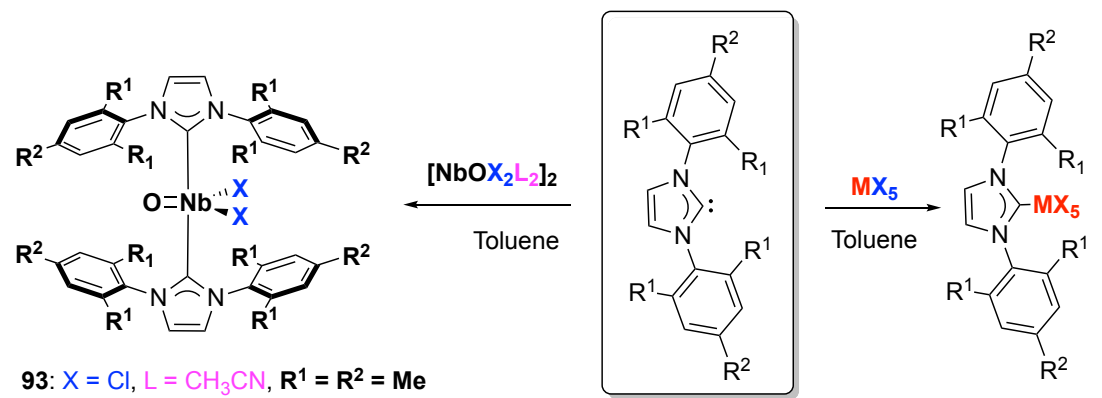

83: $M=N b, X=F, R^{1}={ }^{i} P r, R^{2}=H$ 84: $\mathrm{M}=\mathrm{Nb}, \mathrm{X}=\mathrm{Cl}, \mathrm{R}^{1}={ }^{i} \mathrm{Pr}, \mathrm{R}^{2}=\mathrm{H}$ 85: $M=N b, X=C l, R^{1}=R^{2}=M e$ 86: $\mathrm{M}=\mathrm{Nb}, \mathrm{X}=\mathrm{Br}, \mathrm{R}^{1}={ }^{i} \mathrm{Pr}, \mathrm{R}^{2}=\mathrm{H}$ 87: $M=T a, X=F, R^{1}={ }^{i} \operatorname{Pr}, R^{2}=H$ 88: $M=T a, X=C l, R^{1}={ }^{i} \operatorname{Pr}, R^{2}=H$ 88: $M=T a, X=C l, R^{1}={ }^{i} P r, R^{2}=H$
89: $M=T a, X=B r, R^{1}={ }^{i} P r, R^{2}=H$

93: $X=\mathrm{Cl}, \mathrm{L}=\mathrm{CH}_{3} \mathrm{CN}, \mathbf{R}^{\mathbf{1}}=\mathbf{R}^{\mathbf{2}}=\mathbf{M e}$ 94: $X=B r, L=d m e, \mathbf{R}^{1}=\mathbf{M e}, \mathbf{R}^{2}=\mathbf{H}$
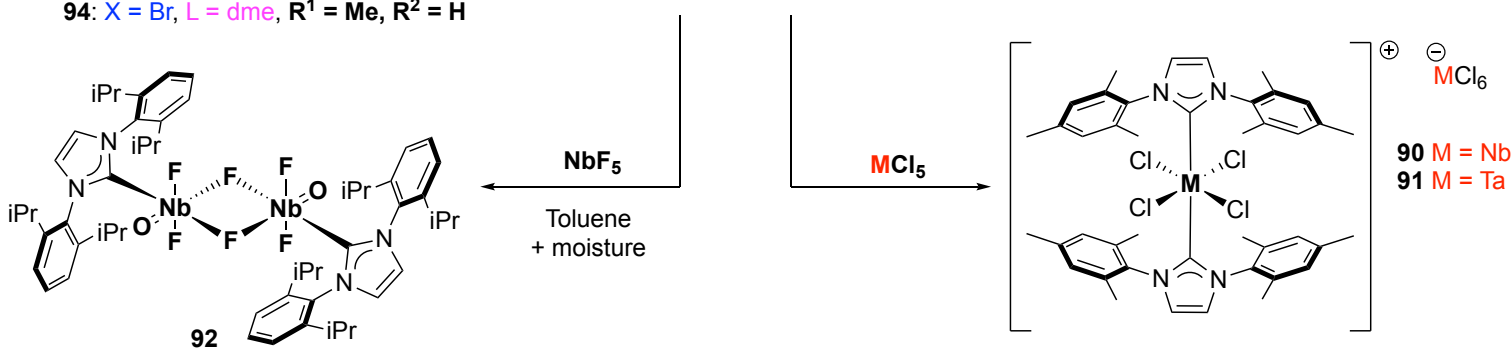

Scheme 27. Synthesis of NHC-Nb(V) and NHC-Nb(IV) adducts 83-94

The first abnormal coordination of an Arduengo-type NHC ligand to an early-transition metal (ETM) was reported in 2017 by Petrov and co-workers ([( $\left.\mathrm{IIMes}) \mathrm{TaCl}_{2}\left(\mathrm{NMe}_{2}\right)_{3}\right], \mathbf{9 5}$, Scheme $28)$, isolated in good yield from the reaction of $\left[\mathrm{TaCl}_{2}\left(\mathrm{NMe}_{2}\right)_{3}\right]_{2}$ with IMes. ${ }^{76}$ The Ta-NHC bond distance in 95 is $2.339(2) \AA$ and lies within the range of other normal and abnormal MNHC bond distances. Reacting $\left[\mathrm{Ta}\left(\mathrm{NMe}_{2}\right)_{5}\right]$ (instead of $\left.\left[\mathrm{TaCl}_{2}\left(\mathrm{NMe}_{2}\right)_{3}\right]_{2}\right)$ with IMes.HCl led to a mixture of 95,96 and IMes. In contrast, the reaction of $\mathrm{Ta}\left(\mathrm{NMe}_{2}\right)_{5}$ with $\mathrm{IMes}_{\mathrm{HBF}} \mathrm{HB}_{4}$ or SMes. $\mathrm{HBF}_{4}$ surprisingly afforded the normal $\mathrm{NHC}-\mathrm{Ta}(\mathrm{V})$ adducts 97 and $\mathbf{9 8}$, with the latter displaying the longest reported Ta-NHC bond (2.43(2) $\AA$ ). The presence of fluoro ligands in 97 and 98 , originating from the $\mathrm{BF}_{4}^{-}$anion, reflects the strong affinity of $\mathrm{Ta}(\mathrm{V})$ for $\mathrm{F}$ atoms. 


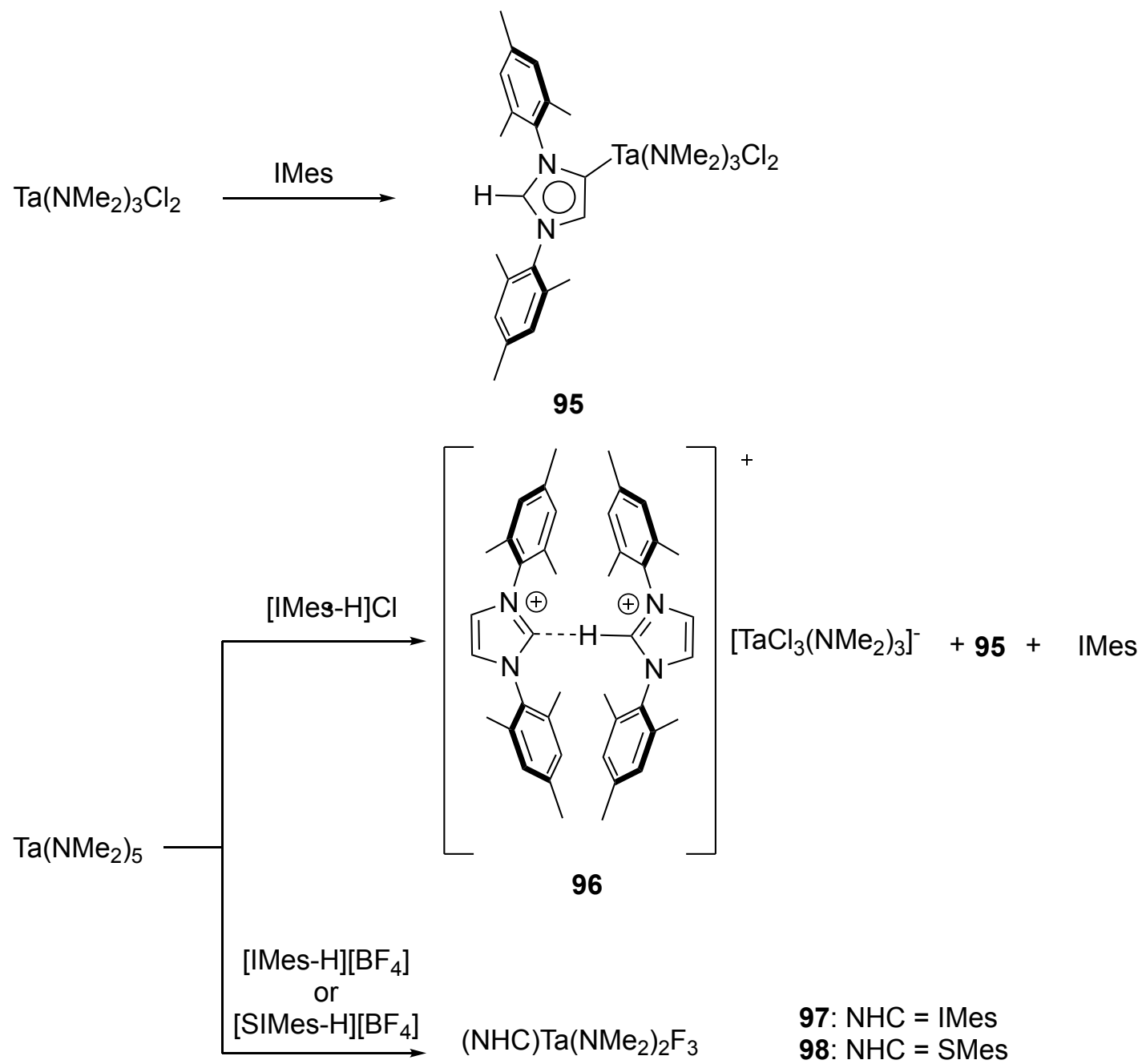

Scheme 28. Reactivity of $\mathrm{Ta}(\mathrm{V})$ amido precursors with NHCs.

Bidentate NHC ligands. Bis-NHC ligands featuring a boryl moiety have been used for the synthesis of high-valent $\mathrm{Nb}(\mathrm{V})$ imido complexes. ${ }^{77}$ In-situ deprotonation of the imidazolium salt with $\mathrm{LiN}^{i} \operatorname{Pr}_{2}$ and subsequent metalation with $\mathrm{Nb}\left(\mathrm{N}^{t} \mathrm{Bu}\right) \mathrm{Cl}_{3} \mathrm{Py}_{2}$ afforded the bis-(NHC)-Nb(V) imido dichloride complex 99 (Scheme 29). Reaction with MeMgCl leads to the formation of the alkyl derivative $\mathbf{1 0 0}$. 


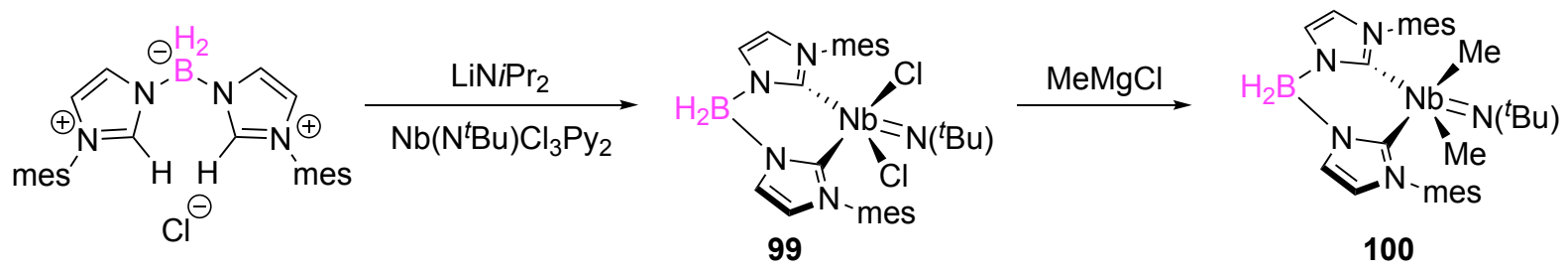

Scheme 29. Synthesis of high-valent NHC-Nb(V) imido complexes 99 and $\mathbf{1 0 0 .}$

The reactivity of $\mathrm{Nb}(\mathrm{V})$ dimethyl species $\mathbf{1 0 0}$ was first investigated with $\mathrm{CO}$, ketones and formaldehyde. Thus, $\mathbf{1 0 0}$ reacted with excess $\mathrm{CO}$ to form acetone which subsequently inserts into the $\mathrm{B}-\mathrm{H}$ bond to form the corresponding $\mathrm{Nb}$ (III) dicarbonyl complex 101 (Scheme 30). Bis-NHC-Nb(V) imido dimethyl complex 103, prepared by hydroboration of two equivalents of acetophenone with 100, reacted with $\mathrm{H}_{2}$ to yield $\mathrm{Nb}$ (III) complex 104. The formation of 104 occurs via hydrogenolysis of $\mathrm{Nb}-M e$ groups of $\mathbf{1 0 3}$ and the product is stabilized by $\mathrm{Nb}(\mathrm{III})$-arene interactions (Scheme 30 ). This leads to short $\mathrm{Nb}-\mathrm{NHC}$ bonds $[2.248(4)-2.267(4) \AA]$.

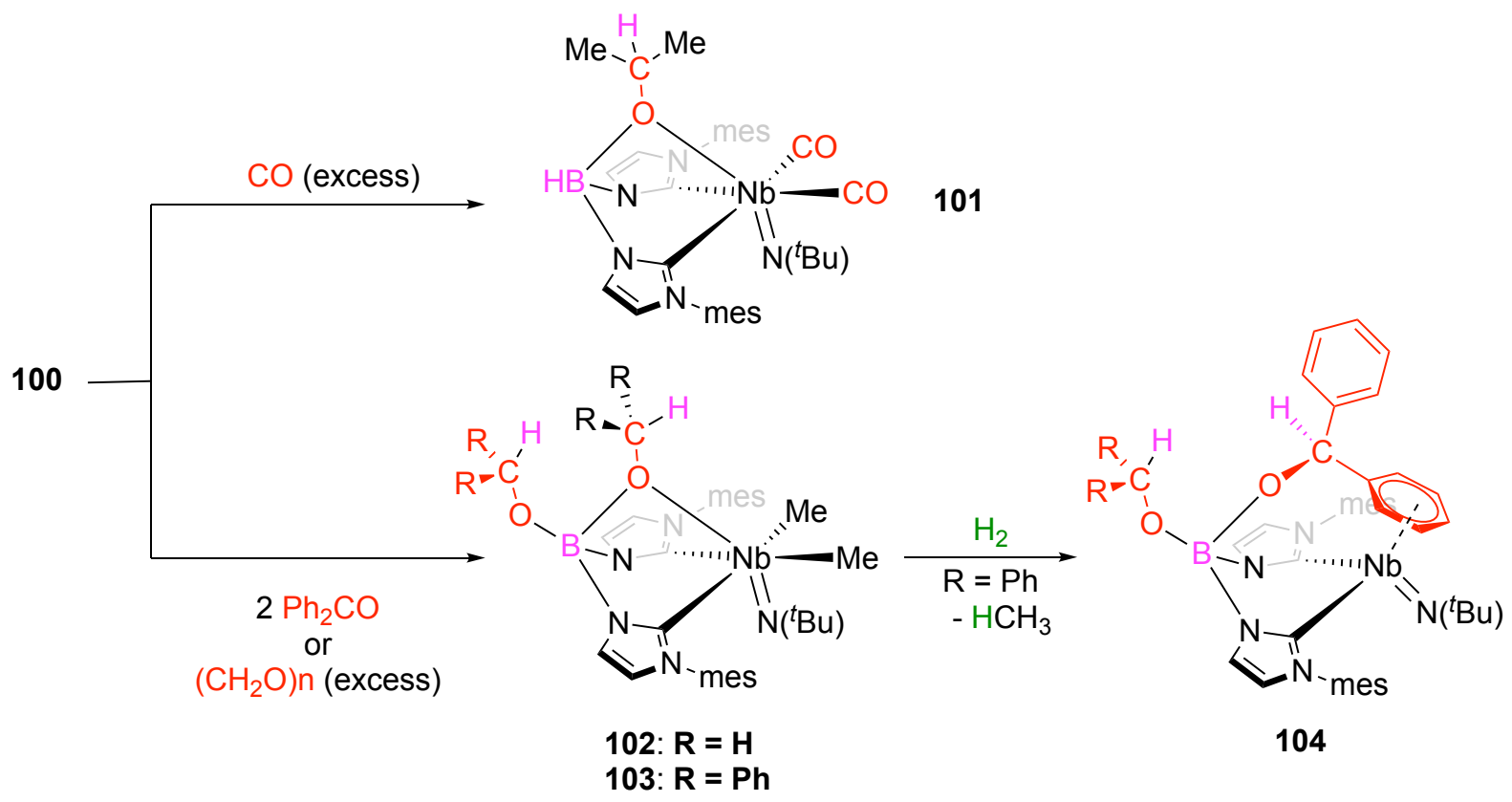

Scheme 30. Reactivity of $\mathrm{NHC}-\mathrm{Nb}(\mathrm{V})$ dimethyl derivative $\mathbf{1 0 0}$ using $\mathrm{C}=\mathrm{O}$ substrates. 
The $\mathrm{Nb}(\mathrm{V})$ dichloro derivative 99 was also used for hydroboration reactions of aldehydes, ketones and isocyanates leading to the isolation of complexes 105-111 (Figure 10).

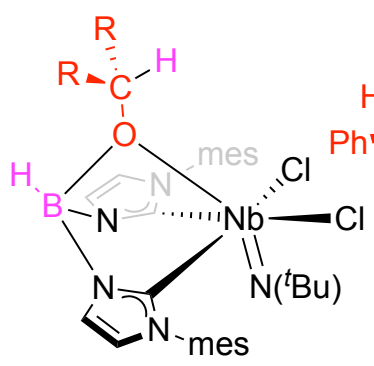

105: $R=P h$

106: $R=H$

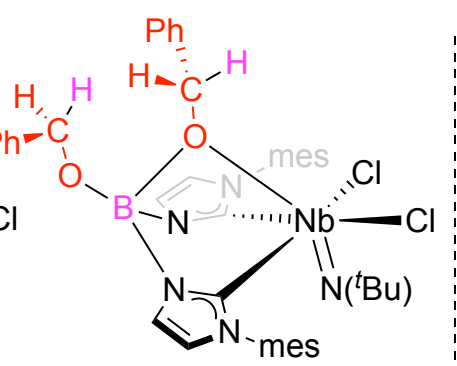

107

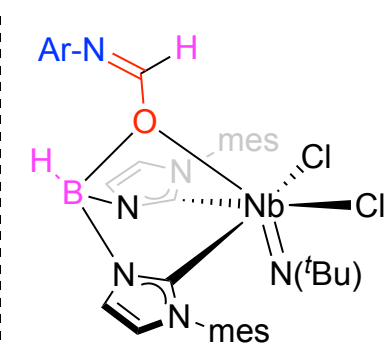

108: $\mathrm{Ar}=\mathrm{p}$-tolyl 109: $\mathrm{Ar}=\mathrm{Dipp}$

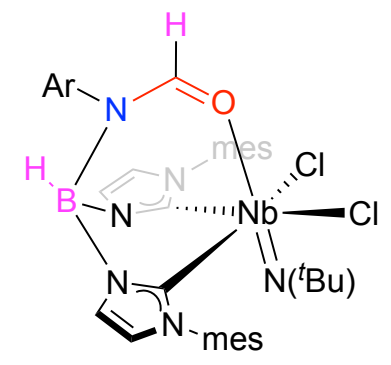

110: $\mathrm{Ar}=\mathrm{p}$-tolyl 111: $\mathrm{Ar}=\mathrm{Dipp}$

Figure 10. Molecular structures of products (105-111) resulting from hydroboration of aldehydes, ketones and isocyanates by $\mathrm{Nb}(\mathrm{V})$ dichloro species 99.

Bis-NHC ligands featuring a boryl moiety have also been investigated for the synthesis of highvalent $\mathrm{Ta}(\mathrm{V})$ alkyl complexes 112 and $\mathbf{1 1 3}{ }^{78}$ Their reactivity with hydrogen have been studied to afford low-valent $\mathrm{Ta}(\mathrm{IV})$ and $\mathrm{Ta}(\mathrm{III})$ complexes. The degree of methylation of the highvalent precursor 112 and $\mathbf{1 1 3}$ drives towards either the formation of bimetallic hydride-bridge Ta(IV) complex 114 or multimetallic $\mathrm{Ta}(\mathrm{III})$ derivatives 115-117. The use of an aromatic solvent (benzene or toluene) in the hydrogenolysis of $\mathbf{1 1 3}$ leads to the formation of bimetallic Ta(III) complexes 115 and 116 which feature an unusual $s y n-\mu-\eta^{4}: \eta^{4}$ arene binding mode due to solvent reduction. On the contrary, the use of hexane leads to the trimetallic Ta(III) complex 117 showing cyclometallation through one of the mesityl group. Species 117 shows amongst the shortest reported Ta-NHC bond distances, in the range [2.228(5) - 2.395(5) $\AA$ ]. 

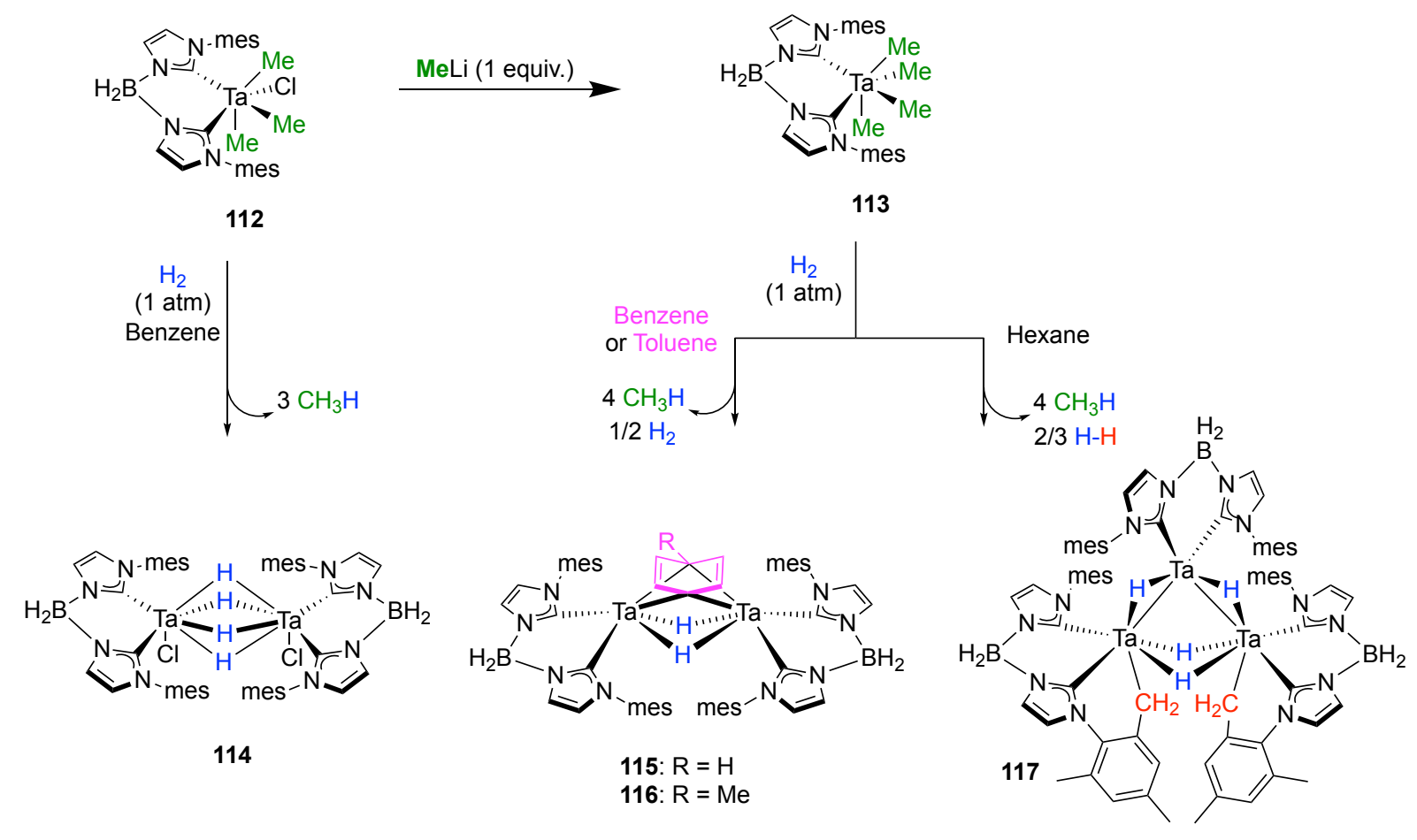

Scheme 31. Synthesis of monometallic $\mathrm{Ta}(\mathrm{V})$ complexes 112-113 and multimetallic $\mathrm{Ta}(\mathrm{IV})$ and $\mathrm{Ta}(\mathrm{III})$ complexes 114-117.

Anionic hydroxyalkyl-functionalised NHC ligands have been investigated by Camp and co-workers for the synthesis of monometallic NHC-Ta(V) complexes as well as for the synthesis of a $\mathrm{Rh}(\mathrm{I}) / \mathrm{Ta}(\mathrm{V})$ heterobimetallic complex. ${ }^{79}$ Reaction of the free carbene (existing as a mixture of zwitterionic form and bicyclic adduct form) with $\mathrm{Ta}\left(\mathrm{XN}^{t} \mathrm{Bu}\right)(\mathrm{Np})_{3}(\mathrm{X}=\mathrm{CH}$ or N) affords the corresponding complexes 118 and 119 as depicted in Scheme 32. Whereas 118 is stable in solution, $\mathbf{1 1 9}$ undergoes $\mathrm{C}-\mathrm{H}$ activation/functionalization of one Me group of a $\mathrm{N}$ Mes substituent to form metallacycle 120. The $\mathrm{Rh}(\mathrm{I}) / \mathrm{Ta}(\mathrm{V})$ heterobimetallic complex $\mathbf{1 2 2}$ can be obtained either from the Rh-NHC adduct 121 or from the Ta(V)-NHC adduct 118 by addition of $\mathrm{Rh}(\mathrm{COD}) \mathrm{Cl}$. The formation of the $\mathrm{Rh}-\mathrm{NHC}$ dinuclear species 122 in both synthesis further highlights the preferred coordination of the soft NHC ligand with the "soft" metal centre [i.e. $\mathrm{Rh}(\mathrm{I})]$ and the stronger affinity of the alkoxide ligand with an oxophilic center such as $\mathrm{Ta}(\mathrm{V})$. 


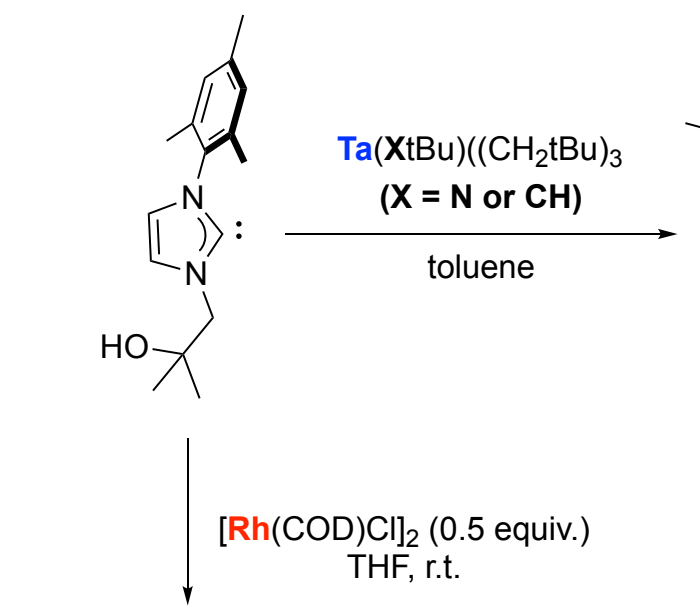

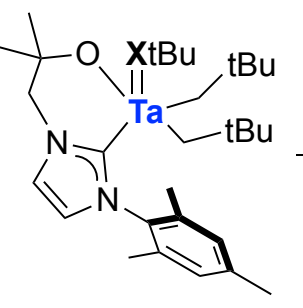

118: $X=N$

119: $\mathrm{X}=\mathrm{CH}$
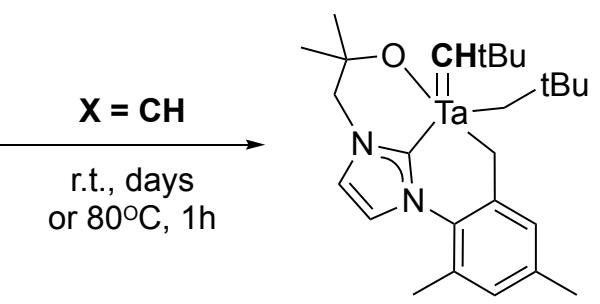

120
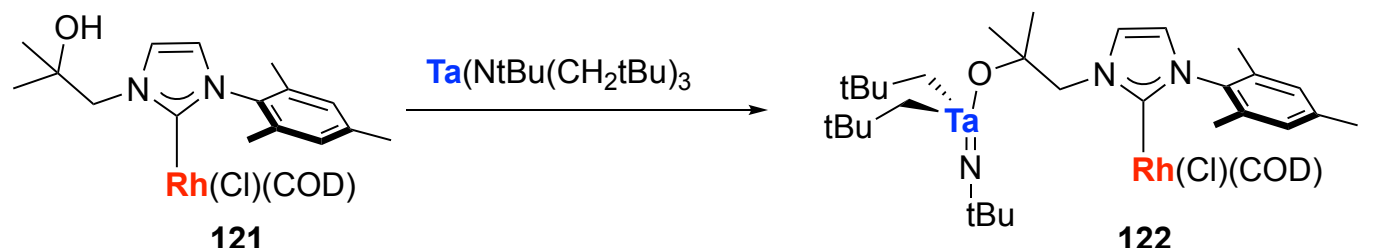

Scheme 32. Synthesis of $\mathrm{Ta}(\mathrm{V})-\mathrm{NHC}$ complexes 118-120 and heterodinuclear $\mathrm{Ta}(\mathrm{V}) / \mathrm{Rh}(\mathrm{I})$ complexes 121 and 122.

Tridentate NHC ligands. Building on their studies with group 4 metals, Hollis and co-workers investigated the use of anionic CCC-tridentate NHC pincer ligands with Tantalum (V). ${ }^{80,81,82}$ Imidazolyl-NHC pincer ligands and triazol-based NHC pincer ligands were successfully coordinated to $\mathrm{Ta}(\mathrm{V})$ to afford a series of diiodo-amido, iodo-imido-amido and bis(imido) complexes 123-126 as depicted in Figure 11. Reaction of the ligand precursors as iodo salts with 3 equivalents of $\mathrm{Ta}\left(\mathrm{N}^{t} \mathrm{Bu}\right)\left(\mathrm{NMe}_{2}\right)_{3}$ led to complexes $\mathbf{1 2 4}$ and $\mathbf{1 2 5}$ in good yield. ${ }^{80}$ On the contrary, the reaction of a (sub)stoichiometric quantity (i.e. 0.9 equiv. or 1.1 equiv.) of $\mathrm{Ta}\left(\mathrm{N}^{\mathrm{t}} \mathrm{Bu}\right)\left(\mathrm{NMe}_{2}\right)_{3}$ with the bis(imidazolium) diiodide salt afforded a mixture of chelates 123 and 124. The bis-imido Ta(V) complex 124 reacted with ${ }^{\mathrm{t} B N H L i}$ to afford the corresponding bis-imido Ta(V) complex $126 .{ }^{81}$ 
<smiles></smiles>

123

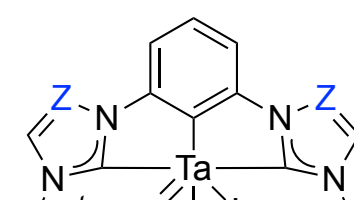

$\left.\mathrm{Bu}^{\prime}\left({ }^{\mathrm{t}} \mathrm{Bu}\right) \mathrm{N}^{\prime \prime}\right|_{\mathrm{NMe}_{2}} ^{\prime} \mathrm{Bu}$

124: $\mathrm{Z}=\mathrm{CH}$

125: $Z=N$

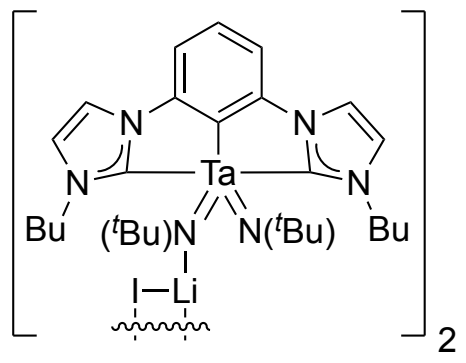

126

Figure 11. $\mathrm{Ta}(\mathrm{V})$ amido and imido complexes bearing a CCC-NHC pincer ligand (123126).

Complex 127 (Scheme 33), serendipitously prepared during the synthesis/isolation of 126, contains a $N$-Heterocyclic DiCarbene (NHDC) with a C4-bonded $\mathrm{Ta}(\mathrm{V})$ center, as determined from X-ray crystallographic data ${ }^{81}$ NHDC-ETM adducts are rare and only an Y(III) analogue is known thus far. ${ }^{83}$ In the presence of adventitious water, $\mathbf{1 2 6}$ leads to the $\mathrm{Ta}(\mathrm{V})$ imido-amido complex 128. ${ }^{81}$

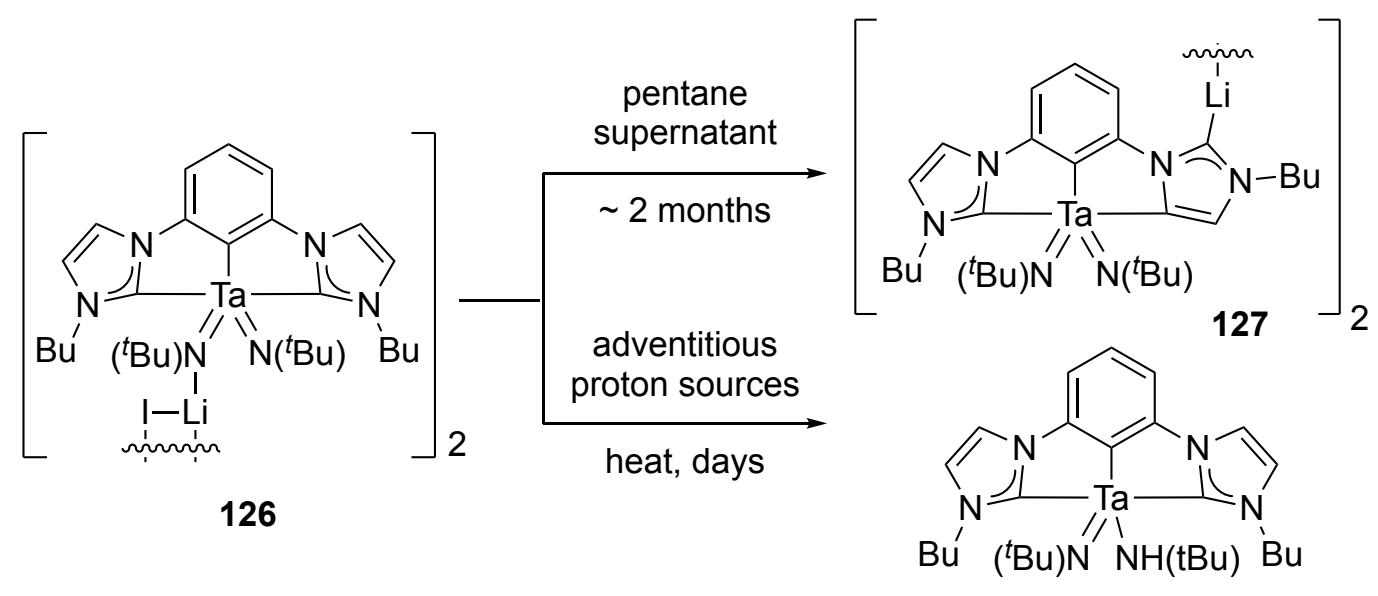

128

Scheme 33. NHC-Ta(V) complexes 127 and 128 from species 126.

The bis-imido $\mathrm{Ta}(\mathrm{V})$ complex $\mathbf{1 2 6}$ was investigated as a catalyst for the oxidative amination of aminoalkenes to afford the corresponding cyclic imine (amine oxidation product) as the major 
species, along with an equivalent of reduced substrate, and a minor hydroamination component (cyclic amine). ${ }^{82}$

Hohloch and coworkers investigated the coordination of bis-phenolate mesoionic carbene ligands with group 5 metals (Scheme 34). ${ }^{56}$ Deprotonation of the ligand precursors with LDA and subsequent reaction with $\mathrm{Nb}\left(\mathrm{N}^{t} \mathrm{Bu}\right) \mathrm{Cl}_{3} \mathrm{Py}_{2}$ afforded the corresponding $\mathrm{Nb}(\mathrm{V})$ complex 129 with moderate yield (62\%). Characterization of 129 by X-ray diffraction shows that the $\mathrm{Nb}$ metal center adopts a distorted octahedral geometry along with a mer-coordination of the tridentate NHC ligand featuring the shortest reported Nb-NHC bond distance $(2.196(3)$ $\AA)$.<smiles></smiles>

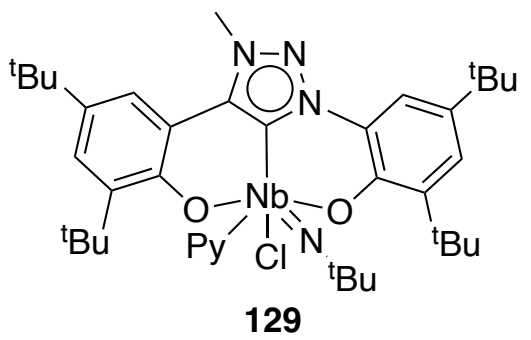

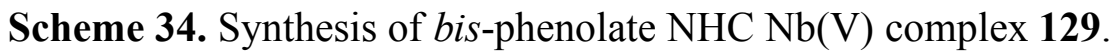

\section{Group 6 Metals}

\section{a) Chromium}

The coordination chemistry of chromium with NHC ligands was pioneered by Öfele over fifty years ago. ${ }^{84,85,86,87,88}$ In the past decade, some examples of $\mathrm{Cr}-\mathrm{NHC}$ complexes have been reported. Danopoulos, Braunstein and coll. developed an anionic 'pincer' ligand of type NHC-phosphino-picoline that was investigated with chromium(II). The desired $\mathrm{Cr}$ (II) NHC compound $\mathbf{1 3 1}$ was readily obtained from the corresponding potassium salt 130, featuring a dearomatized picoline backbone (Scheme 35$).{ }^{89}$ The latter was used as catalyst for ethylene oligomerization albeit with poor activity and selectivity for $\alpha$-olefins. ${ }^{90}$ Tridentate pincer-type $\mathrm{N}_{\text {imine }} \mathrm{C}_{\mathrm{NHCN}} \mathrm{N}_{\text {amine }}$ ligands were also coordinated to $\mathrm{Cr}(\mathrm{III}) .{ }^{91}$ The resulting $\mathrm{Cr}$ (III) complexes are 
moderately active in ethylene oligomerization catalysis. $N$-Phosphanyl and $N, N$ '-diphosphanylsubstituted NHC ligands have been investigated with $\mathrm{Cr}$ (II) and $\mathrm{Cr}$ (III) for use as ethylene oligomerization catalysts. The activities were found highly dependent on the cocatalyst used, the reaction temperature and the solvent. ${ }^{92}$

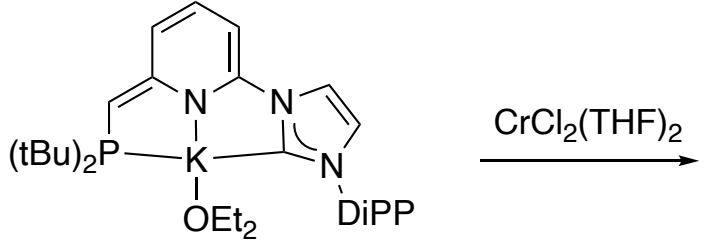

130<smiles></smiles>

131

Scheme 35. Synthesis of 'pincer' NHC-type chromium(II) complex 131.

Jenkins and coll. reported on the first examples of aziridination catalysis with a NHC chromium complex. ${ }^{93}$ Investigation of various metal tetra-carbene complexes for the aziridination of alkenes revealed that the $\mathrm{Cr}(\mathrm{III})-\mathrm{NHC}$ complex $\mathbf{1 3 2}$ was active in a similar manner to a previously reported iron-based system (Scheme 36). ${ }^{94}$ The authors suspected that $\mathbf{1 3 2}$ was reactive both due to the presence of strong donating NHC ligands and the trans position of the chloride ligands. Investigation of substrate scope revealed that chromium catalyst $\mathbf{1 3 2}$ is also effective in the presence of protic groups such as amines or alcohols.

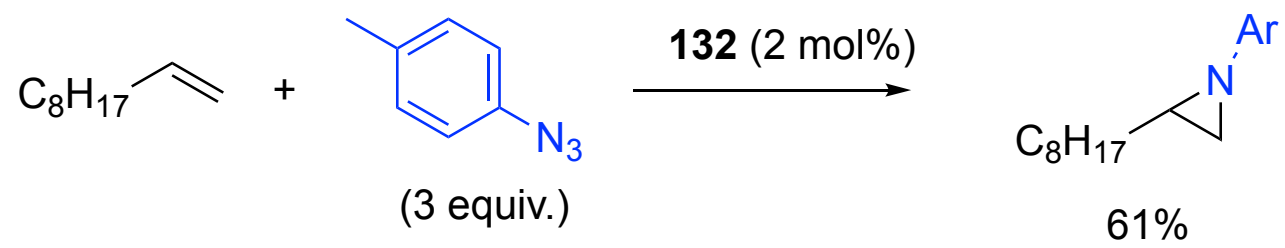

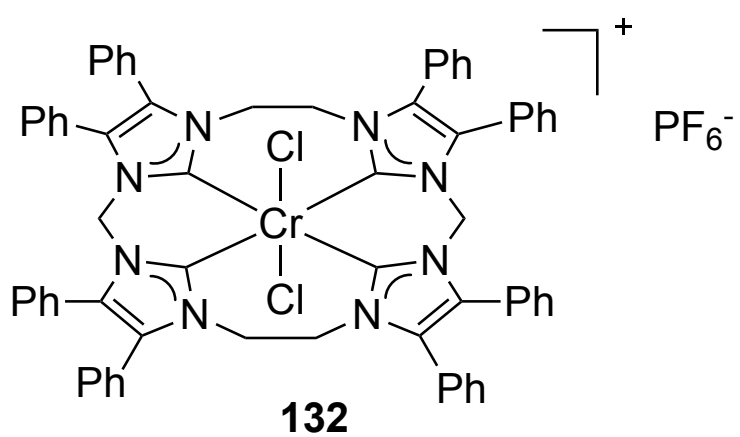

Scheme 36. Catalytic aziridination reaction in presence of $\mathbf{1 3 2}$. 
The conversion of glucose into 5-hydroxymethylfurfural (5-HMF) is a reaction of great interest in the context of renewable chemistry. ${ }^{95}$ Among all investigated catalysts, chromium(II) and (III) have displayed interesting results in particular in combination of ionic liquids. ${ }^{96}$ In this context, NHC-cyclopentadienyl Cr(III) complexes such as complex $\mathbf{1 3 3}$ have been synthesized and were found air-stable in the solid state (Figure 12). These complexes are active in glucose dehydration to form 5-HMF in moderate yields. ${ }^{97}$

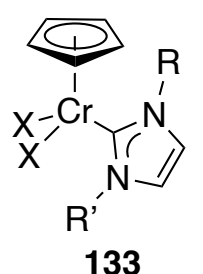

Figure 12. Molecular structure of $\mathrm{Cr}(\mathrm{III})$ complexes 133 that have been investigated in the conversion of glucose into 5-HMF.

The reactivity of NHCs with $\alpha, \beta$-unsaturated $\mathrm{Cr}(0)$ [and $\mathrm{W}(0)]$ Fischer carbene complexes has been investigated. Such addition appears strongly dependent on the electrophilicity of the Fischer carbene atom. Alkoxy-carbene complexes react with NHCs to give zwitterionic $\mathrm{Cr}(0)$ alkenyls whereas less to yield mixed NHC-Fischer bis-carbenes. ${ }^{98}$

Notably, CAAC ligands were also used to stabilize an unprecedented two-coordinate $\mathrm{Cr}(\mathrm{I})$ cation $\left[(\mathrm{CAAC})_{2} \mathrm{Cr}\right]^{+} .{ }^{99}$ The complex was prepared by reduction of $\mathrm{Cr}(\mathrm{II})$ complex $(\mathrm{CAAC})_{2} \mathrm{CrCl}_{2}$ with $\mathrm{KC}_{8}$ to yield $(\mathrm{CAAC})_{2} \mathrm{CrCl}$ followed by treatment with $\mathrm{Na}\left[\mathrm{B}\left(\mathrm{C}_{6} \mathrm{H}_{3}\left(\mathrm{CF}_{3}\right)_{2}\right)_{4}\right]$.

Overall, an analysis of all NHC-Cr complexes deposited in the structural database CCDB revealed that the $\mathrm{Cr}-\mathrm{NHC}$ bond distances are range from 2.02 to $2.17 \AA$ ( $>180$ examples), one example below $2.00 \AA$ and 6 examples between 2.18 to $2.24 \AA$. 


\section{b) Molybdenum and tungsten}

Polydentate NHC adducts of molybdenum (0) carbonyl complexes have been the subjects of various reports. ${ }^{100,101}$ Reaction of $\mathrm{Ag}_{2} \mathrm{O}$ with an unsymmetrical pyrazolylpyridyl bis-functionalized imidazolium salt followed by transmetallation with $\left[\mathrm{Mo}(\mathrm{CO})_{5}(\mathrm{THF})\right]$ gave the corresponding bidentate complex 134 (Figure 13). ${ }^{102}$ Its activity has been investigated in the catalytic oxidation of styrene giving 2,5-diphenyl-1,4-dioxane as a sole product albeit with low yield. Chaplin and collaborators investigated the coordination chemistry of two bis-NHC-based pincer ligands incorporating either a central pyridine or a lutidine moiety. The rigid pyridine-based ligand coordinated the metal in a mer-configuration in $\mathbf{1 3 5}$ whereas the more flexible lutidine-based ligand adopted an uncommon fac-coordination in 136. $^{103}$

The activity of (mostly) monodentate NHC adducts of molybdenum( $(0)$ and tungsten $(0)$ carbonyl complexes has been investigated in olefin epoxidation catalysis. ${ }^{104}$ The complexes displayed moderate activities towards cyclooctene epoxidation with tert-butyl hydroperoxide as oxidant, $\left[\mathrm{Mo}(\mathrm{CO})_{5}(\mathrm{IMes})\right]$ being the best catalyst with ca. $60 \%$ conversion after 24 hours at $55^{\circ} \mathrm{C}$ ( $1 \mathrm{~mol} \%$ cat.). The catalytic activity of a series of group 6 NHC complexes of type $\left[(\mathrm{NHC}) \mathrm{M}(\mathrm{CO})_{5}\right]$ or $\left[(\right.$ bis-NHC $\left.) \mathrm{M}(\mathrm{CO})_{4}\right]$ was investigated in the hydrosilylation of imines. ${ }^{105}$ The activity improved when using a bis-NHC vs. monodentate NHC ligands affording the hydrosilylated products in high yield ( $5 \mathrm{~mol} \% \mathrm{Mo}$ cat.). An example of a $\mathrm{Mo}(0)$ carbonyl complex supported by an abnormal NHC $(a \mathrm{NHC})$ is also known. ${ }^{106}$

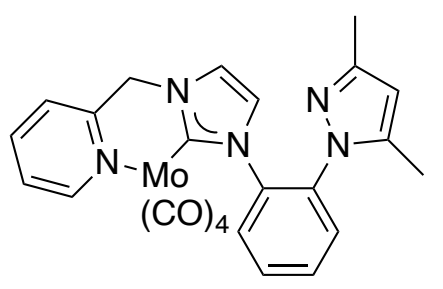

134

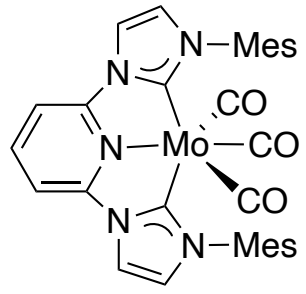

135

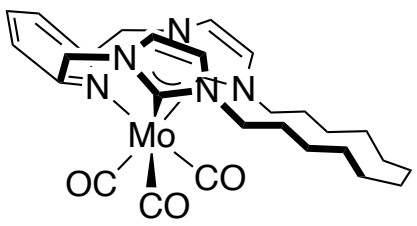

136

Figure 13. Molecular structure of $\operatorname{Mo}(0)$ complexes 134-136. 
Breakthroughs were recently achieved in molybdenum chemistry such as the catalytic reduction of $\mathrm{N}_{2}$ to $\mathrm{NH}_{3}$ or the coordination-induced activation of $\mathrm{NH}$ bonds. ${ }^{107,108,109}$ These results have motivated various groups to investigate molybdenum( $(0)$ dinitrogen complexes supported by NHC ligands. Tuczek and coll. synthesized Mo-N $\mathrm{N}_{2}$ complexes supported by a mixed NHC-phosphine pincer ligand (Scheme 37, eq. 1). ${ }^{110}$ The low $\pi$-accepting character of the NHC ligand may enhance dinitrogen activation when compared to phosphine-based ligands. Molybdenum (III) complex 137 was reduced by a sodium amalgam in the presence of $\mathrm{P}(\mathrm{OMe})_{3}$ and $\mathrm{N}_{2}$. Two different products were isolated: (i) the expected Mo- $\mathrm{N}_{2}$ complex 138 which displays a weaker N-N stretching vibration illustrating the activating character of the NHC unit, and (ii) an unprecedented $\mathrm{NHC} \mathrm{Mo}(0)$ complex 139 that contains a meta-phosphite ligand [i.e. $\mathrm{P}(\mathrm{O})(\mathrm{OMe})]$. Treatment of $\mathrm{Mo}(\mathrm{IV})$ precursor $\mathrm{MoCl}_{4}(\mathrm{THF})_{2}$ with 4 equivalents of $\mathrm{NHC}$ ligand and 4 equivalents of $\mathrm{KC}_{8}$ under an atmosphere of $\mathrm{N}_{2}$ gave the formation $\mathrm{Mo}-\mathrm{N}_{2}$ complexes 140 ( $\mathrm{R}=\mathrm{Me}, \mathrm{Et})$ in moderate to good yields (Scheme 37, eq. 2). ${ }^{111}$ When $\mathrm{R}={ }^{i} \mathrm{Pr}$, the isolated corresponding Mo complex was the tris- $\mathrm{N}_{2}$ complex $\mathrm{Mo}\left(\mathrm{N}_{2}\right)_{3}(\mathrm{NHC})_{3}$. A substantial weakening of the N-N bond was observed in these complexes enabling an unprecedented protonation of the Mo-bounded $\mathrm{N}_{2}$ ligands.

It is also notable that a pyridyl-NHC (pyNHC) ligated tetracarbonyl tungsten complex has been investigated as photocatalyst for $\mathrm{H}_{2}$ production. ${ }^{112}$ Photoactivation gave the $\mathrm{W}($ pyNHC$)(\mathrm{CO})_{3}$ species, a rare example of a mononuclear photocatalyst capable of using visible light for proton reduction. 


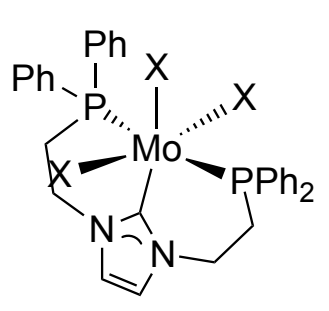

137

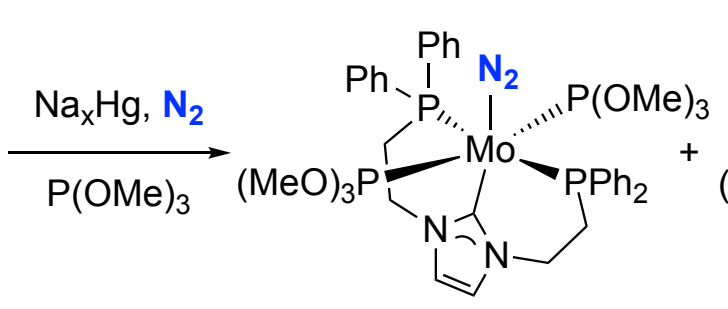

138

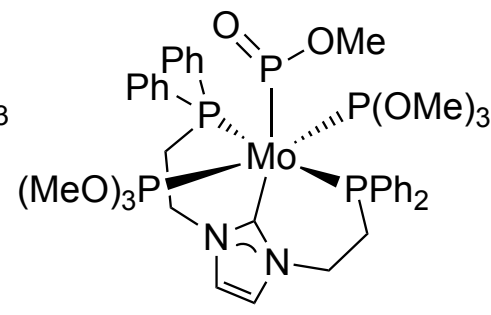

139

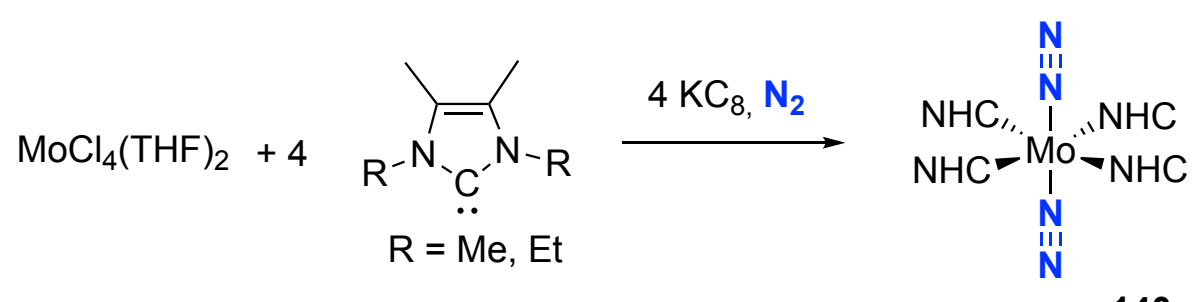

Scheme 37. Synthesis of molybdenum (0) dinitrogen NHC complexes 138 and $\mathbf{1 4 0 .}$

Quadruply bonded group 6 bimetallic complexes have played a major role in the development of coordination chemistry. ${ }^{113}$ Interestingly, it is only in 2015 and 2016 that the first examples of $\mathrm{N}$-heterocyclic carbene adducts of $[\mathrm{Mo}]_{2}{ }^{4+}$ systems were reported by Carmona and KociokKohn, respectively. ${ }^{114,115}$ They found that the steric demand of the NHC is a key feature in determining the stoichiometry and coordination geometry of the system. Monoaxial, diaxial and bis-equatorial coordination modes of NHC ligands were observed to dimolybdenum tetracarboxylate complexes.

Cationic cyclopentadienyl molybdenum/tungsten complexes $\left[\mathrm{CpM}(\mathrm{CO})_{2}(\mathrm{NHC})\right]^{+}$have been established as efficient catalysts for the hydrosilylation of ketones. ${ }^{116}$ The authors proposed a high-valence M(IV) hydride as active species forming by oxidative addition of silane to the metal center. However, recent DFT calculations support an alternative ionic mechanism featuring an $\mathrm{SN}_{2}$-type transition state at $\mathrm{Si}$ with a heterolytic cleavage of a $\eta^{1}$-coordinated $\mathrm{Si}-$ H bond. ${ }^{117}$ Moreover, though M(IV) silyl hydrides could be detected by spectroscopy, calculations show that such species are not involved in the catalytic cycle. In a subsequent report, Oestreich and coll. also investigated this reaction in details with a tungsten-based 
catalyst of type $\left[\mathrm{CpW}(\mathrm{CO})_{2}(\mathrm{IMes})\right]^{+}$and suggested a new $\mathrm{Si}-\mathrm{H}$ bond activation mode where the $\mathrm{CO}$ ligand is cooperating and interacting with the $\mathrm{Si}-\mathrm{H}$ bond. ${ }^{118}$ The $\mathrm{Si}-\mathrm{H}$ bond is heterolytically cleaved to generate a $\mathrm{W}-\mathrm{H}$ species and a $\mathrm{CO}$-stabilized silylium ion.

Hor and coll. investigated the coordination properties of a benzothiazole-carbene ligand with molybdenum. Cyclopentadienyl molybdenum (II) N,C-chelating benzothiazole-NHC complex 141 was easily prepared from the corresponding benzothiazolyl-imidazolium salts and through the silver route (Scheme 38). ${ }^{119}$ These complexes were robust even in the presence of an oxidant and were therefore applied with success in cyclooctene epoxidation catalysis $\left(90 \%\right.$ yield, $55^{\circ} \mathrm{C}$, 3 h). Molybdenum(0) carbonyl complexes and molybdenum (II) diiodo carbonyl complexes both bearing the same $N, C$-chelating benzothiazole-NHCs have also been tested in the epoxidation of alkene with success. ${ }^{100}$
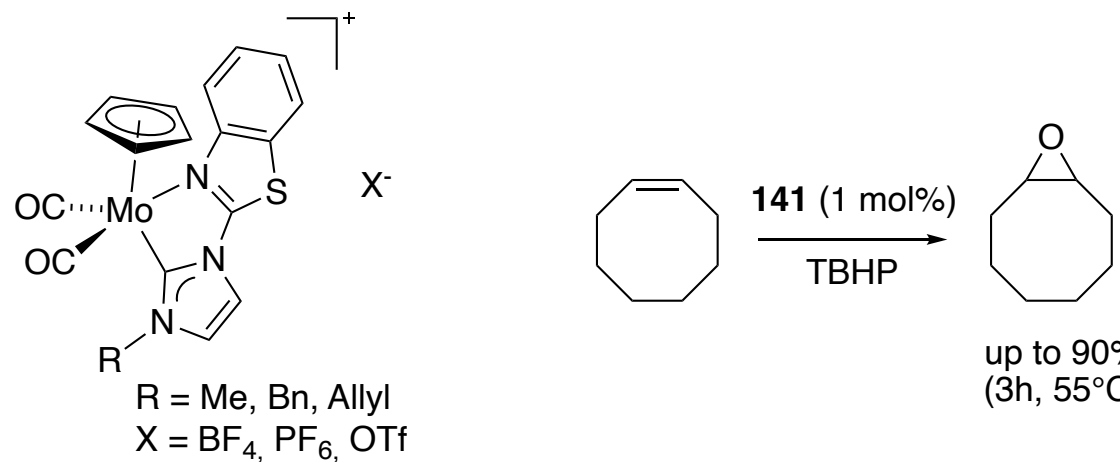

up to $90 \%$

$X=\mathrm{BF}_{4}, \mathrm{PF}_{6}, \mathrm{OTf}$

$\left(3 \mathrm{~h}, 55^{\circ} \mathrm{C}\right)$

141

Scheme 38. Cp-Mo(II) complexes 141 supported by benzothiazole-NHC ligands and application in cyclooctene epoxidation catalysis.

In 2014, Buchmeiser and coll. reported the first example of a NHC-supported Schrock-type molybdenum imido alkylidenes (Scheme 39). ${ }^{120,121,122}$ Direct reaction of Mo(VI) DME adduct precursor 142 with the free carbene ( $\mathrm{I}^{t} \mathrm{Bu}$ or SIMes) resulted in the formation of the expected NHC-Mo complexes 143. The authors investigated its reactivity with norborn-2-ene leading to the formation of an alkylidene cationic species (as an $\mathrm{OTf}^{-}$salt), which remains relatively scarce 
in the literature ${ }^{123,124}$. Interestingly, these complexes displayed catalytic activities in ringclosing metathesis (RCM), ring-opening metathesis polymerization (ROMP) and also in the cyclopolymerization of $\alpha, \omega$-diynes. ${ }^{120,125,126,127,128,129}$ Moreover, these catalysts tolerate the presence of functional groups such as amine, alcohol or carboxylic acid moieties. A correlation between ligand basicity and hydroxyl group tolerance was established in these NHC molybdenum catalysts. ${ }^{130}$ The authors also found that, in these systems, no dissociation of the Mo-NHC bond occurred under catalytic conditions, consistent with the robustness of these species. Also, immobilized versions on silica have been prepared using an hydroxyfunctionalized NHC ligand. These systems displayed catalytic activities that are comparable with the analogous homogeneous systems. ${ }^{131}$ Alternatively, ionically tagged versions of Mo complexes of type 143 were also synthesized through triflate/3-(1-pyridinium)-1-propane sulfonate ligand exchange. ${ }^{132}$ These Mo complexes (and also related W complexes) have been successfully applied to biphasic olefin metathesis with no leaching of metal into the nonpolar phase of the system.

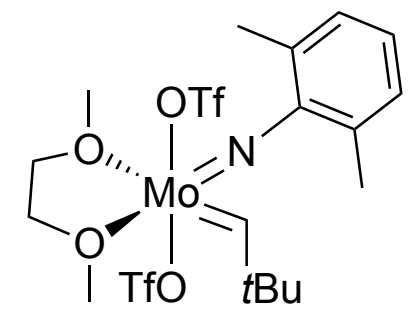

142

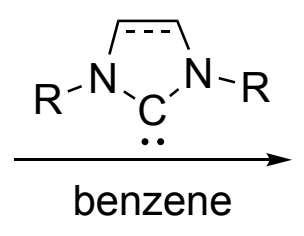

143
active catalyst in RCM, ROMP and
cyclopolymerization of $\alpha, \omega-$ diyne

Scheme 39. Synthesis of high-oxidation-state NHC-bearing Mo(VI) alkylidene complexes 143.

The regio- and stereo-selective cyclopolymerization of 1,6-hepta- and 1,7-octadiyne substrates has been studied with Mo alkylidene species 143 and complexes 144-146 (Scheme 40) to afford highly regio- (> 96\%) and stereo-regular all-trans polyenes. ${ }^{133,134}$ This is in contrast with 
molybdenum imidoalkylidene monoalkoxide monopyrrolide Mo catalysts that showed poor regioselectivity. ${ }^{135}$ Various cationic molybdenum imido alkylidene NHC complexes have also been investigated for the stereoselective olefin ring-opening cross metathesis. ${ }^{136}$ The reactions could be accomplished with high $E$ - or Z-selectivity depending on ligands steric hindrance around the Mo center. Importantly, in presence of most of these catalysts, no post-metathesis isomerization was observed, the products being formed under thermodynamic control.

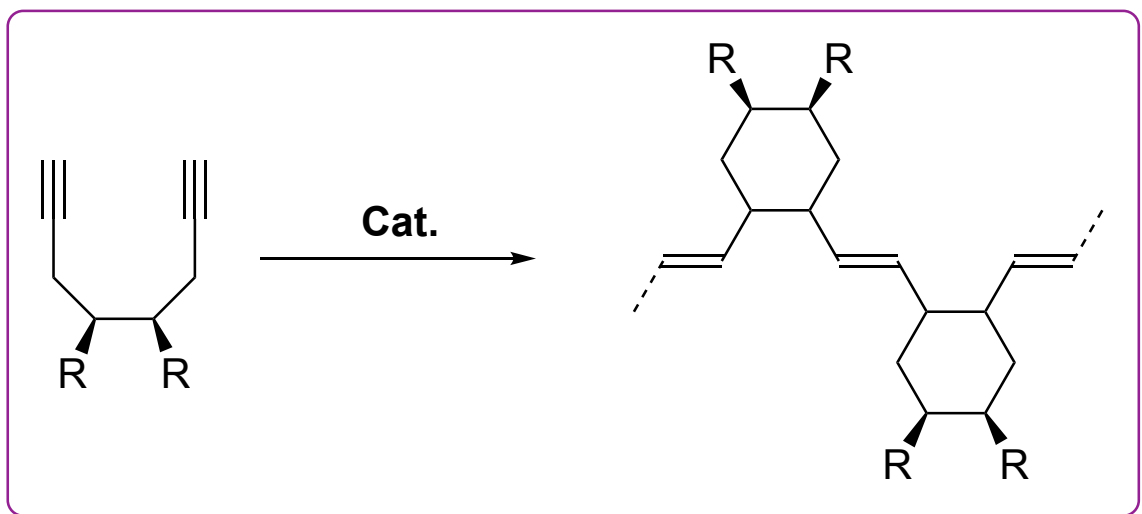

\section{Cat:}

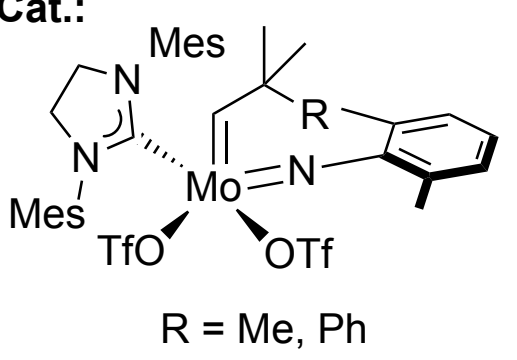

144

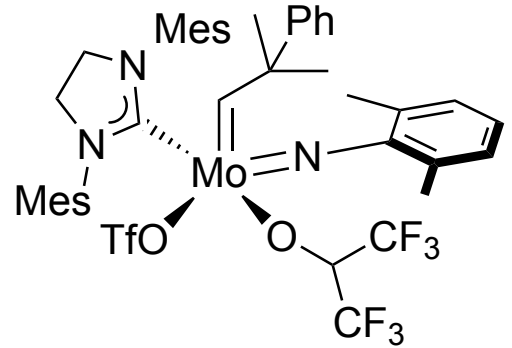

145

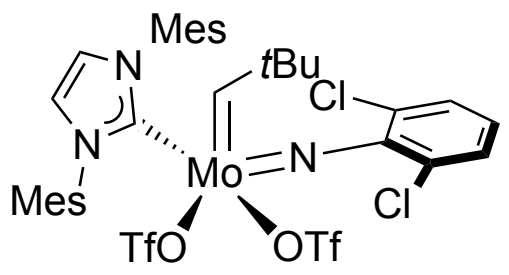

146

Scheme 40. Regio- and stereoselective cyclopolymerization of $\alpha, \omega$-diynes with Mo NHC alkylidene 144-146.

Buchmeiser and coll. tuned the nature of the NHC ligands around the Mo alkylidene core so that to improve the stability or the catalytic activity of all systems. ${ }^{137}$ For example, the introduction of a N- and C-chelating NHC onto the Mo center such as compound 147 (Figure 14) gave complexes with a remarkable stability. ${ }^{138}$ Stable cationic species were easily accessed by triflate abstraction but all found to be inactive in olefin metathesis. The authors noticed that the pyridyl moieties was not hemilabile in all these systems. On the other hand, molybdenum 
complexes bearing an O-chelating NHC, such as 148 (Figure 14), displayed activity in ROMP catalysis and the structures of the first insertion products (syn/anti, cis/trans) in the ROMP of norbornene derivatives were identified. ${ }^{139,140,141}$ This allowed the proposal of a detailed mechanism of the ROMP catalysis and also the synthesis of high cis or high trans polymers by modifying the syn/anti interconversion rates of the catalysts.

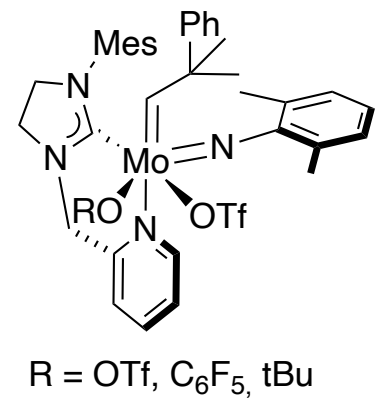

147

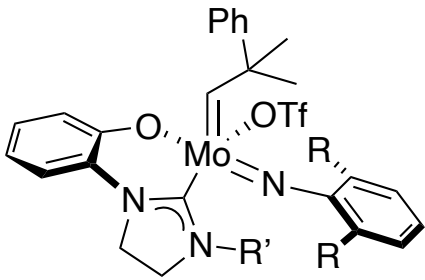

$\mathrm{R}=\mathrm{Me}, \mathrm{iPr}$

$\mathrm{R}^{\prime}=$ Mes, Dipp

148

Figure 14. Molybdenum imido alkylidene complexes bearing bidentate NHC ligands (147 and 148).

Mo- and W-based monoalkoxide pyrrolide complexes (also called MAP-type complexes) are efficient catalysts for the ROMP or cross-metathesis reactions. ${ }^{142,143}$ Inspired by these results, the coordination chemistry of NHC ligands has been investigated in combination with a pyrrolide ligand or a bulky mono-alkoxide ligand and Mo(VI) alkylidene species. ${ }^{144}$ Direct reaction of the Mo bis-pyrrolide imido alkylidene complex 149 with a NHC ligand gave the corresponding pentacoordinated complex $\mathbf{1 5 0}$ in good yield (Scheme 41). The synthesis of the corresponding cationic complexes was then possible by ligand exchange with a weakly coordinating anion such as $\mathrm{B}\left(\mathrm{Ar}^{\mathrm{F}}\right)_{4}^{-}$[tetrakis- $\left(3,5-\left(\mathrm{CF}_{3}\right)_{2}-\mathrm{C}_{6} \mathrm{H}_{3}\right)$ borate] thus giving complexes 151. Neutral complexes of type $\mathbf{1 5 0}$ were inactive in RCM and the cationic species 151 only displayed moderate to good activity in RCM and cross metathesis. Interestingly, both neutral and cationic complexes are excellent precursors to access Mo-NHC complexes with very sterically demanding alkoxides, such as $\mathrm{HMTO}^{-}\left[\mathrm{HMTOH}=\left(2,6-\left(2^{\prime}, 4^{\prime}, 6^{\prime}-\mathrm{Me}_{3} \mathrm{C}_{6} \mathrm{H}_{2}\right)_{2}-\right.\right.$ 
$\left.\mathrm{C}_{6} \mathrm{H}_{3} \mathrm{O}^{-}\right)$], as displayed in Scheme 41 for complex 152. Copéret and co-workers showed that cation of type $\mathbf{1 5 2}$ displays an unusually high activity in olefin metathesis reactions when supported on silica. ${ }^{145}$
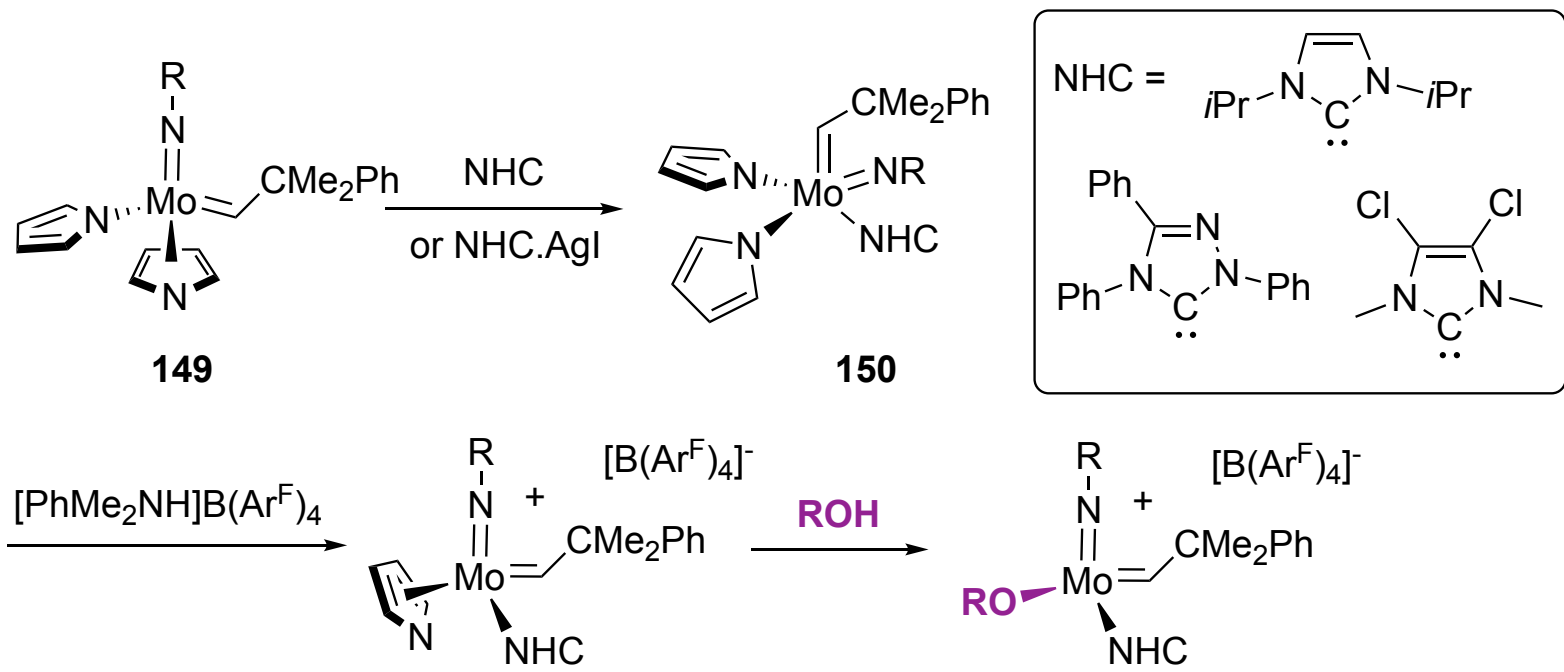

151

152

Scheme 41. Synthesis of Mo imido alkylidene NHC complexes 150-152 $(\mathrm{ROH}=\mathrm{HMTOH})$.

Molybdenum(VI) and tungsten(VI) N-heterocyclic carbene alkylidyne complexes have been reported. Scheme 42 displays three representative examples 153-155 of such compounds, which are easily synthesized from the DME adduct $\mathrm{Mo}\left(\equiv \mathrm{C}-p-\mathrm{OMe}-\mathrm{C}_{6} \mathrm{H}_{4}\right)\left(\mathrm{OCMe}\left(\mathrm{CF}_{3}\right)_{2}\right)_{3}(\mathrm{DME}) .{ }^{146}$ All complexes displayed activity in the self-metathesis of 1-phenyl-1-propyne at room temperature (Scheme 42). The immobilization of the Mo alkylidyne on a silica-supported NHC ligand (such as 154) prevents bimolecular catalyst decomposition, resulting in much higher activities compared to the homogeneous system. ${ }^{147}$ Bi-dentate NHCs have also been used as supporting ligands in Mo alkylidyne species 155, but did not lead to the expected increase in catalytic activity. ${ }^{148}$ 
<smiles>CC#Cc1ccccc1</smiles><smiles>[134Sb]</smiles><smiles>C(#Cc1ccccc1)c1ccccc1</smiles><smiles>COc1ccc(C(OC(C)(C)C(F)(F)F)(OC(C)(C)C(F)(F)F)OC(C)(C)C(F)(F)F)cc1</smiles>

153

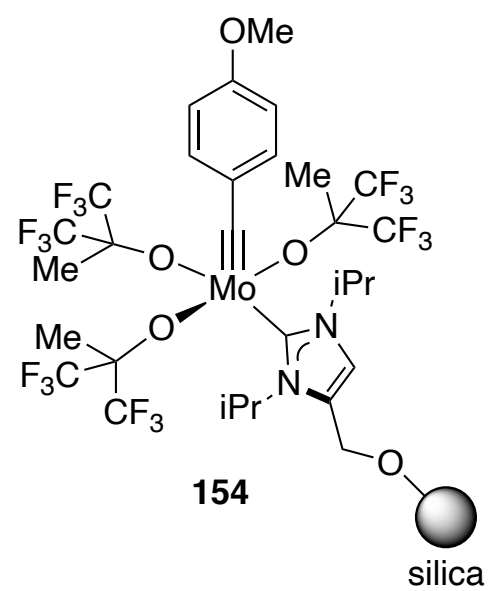<smiles>COc1ccc(COC(C)(C)OC(C)(C(F)(F)F)C(F)(F)F)cc1</smiles>

155

Scheme 42. Molybdenum (VI) N-heterocyclic carbene alkylidyne complexes 153-155 tested in the self-metathesis of 1-phenyl-1-propyne.

Tungsten(VI) N-heterocyclic carbene complexes have been significantly less studied than molybdenum analogues. Figure 15 displays some representative examples of W-NHC species (156-158). Cationic W imido alkylidene NHC complex 156 showed moderate to good activity in various olefin metathesis reactions. ${ }^{149,150}$ Cationic W oxo alkylidene NHC species were also prepared, fully characterized and shown to be highly active in olefin metathesis with turnover numbers up to $10000 .{ }^{151}$ Further synthesis of silica-supported tungsten oxo alkylidene complex 158 allowed an unprecedented activity and stability in in propene self-metathesis catalysis (over 1 million TON). ${ }^{152}$ 


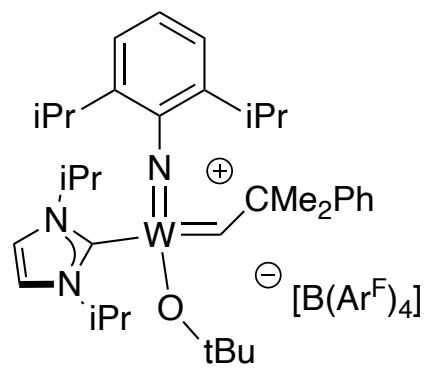

156

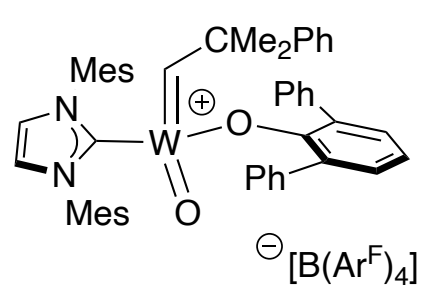

157

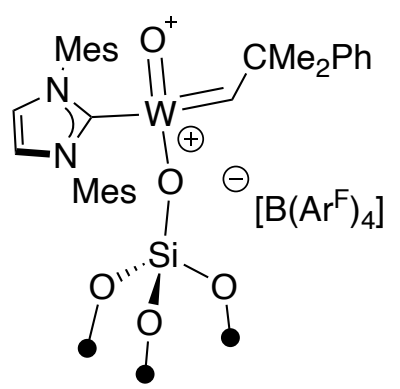

158

highly active olefin metathesis catalyst

Figure 15. Cationic tungsten-oxo and tungsten-imido alkylidene NHC complexes 156-158.

Overall, an analysis of all NHC-Mo complexes deposited in the structural database CCDB showed that the majority of Mo-NHC bond distances range from 1.98 to $2.34 \AA(>175$ examples, $30 \%$ of them being at $2.24 \AA$.) We also note the presence of 8 molecular structures with a Mo-NHC bond distance between 2.52 and $2.71 \AA$, all being dinuclear Mo-NHC complexes. The tungsten complexes display W-NHC bond distances between 2.13 and $2.31 \AA$ (>75 examples).

\section{Group 7 Metals}

\section{a) Manganese}

Valyaev and coll. synthesized the non-symmetrical pyridine-NHC-phosphane ligand 159 and investigated its coordination chemistry with $\mathrm{Mn}(0)$ (Scheme 43). ${ }^{153}$ It was reacted with $\mathrm{Mn}_{2}(\mathrm{CO})_{10}$ under UV irradiation and the corresponding dinuclear $\mathrm{Mn}$ complex 160 was isolated in moderate yield. The molecular structure was determined by X-ray diffraction studies which confirmed the high flexibility of the ligand, thus able to stabilize bimetallic species. $^{154}$ 


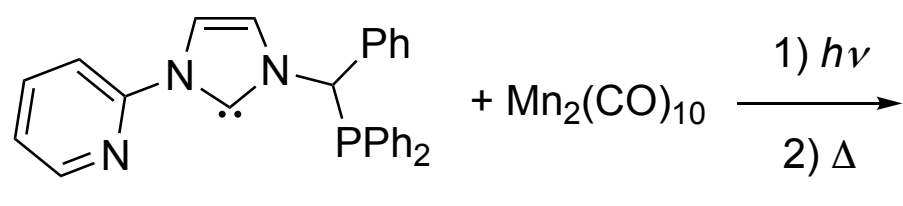

159

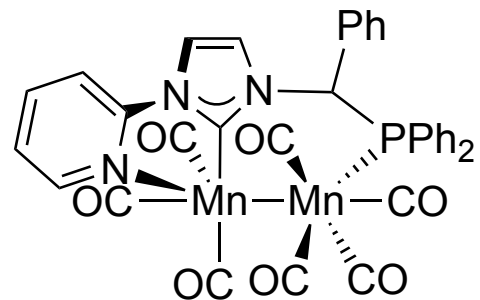

160

Scheme 43. Synthesis of dinuclear Mn (0) complex 159 with bridging ligand $\mathbf{1 6 0 .}$

Monodentate NHC ligands such as IDipp, IMes and CAAC were demonstrated to be effective ligands for the stabilization of three-coordinate manganese $(0)$ complexes $\mathbf{1 6 1 a}$ c (Scheme 44). ${ }^{155}$ They were prepared via reduction of the corresponding ( $\left.\mathrm{NHC}\right) \mathrm{MnCl}_{2}$ adduct by $\mathrm{KC}_{8}$ in the presence of divinyltetramethyldisiloxane. Species 161a-c represent rare examples of isolable low-coordinate and formally zero-valent transition-metal complexes. Strong $\pi$ backdonation from the Mo center to the alkene moieties was evidenced. Characterization data also agree with a $S=3 / 2$ ground-state spin at the Mo center. Intriguing reactivities of reductive coupling reactions were observed, resulting in the formation of $\mathrm{Mn}$ (II) dialkyl species. Adducts of the type $\left[(\mathrm{NHC}) \mathrm{Mn}\left(\eta^{2}-\mathrm{H}_{2} \mathrm{C}=\mathrm{CHPh}\right)_{2}\right]$ are also known. ${ }^{156}$
1) $\mathrm{NHC}$
2) divinyltetramethyl-
$\mathrm{MnCl}_{2}$
-disiloxane<smiles>C=C1C=C[SiH](ONC)O[SiH2]1</smiles>
161a: $\mathrm{NHC}=$ IDipp
161b: $\mathrm{NHC}=\mathrm{IMes}$
3) $2 \mathrm{KC}_{8}$
161c: $\mathrm{NHC}={ }^{\mathrm{Me}} \mathrm{CAAC}$

Scheme 44. Synthesis of tri-coordinate $\mathrm{Mn}(0)-\mathrm{NHC}$ complexes 161a-c.

The growing interest in developing molecular catalysts based on abundant first-row transition metals has strongly encouraged studies about manganese complexes, in particular at the + I oxidation state, which has been relatively underexploited previously. In this context, the 
incorporation of NHC-type ligands has greatly contributed to the development of efficient and effective catalysts.

Lugan, Sortais and coll. evaluated the catalytic activity of manganese (I) NHC complexes of type $\mathrm{CpMn}(\mathrm{NHC})(\mathrm{CO})_{2}$ for the hydrosilylation of ketones and aldehydes. ${ }^{157,158,159}$ Amongst them, complex 162 displayed the highest activity under mild conditions (up to ca. 1000 TON; Scheme 45). Later on, they described the first examples of Mn (I) complexes bearing Cptethered NHC ligands $\left[\left(\mathrm{Cp}\left(\mathrm{CH}_{2}\right)_{\mathrm{n}} \mathrm{NHC}\right) \mathrm{Mn}(\mathrm{CO})_{2}\right]$ 163. However these complexes displayed lower activities compared to $\mathbf{1 6 2} .{ }^{160}$ More recently, Royo and coll. investigated manganese (I) carbonyl complexes bearing a bis-NHC ligand such as complex 164. Interestingly, these Mn species are active in the hydrosilylation of ketones, including $\alpha, \beta$-unsaturated ketones and dialkyl ketones. The catalyst can operate with cheap readily abundant silane PMHS and under atmospheric air. ${ }^{161}$ Noteworthy, manganese complex 164 is also active in the reduction of sulfoxide to sulfide with silane as reducing agents. ${ }^{162}$ It also displayed high activity for the selective $N$-alkylation of anilines with alcohols such as example that in eq. 1 of Scheme 45 , or for the $\alpha$-alkylation of ketones with alcohols such as eq. 2 Scheme 45. ${ }^{163,164}$ Manganese (I) NHC complexes are also potentially interesting to catalytically reduce ketones by transfer hydrogenation with $i \mathrm{PrOH}$ as hydrogen source. Turnover up to $17000 \mathrm{TON}$ were achieved when using a nitrogen-NHC bidentate ligand. ${ }^{165}$ In addition, a phosphine-NHC manganese (I) complex also displayed high activity for ketone hydrogenation with TON up to $6200 .{ }^{166}$ Finally, NHC-containing manganese (I) complexes with either a bidentate pyridine-NHC ligand or a tridentate NHC-pyridine-NHC are able to mediate the reduction of $\mathrm{CO}_{2}$ to $\mathrm{CO}$ by electrocatalysis. ${ }^{167,168,169}$ 


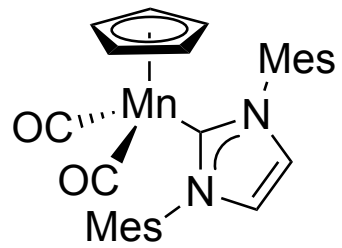

162

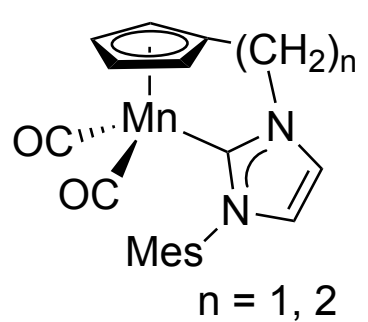

163

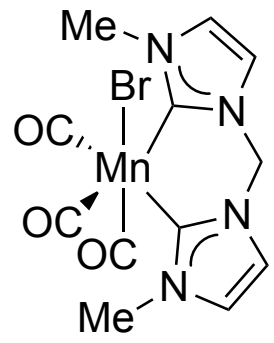

164<smiles>OCc1ccccc1</smiles><smiles>Nc1ccccc1</smiles>

$\underset{t B u O K}{164(1.5 \mathrm{~mol} \%)}$

$\mathrm{RT}, 48 \mathrm{~h}$<smiles>c1ccc(CNc2ccccc2)cc1</smiles>

$98 \%$<smiles>[CH2+]C(=O)c1ccccc1</smiles><smiles>CC(C)(C)[Mg]O[N+](=O)[O-]</smiles>
Toluene, $110^{\circ} \mathrm{C}, 2 \mathrm{~h}$<smiles>O=C(CCc1ccccc1)c1ccccc1</smiles>

$91 \%$

Scheme 45. Manganese (I) NHC complexes that have been evaluated in alcohol/ketoneinvolving functionalization catalysis.

$\mathrm{Mn}(\mathrm{I})-\mathrm{NHC}$ complexes such as $\mathbf{1 6 2}$ are easily available on multigram scale from industrially produced cymantren, $\mathrm{CpMn}(\mathrm{CO})_{3}$, by photochemical substitution of a $\mathrm{CO}$ ligand (Scheme 46 ). Treatment of complex 162 with $n \mathrm{BuLi}$ quantitatively generated the anionic abnormal imidazole-4-ylidene 165, a viable precursor to access unprecedented imidazolium salts. ${ }^{170}$ For example, treatment of compound 165 with $N$-fluorobenzenesulfonimide (NFSI) gave the corresponding mono-fluoro derivative 166 in $88 \%$ yield. ${ }^{171}$ Clean demetallation is possible by reaction with $\mathrm{TfOH}$ to afford the fluorinated imidazolium salt 167 in $95 \%$ yield, with thus the $\mathrm{CpMn}(\mathrm{CO})_{2}$ fragment acting as a NHC protecting group. The difluoro derivative may also be synthesized in high yield by doubling the sequence of lithiation/electrophilic fluorination. Treatment of 165 with $\mathrm{CO}_{2}$ followed by $\mathrm{HCl}$ addition gave the $\mathrm{CO}_{2} \mathrm{H}$-functionalized $\mathrm{Mn}$ complex 168. ${ }^{172}$ Finally, the reaction of 165 with $\mathrm{CuCl}_{2}$ promoted the oxidative coupling 
through the formation of a $\mathrm{C}-\mathrm{C}$ bond between the abnormal carbenes producing dinuclear $\mathrm{Mn}$ complex 169 in high yield. ${ }^{173}$ Acidic treatment with TfOH led to a clean removal of the Mn centers and the corresponding bis-imidazolium salt $\mathbf{1 7 0}$ was isolated in $90 \%$.

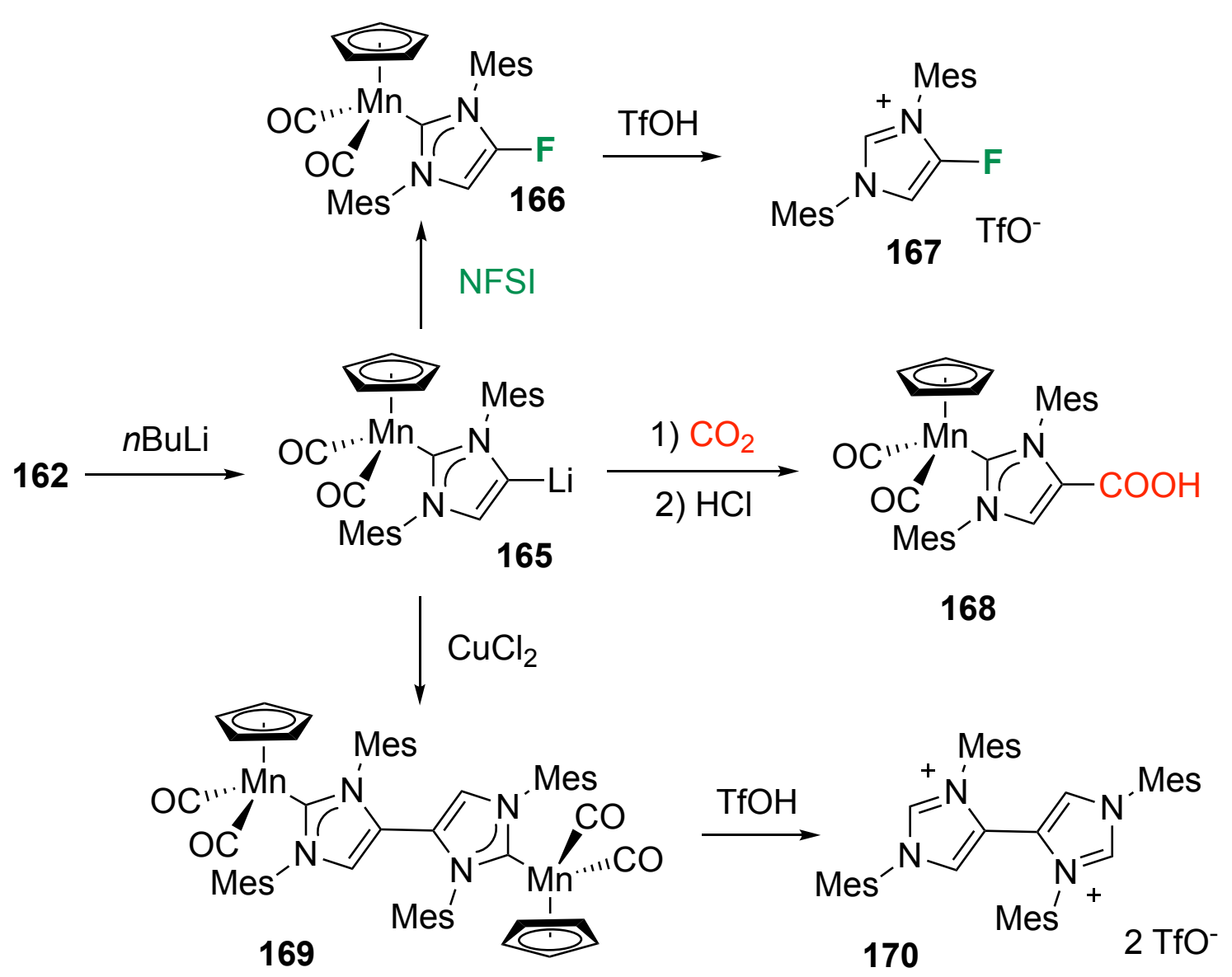

Scheme 46. Post-functionalization of $\mathrm{CpMn}(\mathrm{IMes})(\mathrm{CO})_{2} 162$.

Various manganese (II) complexes have been stabilized by NHC ligands. The first example of NHC-ligated Mn(II) porphyrin complex has been reported in 2019. ${ }^{174,175}$ Tripodal ligands combining NHC and phenolate moieties have been used to stabilize Mn (II) species. ${ }^{176}$ Reaction of manganocene $\mathrm{Mn}\left(\mathrm{C}_{5} \mathrm{H}_{5}\right)_{2}$ with free $\mathrm{NHC}$ carbene forms the neutral Lewis base adducts $(\mathrm{NHC}) \mathrm{Mn}\left(\mathrm{C}_{5} \mathrm{H}_{5}\right)_{2}$ which have been structurally characterized. ${ }^{177}$ Solid-state magnetic susceptibility studies revealed a high spin state of $5 / 2$, which corrects the previous analyses that claimed an intermediate spin of $3 / 2$ (attributed to impurities or partial decomposition of the compound). ${ }^{178}$ Reaction of $\mathrm{MnCl}_{2}$ in THF with free $\mathrm{NHC}$ affords the chloride-bridged dimer 
$\left[\mathrm{MnCl}_{2}(\mathrm{NHC})_{2}\right]$ (171, Scheme 44). ${ }^{179,180}$ These compounds are precursors to dimeric alkyl compounds dimeric alkyl compounds such as $\mathbf{1 7 2}$. Compound $\mathbf{1 7 2}$ may react with $\mathrm{Si}(\mathrm{OEt})_{4}$ to selectively form $\mathrm{MeSi}(\mathrm{OEt})_{3}$. Investigation of their activity for $\mathrm{C}-\mathrm{C}$ bond formation revealed that they were not chemically competent. A tridentate tris-NHC borate ligand has been used to stabilize $\mathrm{Mn}(\mathrm{IV})$ nitride species to produce a chelate of the type (C,C'C')Mn-nitride. ${ }^{181}$ The compound features a central $\mathrm{Mn}(\mathrm{IV})$ in tetrahedral environment, displays single-molecule magnet properties and constitutes a rare example of a low spin configuration $(s=1 / 2) d^{3}$ complex.

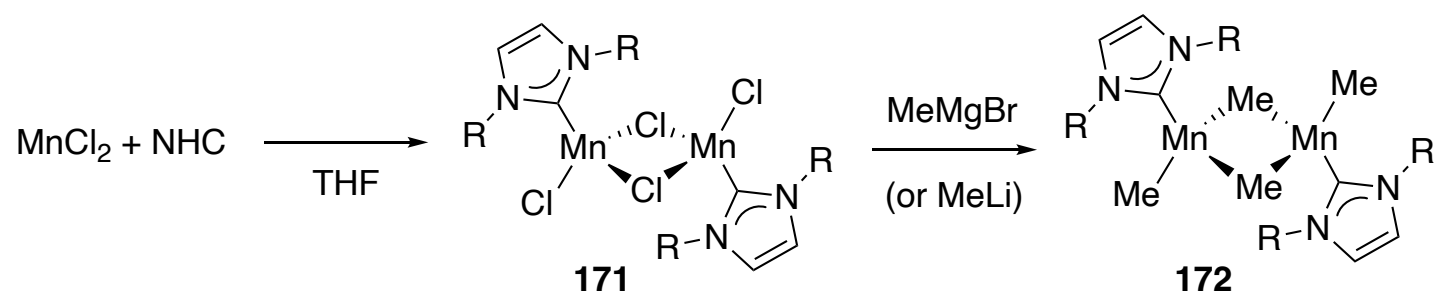

Scheme 47. Synthesis of NHC-supported manganese (II) complexes 171 and 172.

The total number of Mn-NHC structures that have deposited in the Cambridge database CCDC is 110 and the Mn-NHC bond distances range from 1.93 to $2.28 \AA$, evenly divided into two groups with mean values of 2.02 and $2.20 \AA$. The shortest Mn-NHC distance (1.932 $\AA$ ) was observed for a tris(carbene)borate manganese(IV) nitride complex ${ }^{181}$ and the longest Mn-NHC distance $(2.276 \AA)$ for adduct [(IDipp) $\left.\mathrm{Mn}\left(\mathrm{N}\left(\mathrm{SiMe}_{3}\right)_{2}\right)_{2}\right] .{ }^{182}$

\section{b) Technetium and rhenium}

Rhenium offers many advantages compared to 'classical' noble metals that are used in catalysis. It can coordinate a wide variety of ligands to stabilize a large possibility of metal oxidation state going from 0 to + VII. ${ }^{183}$ In addition to catalysis, rhenium complexes are being studied for potential application in medicine as pharmaceuticals for diagnosis or therapy and also in material science for light-emitting devices. 
Since the first report of $\operatorname{Re}(\mathrm{I}) \mathrm{NHC}$ derivatives as photoluminescent materials by Massi and collaborators in 2011 , there is a growing interest for such family of complexes because of their interesting photophysical properties. ${ }^{184,185}$ The molecular diversity of this family has been developed by varying the substituents and the nature of NHC ring: some recent examples are displayed in Figure 16 (complexes 173-175). ${ }^{186,187,188,189,190}$ Overall, ligand structure/ photophysical properties correlations could be established thus allowing a fine-tuning of these properties. In 2020, Mauro and collaborators described a novel class of tricarbonyl $\operatorname{Re}(\mathrm{I})$ complexes bearing a pyridyl pyrido-annelated NHC as a chromophoric ligand, such as $\mathbf{1 7 4}$, which displayed a stable and long-lived, ligand-centered, red phosphorescence. ${ }^{191}$ First examples of chiral-at-rhenium complexes have been prepared and fully characterized through the introduction of a chiral enantiopure NHC-helicene of the form $f a c-\operatorname{ReX}(\mathrm{CO})_{3}(\mathrm{NHC}) \mathbf{1 6 7}{ }^{192}$ These compounds exhibit strong chiroptical activities, especially intense circularly polarized phosphorescence and also phosphorescence lifetimes that are $>4000$ times longer than other NHC and helicene-based rhenium complexes (up to $0.7 \mathrm{~ms}$ ).

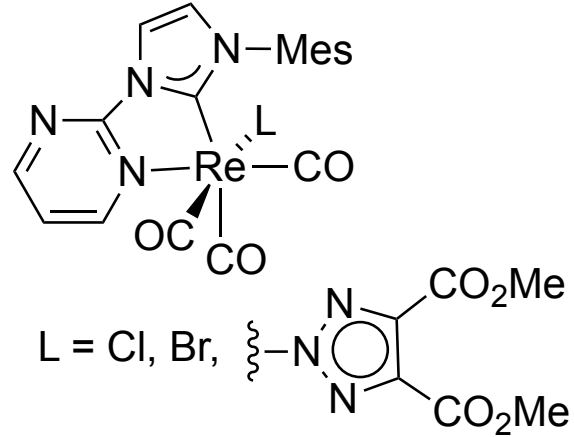

173

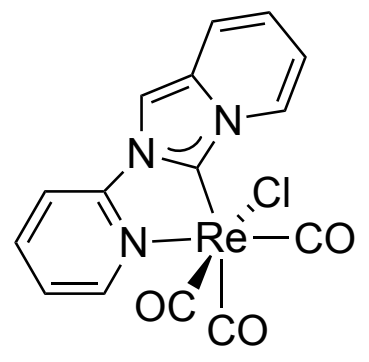

174

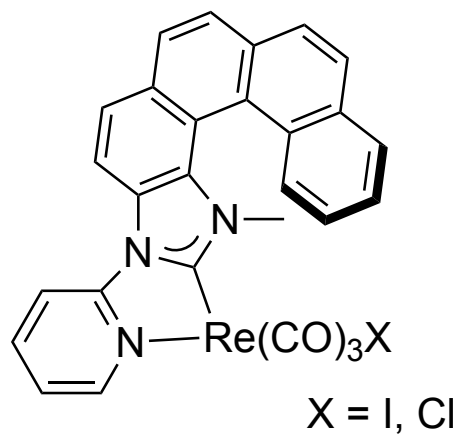

175

Figure 16. Selected examples of Re (I) tricarbonyl NHC complexes with interesting luminescence properties.

Such compounds have also an interest for visible-light-mediated photoredox-catalyzed reactions, some of these Re complexes showing greater or comparable reactivity to photoredox 
catalyst $\left[\mathrm{Ru}(\text { bipy })_{3}\right]^{2+} \cdot{ }^{190}$ It has also been demonstrated that they catalyze the conversion of $\mathrm{CO}_{2}$ to CO under solar-stimulated irradiation. ${ }^{193,194,195}$

Since radioactive rhenium isotopes have found applications in radiochemistry, few complexes have been applied in nuclear medicine. ${ }^{196,197}$ They also are used as analogues of potential Tc-99m diagnostic imaging agents for Alzheimer's disease. ${ }^{198}$ It seemed natural that the incorporation of NHC ligands for this purpose should be studied. It has been found that bidentate and tridentate ligands bearing NHC ligands are suitable for biological applications, including the possibility to functionalize the corresponding Re (I) complexes with biologically active molecules. ${ }^{199,200,201}$ Barnard and collaborators investigated a series of rhenium (I) carbonyl NHC-functionalized complexes that contain an amyloid binding group. ${ }^{202}$ These rhenium species are analogues of potential Tc-99m diagnostic imaging agents for Alzheimer's disease. Among them, complex 176 (Figure 17) binds selectively to the A $\beta$ amyloid plaques with low background fluorescence, which demonstrates the potential of such ligand for the development of diagnostic imaging agent with Tc-99m.

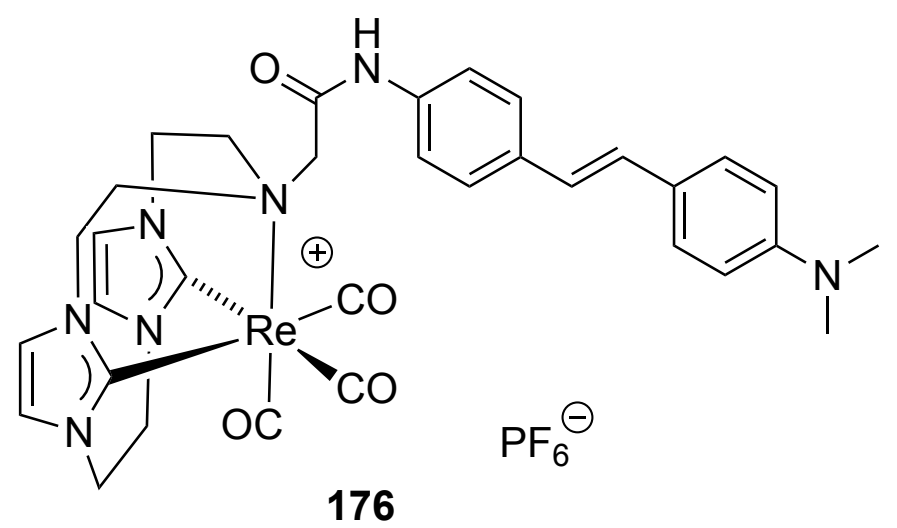

Figure 17. Molecular structure of rhenium (I) complex 176 that displays binding to amyloid plaques in human frontal cortex brain tissue from subjects with Alzheimer's disease.

In addition, Re (I) complexes can be used as luminescent probes in the development of theranostic agents, ${ }^{203}$ with biological studies on rhenium complexes showing that they display 
potent cytotoxic activities towards cancer cells. ${ }^{204,205,206}$ Recent examples have demonstrated the value of including a NHC ligand in these potential anticancer agents. ${ }^{207}$ Some rhenium (I) carbonyl NHC complexes have also been investigated with success for their antimicrobial activity. ${ }^{208}$

Two rhenium (III) chalcogenide cluster complexes have been prepared and characterized by Xray diffraction studies, which represent the first examples of $\left[\mathrm{M}_{6}\left(\mu_{3}-\mathrm{Q}\right)_{8}\right]^{n+}$ or $\left[\mathrm{M}_{6}\left(\mu_{3}-\mathrm{X}\right)_{8}\right]^{n+}$ clusters to contain a carbene ligand. Interestingly and surprisingly, the presence of the NHC ligands attenuate their luminescent properties. ${ }^{209}$ Finally, Various rhenium (V or VII) NHC complexes have been prepared, including water stable or ${ }^{188}$ Re radiolabeled species. ${ }^{210,211,212,213}$ In total, 10 technetium NHC complexes have been characterized by X-ray diffraction studies and the bond distances range from 2.07 to $2.23 \AA$. More than 165 examples of molecular structure of rhenium NHC complexes are known and bond distances range from 2.06 to $2.25 \AA$ with a maximum at $2.14 \AA$ (36 examples).

\section{Conclusion}

Overall, NHC-bearing group 3-7 complexes have thus received significant attention over the past few years, which has mainly been driven by the preparation of organometallics with enhanced stability and performances thanks to NHC stabilization. Most of studies on group 35 metal complexes involve fundamental characterization/reactivity (stabilization of low valent species, small molecules activation and $\mathrm{C}-\mathrm{H}$ activation, primarily) as well as their use in catalysis in unsaturated/polar monomer polymerization and hydro-elementation of $\mathrm{C}=\mathrm{O}$ and $\mathrm{C}=\mathrm{N}$ substrates. In this area, a few reports highlight that fine-tuning of the $\mathrm{NHC}$ steric/electronic properties may be crucial for optimal activity and selectivity. NHC-stabilized Group 6 and 7 complexes have certainly been the most investigated lately, perhaps due to their 
better hydrolytic stability relative to group 3-5 derivatives. This has led to numerous applications based on group 6 and 7 metal complexes spanning from their use for various catalysis (metathesis-based catalytic reactions, hydro-elementation of $\mathrm{C}=\mathrm{O}$ substrates, oxidation reactions, primarily), the development of high performance luminescent molecules to biomedical applications (as radiopharmaceutical and theranostic agents). Undoubtedly, the vast and growing number of readily available NHC scaffolds, with fine-tuned steric/electronic properties, combined with well-established synthetic methods to access M-NHC species should further promote the use of NHC early transition metal species in the coming years, and lead to novel fundamental developments and applications. 


\section{References}

1 For early reviews and electronic properties of NHCs, see:

(a) A.J. Arduengo, Acc. Chem. Res. 32 (1999) 913-921.

(b) D. Bourissou, O. Guerret, F.P. Gabbaï, G. Bertrand, Chem. Rev. 100 (2000) 39-92.

(c) D.J. Nelson, S.P. Nolan, Chem. Soc. Rev. 42 (2013) 6723.

2 Recent books and book chapters, see:

(a) S. P. Nolan, N-Heterocyclic Carbenes: Effective Tools in Organometallic Synthesis, Wiley-VCH, Weinheim, 2014.

(b) A. Kruger, Martin. Albrecht, RSC Catal. Ser. 27 (2017) 99-119.

(c) R.A. Moss, M.P. Doyle, Editors., Contemporary Carbene Chemistry [In: Wiley Ser. React. Intermed. Chem. Biol., 2014; 7], John Wiley \& Sons, Inc., 2014.

3 Representative and/or recent reviews :

(a) W.A. Herrmann, C. Köcher, Angew. Chem. Int. Ed. 36 (1997) 2162-2187.

(b)V. César, S. Bellemin-Laponnaz, L.H. Gade, Chem. Soc. Rev. 33 (2004) 619-636.

(c) L.H. Gade, S. Bellemin-Laponnaz, Coord. Chem. Rev. 251 (2007) 718-725.

(d) P.L. Arnold, S. Pearson, Coord. Chem. Rev. 251 (2007) 596-609.

(e) D. Pugh, A.A. Danopoulos, Coord. Chem. Rev. 251 (2007) 610-641.

(f) S. Díez-González, S.P. Nolan, Coord. Chem. Rev. 251 (2007) 874-883.

(g) F.E. Hahn, M.C. Jahnke, Angew. Chem. Int. Ed. 47 (2008) 3122-3172.

(h) W. Liu, Ronald. Gust, Coord. Chem. Rev. 329 (2016) 191-213.

(i) B. Sarkar, Lisa. Suntrup, Angew. Chem., Int. Ed. 56 (2017) 8938-8940.

(j) N. Sinha, F. Ekkehardt Hahn, Acc. Chem. Res. 50 (2017) 2167-2184.

(k) M. Melaimi, R. Jazzar, M. Soleilhavoup, G. Bertrand, Angew. Chem. Int. Ed. 56 (2017) 10046-10068.

(1) S. Dagorne, Synthesis. 50 (2018) 3662-3670.

(m) E. Peris, Chem. Rev. 118 (2018) 9988-10031.

(n) A. Vivancos, C. Segarra, Martin. Albrecht, Chem. Rev. 118 (2018) 9493-9586.

(o) A.A. Danopoulos, T. Simler, Pierre. Braunstein, Chem. Rev. 119 (2019) 3730-3961.

(p) C.A. Smith, M.R. Narouz, P.A. Lummis, I. Singh, A. Nazemi, C.-H. Li, C.M. Crudden, Chem.1 Rev. 119 (2019) 4986-5056.

(q) Q. Liang, D. Song, Chem. Soc. Rev.. 49 (2020) 1209-1232.

(r) S.C. Sau, P.K. Hota, S.K. Mandal, M. Soleilhavoup, Guy. Bertrand, Chem. Soc. Rev. 49 (2020) 1233-1252.

(s) Q. Zhao, G. Meng, S.P. Nolan, M. Szostak, Chem. Rev. 120 (2020) 1981-2048.

4 For a comprehensive review on the synthetic routes to NHC precursors, see: L. Benhamou, E. Chardon, G. Lavigne, S. Bellemin-Laponnaz, V. César, Chem. Rev. 111 (2011) 27052733. 
5 Selected reviews on main group NHC species:

(a) Y. Wang, G.H. Robinson, Dalton Trans. 41 (2012) 337-345.

(b) H.W. Roesky, J. Organomet. Chem. 730 (2013) 57-62.

(c) C. Fliedel, G. Schnee, T. Avilés, S. Dagorne, Coord. Chem. Rev. 275 (2014) 63-86.

(d) V. Nesterov, D. Reiter, P. Bag, P. Frisch, R. Holzner, A. Porzelt, S. Inoue, Chem. Rev. 118 (2018) 9678-9842.

(e) T.W. Hudnall, R.A. Ugarte, T.A. Perera, RSC Catal. Ser. 27 (2017) 178-237.

(f) A. Doddi, M. Peters, M. Tamm, Chem. Rev. 119 (2019) 6994-7112.

(g) S. Khan, H.W. Roesky, Chem. - Eur. J. 25 (2019) 1636-1648.

6 S. Bellemin-Laponnaz, S. Dagorne, Chem. Rev. 114 (2014) 8747-8774.

7 J. Cheng, L. Wang, P. Wang, L. Deng, Chem. Rev. 118 (2018) 9930-9987.

8 D. Zhang, G. Zi, Chem. Soc. Rev. 44 (2015) 1898-1921.

9 Z. Wang, L. Jiang, D. K. B. Mohamed, J. Zhao, T. S. A. Hor, Coord. Chem. Rev. 293-294 (2015) 292-326.

10 C. Hille, F. E. Kühn, Dalton Trans. 45 (2016) 15-31.

11 S. J. Hock, L. -A. Schaper, W. A. Herrmann, F. E. Kühn, Chem. Soc. Rev. 42 (2013) 5073.

12 For an early review on the use of NHC-bearing chelating ligand to oxophilic metal centers, see: S. T. Liddle, I. S. Edworthy, P. L. Arnold, Chem. Soc. Rev. 36 (2007) 1732-1744.

13 D. Tapu, D.A. Dixon, C. Roe, Chem. Rev. 109 (2009) 3385-3407.

14 R. Grindell, B. M. Day, F. -S. Guo, T. Pugh, R. A. Layfield, Chem. Commun. 53 (2017) 9990-9993.

15 R. H. Crabtree, Coord. Chem. Rev. 257 (2013) 755-766.

16 V. Nesterov, D. Reiter, P. Bag, P. Frisch, R. Holzner, A. Porzelt, S. Inoue, Chem. Rev. 118 (2018) 9678-9842.

17 J. A. Seed, M. Gregson, F. Tuna, N. F. Chilton, A. J. Wooles, E. J. L. McInnes, Angew. Chem. Int. Ed. 56 (2017) 11534-11538.

18 Y. Pan, A. Zhao, Y. Li, W. Li, Y. -M. So, X. Yan, G. He, G. Dalton Trans. 47 (2018) $13815-13823$.

19 P. L. Arnold, T. Cadenbach, I. H. Marr, A. A. Fyfe, N. L. Bell, R. Bellabarba, R. Tooze, J. B. Love, Dalton Trans. 43 (2014) 14346-14358. 
20 P. L. Arnold, I. A. Marr, S. Zlatogorsky, R. Bellabarba, R. P. Tooze, R. P. Dalton Trans. 43 (2014) 34-37.

21 S. Long, B. Wang, H. Xie, C. Yao, C. Wu, D. Cui, New J. Chem. 39 (2015) 7682-7687.

22 Y. Wang, A. Mehmood, Y. Zhao, J. Qu, Y. Luo, Inorganics. 5 (2017) 46.

23 S. Li, D. Liu, Z. Wang, D. Cui, ACS Catalysis. 8 (2018) 6086-6093.

24 X. Wang, F. Lin, J. Qu, Z. Hou, Y. Luo, Organometallics. 35 (2016) 3205-3214.

25 F. Guo, M. Nishiura, Y. Li, Z. Hou, Sci. China Chem. 57 (2014) 1150-1156.

26 M. Zhang, X. Ni, Z. Shen, Organometallics. 33 (2014) 6861-6867.

27 M. Zhang, J. Zhang, X. Ni, Z. Shen, RSC Adv. 5 (2015) 83295-83303.

28 X. Gu, X. Zhu, Y. Wei, S. Wang, S. Zhou, G. Zhang, X. Mu, Organometallics. 33 (2014) $2372-2379$.

29 Z. Huang, S. Wang, X. Zhu, Q. Yuan, Y. Wei, S. Zhou, X. Mu, Inorg. Chem. 57 (2018) 15069-15078.

30 H. Braunschweig, C. Brückner, M.A. Celik, K. Dück, F. Hupp, T. Kramer, J. Krebs, I. Krummenacher, Chem. Eur. J. 21 (2015) 11056-11064.

31 M. Manßen, C. Adler, R. Beckhaus, Chem. Eur. J. 22 (2016) 4405-4407.

32 N. Tsoureas, J. C. Green, F. G. N. Cloke, Chem. Commun. 53 (2017) 13117-13120.

33 N. Tsoureas, J. C. Green, F. G. N. Cloke, Dalton Trans. 47 (2018) 14531-14539.

34 Q. Liu, Q. Chen, X. Leng, Q. -H. Deng, L. Deng, Organometallics. 37 (2018) 4186-4188.

35 W. Ma, J. -X. Zhang, Z. Lin, T. D. Tilley, Q. Ye, Dalton Trans. 48 (2019) 14962-14965.

36 G. Horrer, M.J. Krahfuß, K. Lubitz, I. Krummenacher, H. Braunschweig, U. Radius, Eur. J. Inorg. Chem. (2020) 281-291.

37 K. Nomura, G. Nagai, A. Nasr, K. Tsutsumi, Y. Kawamoto, K. Koide, M. Tamm, Organometallics. 38 (2019) 3233-3244.

38 H. Braunschweig, F.M. Breitling, Coord. Chem. Rev. 250 (2006) 2691-2720.

39 Z. Dong, K. Bedbur, M. Schmidtmann, T. Müller, J. Am. Chem. Soc. 140 (2018) 30523060 .

40 S. Dutta, T. Mondal, S. De, K. Rudra, D. Koley, Inorg. Chim. Act. 485 (2019) 162-172 
41 M. van der Ende, P.M. Hauser, C. Lienert, D. Wang, W. Frey, M.R. Buchmeiser, ChemCatChem. 11 (2019) 744-752.

42 C.C. Quadri, R. Lalrempuia, N.Å. Frøystein, K.W. Törnroos, E. Le Roux, J. Organomet. Chem. 860 (2018) 106-116.

43 D. Prema, Y.L.N. Mathota Arachchige, R.E. Murray, L.M. Slaughter, Chem. Commun. 51 (2015) 6753-6756.

44 C. Romain, K. Miqueu, J.-M. Sotiropoulos, S. Bellemin-Laponnaz, S. Dagorne, Angew. Chem. Int. Ed. 49 (2010) 2198-2201.

45 C. Romain, S. Choua, J.-P. Collin, M. Heinrich, C. Bailly, L. Karmazin-Brelot, S. Bellemin-Laponnaz, S. Dagorne, Inorg. Chem. 53 (2014) 7371-7376.

46 C. Romain, D. Specklin, K. Miqueu, J.-M. Sotiropoulos, C. Fliedel, S. Bellemin-Laponnaz, S. Dagorne, Organometallics. 34 (2015) 4854-4863.

47 E. Despagnet-Ayoub, M.K. Takase, J.A. Labinger, J.E. Bercaw, J. Am. Chem. Soc. 137 (2015) 10500-10503.

48 E. Despagnet-Ayoub, M.K. Takase, L.M. Henling, J.A. Labinger, J.E. Bercaw, Organometallics. 34 (2015) 4707-4716.

49 C.C. Quadri, E. Le Roux, Dalton Trans. 43 (2014) 4242-4246.

50 C.C. Quadri, R. Lalrempuia, J. Hessevik, K.W. Törnroos, E. Le Roux, Organometallics. 36 (2017) 4477-4489.

51 J. Hessevik, R. Lalrempuia, H. Nsiri, K.W. Törnroos, V.R. Jensen, E. Le Roux, Dalton Trans. 45 (2016) 14734-14744.

52 R. Lalrempuia, F. Breivik, K.W. Törnroos, E. Le Roux, Dalton Trans. 46 (2017) 8065-8076.

53 R. Lalrempuia, J. Underhaug, K.W. Törnroos, E. Le Roux, Chem. Commun. 55 (2019) 7227-7230.

54 N. Zhao, G. Hou, X. Deng, G. Zi, M.D. Walter, Dalton Trans. 43 (2014) 8261-8272.

55 S. Barroso, S.R.M.M. de Aguiar, R.F. Munhá, A.M. Martins, J. Organomet. Chem. 760 (2014) 60-66.

56 M. Baltrun, F.A. Watt, R. Schoch, C. Wölper, A.G. Neuba, S. Hohloch, Dalton Trans. 48 (2019) 14611-14625. 
57 W.D. Clark, J. Cho, H.U. Valle, T.K. Hollis, E.J. Valente, J. Organomet. Chem. 751 (2014) 534-540.

58 W.D. Clark, K.N. Leigh, C.E. Webster, T.K. Hollis, Aust. J. Chem. 69 (2016) 565-572.

59 S.W. Reilly, C.E. Webster, T.K. Hollis, H.U. Valle, Dalton Trans. 45 (2016) 2823-2828.

60 T.O. Howell, A.J. Huckaba, T.K. Hollis, Organic Letters. 16 (2014) 2570-2572.

61 A. Igarashi, E.L. Kolychev, M. Tamm, K. Nomura, Organometallics. 35 (2016) 1778-1784.

62. S. Bellemin-Laponnaz, R. Welter, L. Brelot, S. Dagorne, J. Organomet. Chem. 694 (2009) 604-606.

63 K. Nomura, Catalysts. 9 (2019) 1016.

64 K. Nomura, G. Nagai, I. Izawa, T. Mitsudome, M. Tamm, S. Yamazoe, ACS Omega. 4 (2019) 18833-18845.

65 G. Nagai, T. Mitsudome, K. Tsutsumi, S. Sueki, T. Ina, M. Tamm, K. Nomura, J. Japan Petroleum Inst. 60 (2017) 256-262.

66 S. Zhang, W.-C. Zhang, D.-D. Shang, Y.-X. Wu, J. Polym. Sci. Part A: Polym. Chem. 57 (2018) 553-561.

67 S. Zhang, W.-C. Zhang, D.-D. Shang, Z.-Q. Zhang, Y.-X. Wu, Dalton Trans. 44 (2015) $15264-15270$.

68 C. Weetman, S. Notman, P.L. Arnold, Dalton Trans. 47 (2018) 2568-2574.

69 Ž. Zupanek, M. Tramšek, A. Kokalj, G. Tavčar, Inorg. Chem. 57 (2018) 13866-13879.

70 M. Bortoluzzi, E. Ferretti, F. Marchetti, G. Pampaloni, S. Zacchini, Chem. Commun. 50 (2014) 4472-4474.

71 M. Bortoluzzi, E. Ferretti, F. Marchetti, G. Pampaloni, S. Zacchini, Dalton Trans. 45 (2016) 6939-6948.

72 Z. Wei, W. Zhang, G. Luo, F. Xu, Y. Mei, H. Cai, New J. Chem. 40 (2016) 6270-6275.

73 Ž. Zupanek, M. Tramšek, A. Kokalj, G. Tavčar, J. Fluor. Chem. 227 (2019) 109373.

74 M. Bortoluzzi, E. Ferretti, F. Marchetti, G. Pampaloni, S. Zacchini, J. Coord. Chem. 69 (2016) 2766-2774.

75. M. Bortoluzzi, E. Ferretti, F. Marchetti, G. Pampaloni, C. Pinzino, S. Zacchini, Inorg. Chem. 55 (2016) 4173-4182.

76. P.A. Petrov, T.S. Sukhikh, M.N. Sokolov, Dalton Trans. 46 (2017) 4902-4906. 
77. J.A. Ziegler, C. Prange, T.D. Lohrey, R.G. Bergman, J. Arnold, Inorg. Chem. 57 (2018) 5213-5224.

78. J.I. Fostvedt, T.D. Lohrey, R.G. Bergman, J. Arnold, Chem. Commun. 55 (2019) $13263-$ 13266.

79 R. Srivastava, R. Moneuse, J. Petit, P.-A. Pavard, V. Dardun, M. Rivat, P. Schiltz, M. Solari, E. Jeanneau, L. Veyre, C. Thieuleux, E.A. Quadrelli, C. Camp, Chem. Eur. J. 24 (2018) 43614370 .

80. T.R. Helgert, T.K. Hollis, A.G. Oliver, H.U. Valle, Y. Wu, C.E. Webster, Organometallics. 33 (2014) 952-958.

81 T.R. Helgert, C.E. Webster, T.K. Hollis, H.U. Valle, P. Hillesheim, A.G. Oliver, Inorganica Chimica Acta. 469 (2018) 164-172.

82 T.R. Helgert, X. Zhang, H.K. Box, J.A. Denny, H.U. Valle, A.G. Oliver, G. Akurathi, C.E. Webster, T.K. Hollis, Organometallics. 35 (2016) 3452-3460.

83 P.L. Arnold, S.T. Liddle, Organometallics. 25 (2006) 1485-1491.

84 K. Öfele, M. Herberhold, Angew. Chem. Int. Ed. Engl. 9 (1970) 739.

85 K. Öfele, M. Herberhold, Z. Naturforsch. B 28 (1973) 306.

86 B. Cetinkaya, P. Dixneuf, M. F. Lappert, J. Chem. Soc., Chem. Commun. (1973) 206.

87 For examples of group 6 carbonyl complexes with acyclic diamino carbenes, see: (a) W. A. Herrmann, K. Öfele, D. v. Preysing, E. Herdtweck, J. Organomet. Chem. 684 (2003) 235; (b) G. D. Frey, E. Herdtweck, W. A. Herrmann, J. Organomet. Chem. 691 (2006) 2465.

88 For a review on NHC complexes of group 6 metals, see: Z. Wang, L. Jiang, D. K. B. Mohamed, J. Zhao, T. S. Hor, Coord. Chem. Rev. 293-294 (2015) 292-326.

89 T. Simler, A. A. Danopoulos, P. Braunstein, Chem. Commun. 51 (2015) 10699.

90 T. Simler, P. Braunstein, A. A. Danopoulos, Organometallics 35 (2016) 4044.

91 X. Ren, M. Wesolek, P. Braunstein, Dalton Trans. 48 (2019) 12895.

92 P. Ai, A. A. Danopoulos, P. Braunstein, Organometallics 34 (2015) 4109-4116.

93 C. L. Keller, J. L. Kern, B. D. Terry, S. Roy, D. M. Jenkins, Chem. Commun. 54 (2018) 1429.

94 S. A. Cramer, D. M. Jenkins, J. Am. Chem. Soc. 133 (2011) 19342. 
95 E. A. Pidko, V. Degirmenci, R. A. van Santen, E. J. M. Hensen, Angew. Chem. Int. Ed. 49 (2010) 2530.

96 H. Zhao, J. E. Holladay, H. Brown, Z. C. Zhang, Science 316 (2007) 1597.

97 F. P. Malan, E. Singleton, P. H. van Rooyen, J. Conradie, M. Landman, New. J. Chem. 42 (2018) 19193-19204.

98 M. A. Sierra, A. D. Merinero, E. A. Giner, M. Gomez-Gallego, C. Ramirez de Arellano, Chem. Eur. J. 22 (2016) 13521-13531.

99 P.P. Samuel, R. Neufeld, K. Chandra Mondal, H.W. Roesky, R. Herbst-Irmer, D. Stalke, S. Demeshko, F. Meyer, V.C. Rojisha, S. De, P. Parameswaran, A.C. Stückl, W. Kaim, J.H. Christian, J.K. Bindra, N.S. Dalal, Chem. Sci. 6 (2015) 3148-3153.

100 Z. Wang, X. Song, L. Jiang, T. T. Lin, M. K. Schreyer, J. Zhao, T. S. A. Hor, Asian J. Org. Chem. 7 (2018) 395-403.

101 For example of $\mathrm{NHC} \mathrm{Mo}(0)$ complexes with potentially ambivalent coordination capability, see: J. Ruiz, A. F. Mesa, D. Sol, Organometallics 34 (2015), 5129-5135.

102 C. H. Cheng, R. Y. Yuo, Q. Cui, H. B. Song, L. F. Tang, Transition Met. Chem. 40 (2015) 297-304.

103 S. L. Apps, R. E. Alflatt, B. Leforestier, C. M. Storey, A. B. Chaplin, Polyhedron 143 (2018) 57-61.

104 Z. Wang, S. Li, W. J. teo, Y. T. Zhao, T. S. A. Hor, J. Organomet. Chem. 775 (2015) 188194.

105 N. U D. Reshi, L. Kathuria, A. G. Samuelson, Inorg. Chim. Acta 486 (2019) 119-128.

106 For an example of carbonyl group $6(0)$ abnormal NHC complexes, see: R. Ghadwal, D. Rottschäfer, D. M. Andrada, G. Frenking, C. J. Schürmann, H. -G. Stammler, Dalton Trans. 46 (2017) 7791-7799.

107 K. Arashiba, Y. Miyake, Y. Nishibayashi, Nat. Chem. 3 (2010) 120.

108 A. Eizawa, K. Arashiba, H. Tanaka, S. Kuriyama, Y. Matsuo, K. Nakajima, K. Yoshizawa, Y. Nishibayashi Nat. Commun. 8 (2017) 14874.

109 M.J. Bezdek, S. Guo, P.J. Chirik, Science 354 (2016) 730.

110 C. Gradert, N. Stucke, J. Krahmer, C. Näther, F. Tuczek, Chem. Eur. J. 21 (2015) 11301137. 
111 Y. Ohki, K. Aoyagi, H. Seino, Organometallics 34 (2015)3414-3420.

112 A. J. Huckaba, H. P. Shirley, R. Lamb, S. Guertin, S. A. Autry, H. Cheema, K. Talukdar, T. C. Jones, J. W. Jurss, A. Dass, N. I. Hammer, R. H. Schmehl, S. E. Webster, J. H. Delcamp, ACS Catal. 8 (2018) 4838-4847.

113 M. H. Chisholm, A. M. Macintosh, Chem. Rev. 105 (2005) 2949-2976.

114 M. Carrasco, I. Mendoza, E. Alvarez, A. Grirrane, C. Maya, R. Peloso, A. Rodriguez, A. Falceto, S. Alvarez, E. Carmona, Chem. Eur. J. 21 (2015) 410-421.

115 T. P. Robinson, A. L. Johnson, P. R. Raithby, G. Kociok-Kohn, Organometallics 35 (2016) 2494-2506.

116 V. K. Dioumaev, R. M. Bullock, Nature 424 (2003) 530.

117 S. fang, H. Chen, W. Wang, H. Wei, New J. Chem. 42 (2018) 4923-4932.

118 J. Fuchs, E. Irran, P. Hrobarik, H. F. T. Klare, M. Oestreich, J. Am. Chem. Soc. 141 (2019) 18845-18850.

119 Z. Wang, S. W. B. Ng, L. Jiang, W. J. Leong, J. Zhao, T. S. A. Hor, Organometallics 33 (2014) 2457.

120 M. R. Buchmeiser, S. Sen, J. Unold, W. Frey, Angew. Chem. Int. Ed. 53 (2014) 93849388.

121 For a review on Mo and W imido NHC complexes, see: M. R. Buchmeiser, Chem. Eur. J. 24 (2018) 14295-14301.

122 For an example of Mo (IV) bis-imido NHC adduct, see: M. A. Land, K. N. Robertson, S. T. Barry, Organometallics (2019) doi: 10.1021/acs.organomet.9b00578.

123 Z. J. Tonzetich, A. J. Jiang, R. R. Schrock, P. Müller, Organometallics 25 (2006) 4725 4727.

124 A. J. Jiang, R. R. Schrock, P. Müller, Organometallics 27 (2008) 4428-4438.

125 J. Beerhues, S. Sen, R. Schowner, G. M. Nagy, D. Wang, M. R. Buchmeiser, J. Polym. Science A 55 (2017) 3028-3033.

126 I. Elser, B. R. Kordes, W. Frey, K. Herz, R. Schowner, L. Stöhr, H. J. Altmann, M. R. Buchmeiser, Chem. Eur. J. 24 (2018) 12652-12659.

127 M. J. Benedikter, R. Schowner, I. Elser, P. Werner, K. Herz, L. Stöhr, D. A. Imbrich, G. M. Nagy, D. Wang, M. R. Buchmeiser, Macromolecules 52 (2019) 4059-4066. 
128 For a combined experimental and theoretical studies of the mechanism of olefin metathesis with Mo imido alkylidene NHC complexes, see: K. Herz, M. Podewitz, L. Stöhr, D. Wang, W. Frey, K. R. Liedl, S. Sen, M. R. Buchmeiser, J. Am. Chem. Soc. 141 (2019) 8264-8276.

129 M. R. Buchmeiser, Polymer Reviews 57 (2017) 15-30

130 R. Schowner, I. Elser, M. Benedikter, M. Momim, W. Frey, T. Schneck, L. Stöhr, M. R. Buchmeiser, Angew. Chem. Int. Ed. 59 (2020) 951-958.

131 S. Sen, R. Schowner, D. A. Imbrich, W. Frey, M. Hunger, M. R. Buchmeiser, Chem. Eur. J. 21 (2015) 13778-13787.

132 I. Elser, R. Schowner, W. Frey, M. R. Buchmeiser, Chem Eur. J. 23 (2017) 6398-6405.

133 K. Herz, J. Unold, J. Hänle, R. Schowner, S. Sen, W. Frey, M. R. Buchmeiser, Macromolecules 48 (2015) 4768-4778.

134 P. Probst, I. Elser, R. Schowner, M. J. Benedikter, M. R. Buchmeiser, Macomol. Rapid. Commun. 41 (2020) 1900398.

135 R. Singh, R. R. Schrock, P. Müller, A. H. Hoveyda, J. Am. Chem. Soc. 129 (2007) 12654.

136 M. Momin, G. M. Nagy, M. R. Buchmeiser, Adv. Synth. Catal. 362 (2019) 5596-5604.

137 R. Schowner, W. Frey, M. R. Buchmeiser, Eur. J. Inorg. Chem. (2019) 1911-1922.

138 I. Elser, W. Frey, K. Wurst, M. R. Buchmeiser, Organometallics 35 (2016) 4106-4111.

139 M. R. Buchmeiser, S. Sen, C. Lienert, L. Widmann, R. Schowner, K. Herz, P. Hauser, W. Fery, D. Wang, ChemCatChem 8 (2016) 2710-2723.

140 C. Leinert, W. Frey, M. R. Buchmeiser, Macromolecules 50 (2017) 5701-5710.

141 M. R. Buchmeiser, Macromol. Rapid. Commun. 40 (2019) 1800492.

142 H. Jeong, D. J. Kozera, R. R. Schrock, S. J. Smith, J. Zhang, N. Ren, M. A. Hillmyer, Organometallics 32 (2013) 4843-4850.

143 A. J. Jiang, Y. Zhao, R. R. Schrock, A. H. Hoveyda, J. Am. Chem. Soc. 131 (2009) 1663016631.

144 I. Elser, M. J. Benedikter, R. Schowner, W. Frey, D. Wang, M. R. Buchmeiser, Organometallics 38 (2019) 2461-2471.

145 M. Pucino, M. Inoue, C. P. Gordon, R. Schowner, L. Stöhr, S. Sen, C. Hegedüs, E. Robé, F. Toth, M. R. Buchmeiser, C. Copéret, Angew. Chem. Int. Ed. 57 (2018) 14566-14569. 
146 M. Koy, I. Elser, J. Meisner, W. Frey, K. Wurst, J. Kästner, M. R. Buchmeiser, Chem. Eur. J. 23 (2017) 15484-15490.

147 P. M. Hauser, M. Hunger, M. R. Buchmeiser, ChemCatChem 201810 (2018) 1829-1834.

148 I. Elser, J. Groos, P. M. Hauser, M. Koy, M. van der Ende, D. Wang, W. Frey, K. Wurst, J. Meisner, F. Ziegler, J. Kästner, M. R. Buchmeiser, Organometallics 38 (2019) 4133-4146.

149 D. A. Imbrich, I. Elser, W. Frey, M. R. Buchmeiser, ChemCatChem 9 (2017) 2996-3002.

150 D. A. Imbrich, W. Frey, M. R. Buchmeiser, Chem. Commun. 53 (2017) 12036-12039.

151 R. Schowner, W. Frey, M. R. Buchmeiser, J. Am. Chem. Soc. 137 (2015) 6188-6191.

152 M. Pucino, V. Mougel, R. Schowner, A. Federov, M. R. Buchmeiser, C. Copéret, Angew. Chem. Int. Ed. 55 (2016) 4300-4302.

153 J. Willot, N. Lugan, D. A. Valyaev, Eur. J. Inorg. Chem. (2019) 4358-4364.

154 For an example of bimetallic Mn carbonyl complex bearing a monodentate NHC, see: R; Fraser, C. G. C. E. van Sittert, P. H. van Rooyen, M. Landman, J. Organomet. Chem. 835 (2017) 60-69.

155 J. Cheng, Q. Chen, X. Leng, Z. Ouyang, Z. Wang, S. Ye, L. Deng, Chem 4 (2018) $2844-$ 2860.

156 W. Chen, Q. Chen, Y. Ma, X. Leng, S. -D. Bai, L. Deng, Chin. Chem. Lett. (2020) doi.org/10.1016/j.cclet.2019.11.019.

157 J. Zheng, S. Elangovan, D. A. Valyaev, R. Brousses, V. César, J. -B. Sortais, C. Darcel, N. Lugan, G. Lavigne, Adv. Synth. Catal. 356 (2014) 1093-1097.

158 Dehydrogenative dimerization reaction of thiols has been investigated with asymmetrical Mn (I) NHC complexes albeit with low activity, see: R. Fraser, P. H. van Rooyen, J. de Lange, I. Cukrowski, M. landman, J. Organomet. Chem. 840 (2017) 11-22.

159 The radical cation of such species has been characterized, see: K. Wu, M. A. Conger, R. Waterman, M. Liptak, W. E. Geiger, Polyhedron 157 (2019) 442-448.

160 D. A. Valyaev, D. Wei, S. Elangovan, M. Cavailles, V. Dorcet, J. -B. Sortais, C. Darcel, N. Lugan, Organometallics 35 (2016) 4090-4098.

161 M. Pinto, S. Friaes, F. Franco, J. Lloret-Fillol, B. Royo, ChemCatChem 10 (2018) 27342740 .

162 S. C. A. Sousa, C. J. Carrasco, M. F. Pinto, B. Royo, ChemCatChem 11 (2019) 3889-3843. 
163 M. Huang, Y. Li, Y. Li, J. Liu, S. Shu, Y. Liu, Z. Ke, Chem. Commun. 55 (2019) 62136216.

164 X. -B. Lan, Z. Ye, M. Huang, J. Liu, Y. Liu, Z. Ke, Org. Lett. 21 (2019) 8065-8070.

165 R. van Putten, J. Benschop, V. J. de Munck, M. Weber, C. Müller, G. A. Filonenko, E. A. Pidko, ChemCatChem 11 (2019) 5232-5235.

166 R. Buhaibeh, O. A. Filippov, A. Bruneau-Voisine, J. Willot, C. Duhayon, D. A. Valraev, N. Lugan, Y. Canac, J. -B. Sortais, Angew. Chem. Int. Ed. 58 (2019) 6727-6731.

167 J. Agarwal, T. W. Shaw, C. J. Stanton III, G. F. Majetich, A. B. Bocarsly, H. F. Schaefer III, Angew. Chem. Int. Ed. 53 (2014) 5152-5155.

168 J. Agarwal, C. J. Stanton III, T. W. Shaw, J. E. Vandezande, G. F. Majetich, A. B. Bocarsly, H. F. Schaefer III, Dalton Trans. 44 (2015) 2122-2131.

169 T. H. T. Myren, A. M. Lilio, C. G. Huntzinger, J. W. Horstman, T. A. Stinson, T. B. Donadt, C. Moore, B. Lama, H. H. Funke, O. R. Luca, Organometallics 38 (2019) 1248-1253.

170 For a related access to abnormal carbene in presence of a Mn (II) complex, see: A. Thakur, V. Bheemireddy, S. R. Bhatta, J. Organomet. Chem. 832 (2017) 42-46.

171 A. A. Grineva, O. A. Filippov, S. E. Nefedov, N. Lugan, V. César, D. A. Valyaev, Organometallics 38 (2019) 2330-2337.

172 D. A. Valyaev, M. A. Uvarova, A. A. Grineva, V. César, S. N. Nefedov, N. Lugan, Dalton Trans. 45 (2016) 11953-11957.

173 A. A. Grineva, D. A. Valyaev, V. César, O. A. Filippov, V. N. Khrustalev, S. E. Nefedov, N. Lugan, Angew. Chem. Int. Ed. 57 (2018) 7986-7991.

174 Z. Yao, H. Li, X. Liang, X. Xu, J. Li, Dyes and Pigments 162 (2019) 75-79.

175 Z. Yao, H. Li, Y. Fan, X. Liang, X. Xu, J. Li, Dyes and Pigments 173 (2020) 107961.

176 M. Käß, Hohenberger, M. Adelhardt, E. M. Zolnhofer, S. Mossin, F. W. Heinemann, J. Sutter, K. Meyer, Inorg. Chem. 53 (2014) 2460-2470.

177 M. D. Walter, D. Baabe, M. Freytag, P. G. Jones, Z. Anorg. Allg. Chem. 642 (2016) 12591263.

178 C. D. Abernethy, A. H. Cowley, R. A. Jones, C. L. B. MacDonald, P. Shukla, L. K. Thompson, Organometallics 20 (2001) 3629-3631. 
179 M. H. Al-Afyouni, V. M. Krishnan, H. D. Arma, Z. J. Tonzetich, Organometallics 34 (2015) 5088-5094.

180 T. Hashimoto, Y. Kawato, Y. Nakajima, Y. Ohki, K. Tatsumi, W. Ando, K. Sato, S. Shimada, J. Organomet. Chem. 820 (2016) 14-19.

181 M. Ding, G. E. Cutsail III, D. Aravena, M. Amoza, M. Rouzières, P. Dechambenoit, Y. Losovyj, M. Pink, E. Ruiz, R. Clérac, J. M. Smith, Chem. Sci. 7 (2016) 6132-6140.

182. A.R. Kennedy, J. Klett, R.E. Mulvey, S.D. Robertson, Eur. J. Inorg. Chem. (2011) 4675 4679.

183 For a review on cationic rhenium complexes with NHC ligands, see: C. Hille, F. E. Kuehn, Dalton Trans. 45 (2016) 15-31.

184 L. A. Casson, S. Muzzioli, P. Raiteri, B. W. Skelton, S. Stagni, M. Massi, Dalton Trans. 40 (2011) 11960.

185 For a review on the properties of rhenium (I) carbonyl NHC complexes, see: P. V. Simpson, M. Falasca, M. Massi, Chem. Commun. 54 (2018) 12429-12438.

186 J. G. Vaughan, B. L. Reid, P. J. Wright, S; Ramchandani, B. W. Skelton, P. Raiteri, S. Muzzioli, D. H. Brown, S. Stagni, M. Massi, Inorg. Chem. 53 (2014) 3629-3641.

187 P. V. Simpson, B. W. Skelton, P. Raiteri, M. Massi, New. J. Chem. 40 (2016) 5797-5807.

188 C. -O. Ng, S. -C. Cheng, W. -K. Chu, K. -M. Tang, S. -M. Yiu, C. -C. Ko Inorg. Chem. 55 (2016) 7969-7979.

189 T. Mukuta, P. V. Simpson, J. G. Vaughan, B. W. Skelton, S. Stagni, M. Massi, K. Koike, O. Ishitani, K. Onda, Inorg. Chem. 56 (2017) 3404-3413.

190 T. P. Nicholls, L. K. Burt, P. V. Simpson, M. Massi, A. C. Bissember, Dalton Trans. 48 (2019) 12749-12754.

191 A. Bonfiglio, K. Magra, C. Cebrian, F. Polo, P. C. Gros, P. Mercandelli, M. Mauro, Dalton Trans. 49 (2020) 3102-3111.

192 E. S. Gauthier, L. Abella, N. Hellou, B. Darquié, E. Caytan, T. Roisnel, N. Vanthuyne, L. Favereau, M. Srebro-Hooper, J. A. G. Williams, J. Autschbach, J. Crassous, Angew. Chem. Int. Ed. 10.1002/anie.202002387.

193 A. J. Huckaba, E. A. Sharpe, J. H. Delcamp, Inorg. Chem. 55 (2016) 682-690.

194 N. P. Liyanage, H. A. Dulaney, A. J. Huckaba, J. W. Jurss, J. H. Delcamp, Inorg. Chem. 55 (2016) 6085-6094. 
195 C. J. Stanton, C. W. Machan, J. E. Vandezande, T. Jin, G. F. Majetich, H. F. Schaefer III, C. P. Kubiak, G. Li, J. Agarwal, Inorg. Chem. 55 (2016) 3136-3144.

196 R. Alberto, R. Schibli, R. Waibel, U. Abram, A. P. Schubiger, Coord. Chem. Rev. 190-192 (1999) 901-919.

197 N. C. Okoye, J. E. Baumeister, F. N. Khosroshahi, H. M. Hennkens, S. S. Jurisson. Radiochimica Acta 107 (2019) 1087-1120.

198 D. J. Hayne, A. J. North, M. Fodero-Tavoletti, J. M. White, L. W. Hung, A. Rigopoulos, C. A. McLean, P. A. Adlard, U. Ackermann, H. Tochon-Danguy, V. L. Villemagne, K. J. Barnham, P. S. Donnely, Dalton Trans. 44 (2015) 4933-4944 and references therein.

199 S ; J. Hock, L. -A. Schaper, A. Pöthig, M. Drees, E. Herdtweck, O. Hiltner, W. A. Herrmann, F. E. Kühn, Dalton Trans. 43 (2014) 2259-2271.

200 C. Ying, P. J. Barnard, Dalton Trans. 44 (2015) 19126-19140.

201 C. Y. Chan, P. A. Pellegrini, I. Greguric, P. J. Barnard, Inorg. Chem. 53 (2014) 1086210873.

202 C. Y. Chan, A. Noor, C. A. McLean, P. S. Donnely, P. J. Barnard, Chem. Commun. 53 (2017) 2311-2314.

203 A. Luengo, V. Fernandez-Moreira, I. marzo, M. C. Gimeno, Organometallics 37 (2018) 3993-4001.

204 D. Gupta, M. Sathiyendiran, ChemistrySelect 3 (2018) 7439-7458.

205 A. Leonidova, G. Gasser, A.C.S. Chem. Biol. 9 (2014) 2180-2193.

206 Kühn, Crans and collaborators reviewed recently the coordination chemistry of rhenium and their application in cancer therapy, see: E. B. bauer, A. A. Haase, R. M. Reich, D. C. Crans, F. E. Kühn, Coord. Chem. Rev. 393 (2019) 79-117.

207 P. V. Simpson, I. silvano, S. Paternoster, B. W. Skelton, M. Falasca, M. Massi, Chem. Eur. J. 23 (2017) 6518-6521.

208 D. Sigmund, N. Lorenz, Y. Gothe, C. Spies, B. Geissler, P. Prochnow, P. Nuernberger, J. E. Bandow, N. Metzler-Nolte, Dalton Trans. 46 (2017) 15269-15279.

209 J. L. Durham, W. B. Wilson, D. N. Huh, R. McDonald, L. F. Szczepura, Chem. Commun. 51 (2015) 10536-10538.

210 D. Bornemann, L. Schlemper, N. Trapp, A. Togni, Eur. J. Inorg. Chem. (2020) 1004-1010. 
211 T. Wagner, B. M. Zeglis, S. Groveman, C. Hille, A. Pöthig, L. C. Francesconi, W. A. Herrmann, F. E. Kühn, T. Reiner, J. Labelled Compd. Radiopharm. 57 (2014) 441-447.

212 J. M. Hoffman, A. G. Oliver, S. N. Brown, J. Am. Chem. Soc. 139 (2017) 4521-4531.

213 G. Grieco, O. Blacque, Eur. J. Inorg. Chem. (2019) 3810-3819. 